\title{
UMA FORMA DE IMPLANTAÇÃO DE GERENCIAMENTO DE CONFIGURAÇÃO DE SOFTWARE EM EMPRESAS DE PEQUENO PORTE
}

\author{
Renato Ferrari Pacheco
}

Orientadora: Prof. Dra. Rosely Sanches

Dissertação apresentada ao Instituto de Ciências Matemáticas de São Carlos - USP, como parte dos requisitos para a obtenção do título de Mestre em Ciências - Área: Ciências de Computação e Matemática Computacional. 
À Silvana, minha amada, que me dá forças para atingir os mais altos objetivos. 


\section{Agradecimentos}

À Rosely Sanches, que muito além de orientar a pesquisa, dá dedicação, compreensão e amor a cada um de seus orientados. Não apenas uma orientadora para assuntos acadêmicos, mas uma grande amiga para qualquer hora.

À Silvana, que sofreu a cada partida, e sorriu a cada chegada.

Ao meu irmão Ricardo, que sempre me incentivou a voltar à universidade.

À minha irmã Eliane e ao Maurício, que nunca reclamaram de todo o trabalho que thes dei.

Aos meus pais, pelo amor e dedicação.

À Renata, que fez de tudo para que eu nåo estudasse em outra universidade.

Aos colegas do grupo: Marcos, Lairce, Rejane, Paola, Fátima, Gelza e Cristina, pela amizade.

À FATEB e à UNIP, que fizeram todos os esforços para que os horários se acertassem.

A todos os professores e funcionários do ICMSC, pela dedicação.

Ao CNPq pelo apoio financeiro. 


\section{Resumo}

Gerenciamento de configuração de software é uma das primeiras exigências para se ter um processo de software com qualidade. Entretanto, essa atividade é difícil de ser implantada, principalmente em empresas de pequeno porte. Este trabalho propõe um plano de implantação de gerenciamento de configuração de software destinado a essas empresas. Para isso foi realizada uma pesquisa empírica -- utilizando o método Goall Question/ Metric (GQM) - para identificar como as empresas de pequeno de porte realizam gerenciamento de configuração. $O$ resultado mostrou que elas não realizam gerenciamento de configuração $e$, por isso, as atividades contidas no padrão IEEE Std 828-1990 foram consideradas como base para - plano proposto. O plano detalha os procedimentos técnicos e administrativos necessários para (a) a execução das atividades de identificação da configuração, (b) relato de situação e (c) controles de versões e mudanças. O controle de versões é apoiado pela ferramenta de controle de versões de baixo custo --- Quma Version Control System (QVCS) -- uma exigência necessária para a implantação do plano em empresas de pequeno porte. Esse plano permite que essas empresas dêem o primeiro passo na direção da melhoria de qualidade de processos de software. 


\begin{abstract}
Software configuration management is one of the first requirements to achieve quality in the software process. However, these activities is very difficult to be introduced, mainly in small software business. This work proposes a software configuration management plan for small software business. In order to accomplish this goal, an empirical research was carried out --- using the Goal/ Question/ Metric method (GQM) --- to identify how small software business perform software configuration management. The result showed that these software business do not perform software configuration management, then the IEEE Standard 828-1990 activities were considered as base for the proposed plan. This plan details the management and technical procedures needed to the accomplishment of the (a) identification, (b) status report and (c) version and change control tasks. This plan is the first step to improve the software processes quality.
\end{abstract}




\section{ÍNDICE}

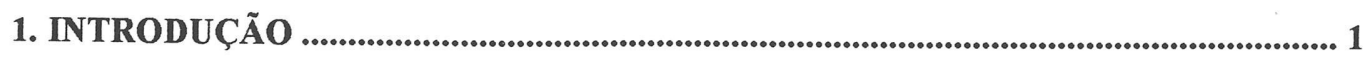

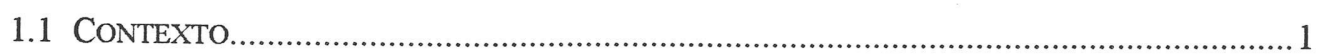

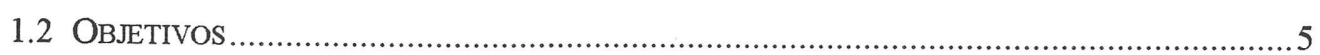

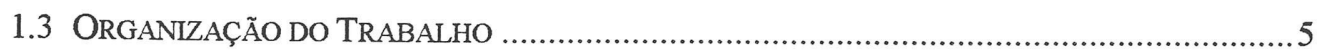

2. GERENCIAMENTO DE CONFIGURAÇÃO DE SOFTWARE......................................7

2.1 Conceitos Fundamentais de Gerenciamento de Configuração de Software...... 7

2.2 TAREFAS dE GERENCIAMENTO dE CONFIGURAÇÃo dE SOFTWARE .............................. 10

2.2.1 - Tarefa 1-Identificação da Configuração de Software....................................... 10

2.2.2 - Tarefa 2 - Controles de Mudança e de Versões............................................. 12

2.2.3 - Tarefa 3 - Auditoria da Configuração .......................................................... 16

2.2.4 - Tarefa 4 - Relato da Situação .................................................................... 16

2.2.5 - Tarefa 5 - Controle de interface .............................................................. 17

2.2.6 - Tarefa 6 - Controle de subcontratados e fornecedores................................... 18

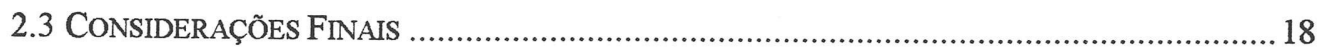

3. PLANO DE GERENCIAMENTO DE CONFIGURAÇÃO DE SOFTWARE ......... 20

3.1 Elementos envolvidos no Plano de Gerenciamento de Configuração ............ 20

3.2 Alguns Padrões de Planos de Gerenciamento de Configuração de Software 23

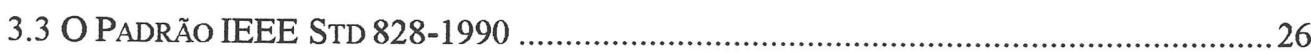

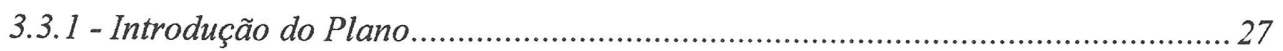

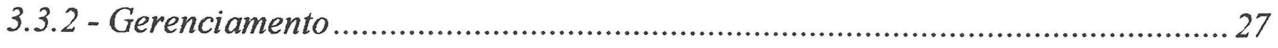

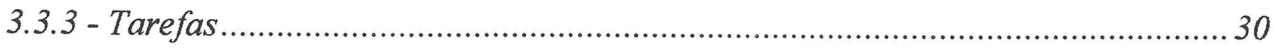

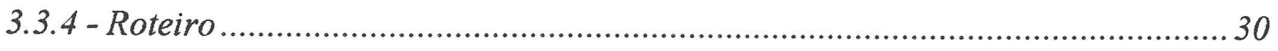

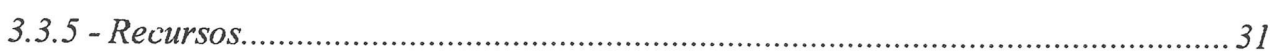

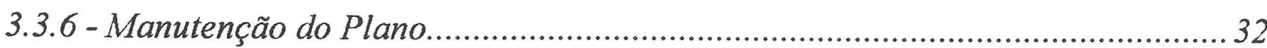

3.4 RECOMENDAÇÕES PARA A ELABORAÇÃO DO PLANO DE GERENCIAMENTO DE CONFIGURAÇÃO DE SOFTWARE 33

4. A DETERMINAÇÃO DE UM TÍPICO PROCESSO DE GERENCIAMENTO DE CONFIGURAÇÃO DE SOFTWARE EM EMPRESAS DE PEQUENO PORTE 36

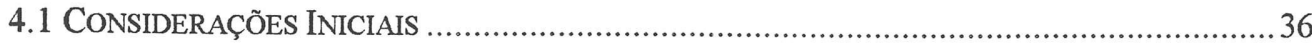

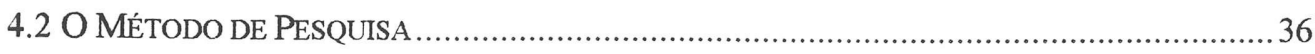

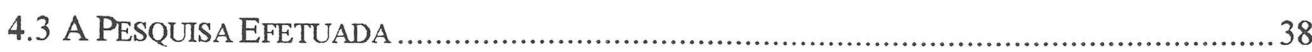


4.3.1- Passo 1 - Objetivos da Coleta de Dados............................................................... 38

4.3.2- Passo 2 - Lista de Questões de Interesse ............................................................... 38

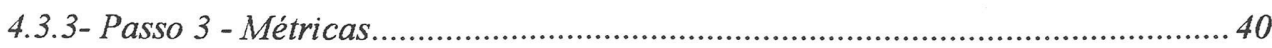

4.3.4- Passo 4-Projeto e Teste do Formulário de Coleta dos Dados........................... 49

4.3.5- Passo 5 - Coleta e Validação dos Dados.............................................................. 49

4.3.6- Passo 6 - Análise dos Dados.............................................................................50

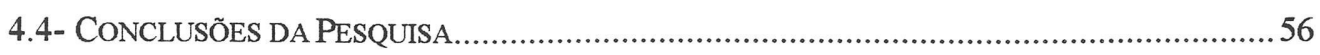

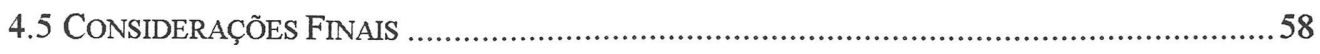

\section{A ELABORAÇÃO DO PLANO DE GERENCIAMENTO DE CONFIGURAÇÃO DE}

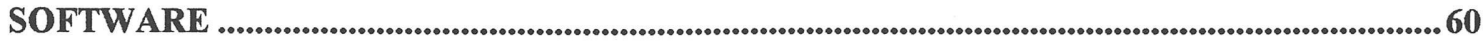

5.1 CONSIDERAÇõES INICIAIS . 60

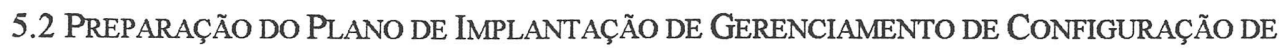
SOFTWARE .60

5.3 ELABORAÇÃO DA SEÇÃO 1 DO PlANO - INTRODUÇÃO …………….................................63

5.4 ElaboraÇão dA SEÇÃo 2 do PLANO - GERENCIAMENTO ..............................................66

5.5 ElABORAÇÃo DA SEÇÃo 3 do Plano - TAREFAS .............................................................. 70

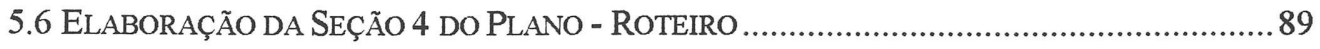

5.7 ELABORAÇÃO DA SEÇão 5 Do PLANO - RECURSOS ........................................................... 91

5.8 ElaboraÇÃo DA SEÇÃo 6 do Plano - MANUTENÇÃo................................................. 94

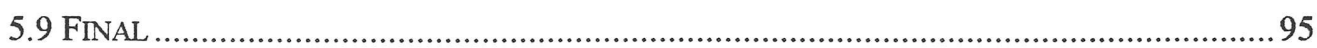

6. CONCLUSÕES E TRABALHOS FUTUROS .................................................................96

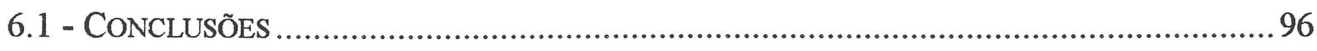

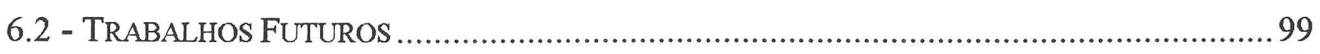

REFERÊNCIAS BIBLIOGRÁFICAS ................................................................................ 101 


\section{Lista DE Figuras}

Figura 2.1 Linha de referência / controle de concorrência............................................ 9

Figura 2.2 Processo de controle de mudanças ..........................................................13

Figura 2.3 Árvore de revisões em um item de configuração, usando delta negativo ...15

Figura 3.1 Elementos relacionados ao plano de gerenciamento de configuração........22

Figura 3.2 Exemplo de organograma para gerenciamento de configuração.................28

Figura 4.1 Gerenciamento de Configuração em Empresas de Pequeno Porte.............57

Figura 5.1 Elementos Relacionados ao Plano de Gerenciamento de Configuração ....63 


\section{LISTA DE QUADROS}

Quadro 1.1 Tarefas de gerenciamento de configuração de software ............................ 2

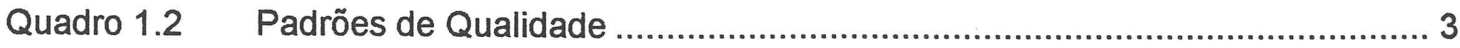

Quadro 2.1 Fases de Desenvolvimento de Software ............................................... 8

Quadro 2.2 Hierarquia dos itens de configuração ......................................................10

Quadro 2.3 Identificação dos itens de configuração ...................................................11

Quadro 3.1 Comparação entre padrões de planos de gerenciamento de configuração.25

Quadro 3.2 Estrutura do plano de gerenciamento de configuração...............................26

Quadro 4.1 O Método de Pesquisa GQM(Goal/Question/Metric) ................................37

Quadro 4.2 Lista de Questões a Serem Respondidas Pela Pesquisa ...........................39 


\section{INTRODUÇÃO}

\subsection{Contexto}

Durante o desenvolvimento de um software, é produzida uma grande quantidade de informações, tais como: especificações, planos de projeto, programas fonte, casos e planos de testes, manuais, arquivos de dados, etc. Cada um desses documentos é chamado de item de configuração de software. A configuração de software compreende todos os itens de configuração produzidos durante o processo de engenharia de software, ou seja, no processo de desenvolvimento disciplinado de sistemas [Pressman, 1995].

No período de desenvolvimento, há uma grande mutabilidade nos itens de configuração, pois itens novos podem ser criados e itens já existentes podem ser modificados, gerando novas versões. Para que haja maior controle no processo de desenvolvimento de sistemas, é necessário o estabelecimento de normas para a criação e alteração dos itens de configuração. A essas normas dá-se o nome de gerenciamento de configuração de software.

Gerenciamento de configuração de software (SCM) já foi definido de várias formas. Bersoff, Henderson e Siegel [Bersoff, 1980] o definem como "uma disciplina de identificação de um sistema em pontos discretos no tempo com a finalidade de controlar sistematicamente as mudanças em sua configuração e manter a integridade e a rastreabilidade dessa configuração, através de todo o ciclo de vida do software". Para Pressman [Pressman, 1995], gerenciamento de configuração de software é "uma atividade de 
garantia de qualidade de software que é aplicada durante todas as fases do processo de engenharia de software". Feiler [Feiler, 1991] descreve gerenciamento de configuração de software como "uma disciplina que proporciona estabilidade para a produção de um sistema de software, por controlar a evolução do produto". Segundo Babich [Babich, 1986], "grerenciamento de configuração de software é a arte de identificar, organizar e controlar modificações no software que está sendo construído por uma equipe de programação".

O quadro 1.1 apresenta, resumidamente, as tarefas de gerenciamento de configuração de software e as questões centrais a serem abordadas por elas [Bersoff, 1979; Berlack, 1992; Capretz, 1994; Narayanaswamy, 1987; Pressman, 1995].

Quadro 1.1 - Tarefas de gerenciamento de configuração de software

\begin{tabular}{|l|l|}
\hline \multicolumn{1}{|c|}{ Tarefa } & \multicolumn{1}{|c|}{ Questão } \\
\hline Identificação & $\begin{array}{l}\text { Como uma organização identifica e administra as muitas versões } \\
\text { existentes dos itens de configuração de forma que possibilite que } \\
\text { mudanças sejam feitas eficientemente? }\end{array}$ \\
\hline $\begin{array}{l}\text { Controle de } \\
\text { Mudanças }\end{array}$ & $\begin{array}{l}\text { Quem tem a responsabilidade pela aprovação e pela determinação } \\
\text { de prioridades para as mudanças? }\end{array}$ \\
\hline Controle de Versão & $\begin{array}{l}\text { Como uma organização controla as várias versões geradas pelas } \\
\text { mudanças feitas antes e depois que o software é liberado? }\end{array}$ \\
\hline $\begin{array}{l}\text { Auditoria de } \\
\text { Configuração }\end{array}$ & $\begin{array}{l}\text { Como se pode garantir que as mudanças foram feitas } \\
\text { adequadamente? }\end{array}$ \\
\hline Relato de Situação & $\begin{array}{l}\text { Qual o mecanismo usado para avisar outras pessoas sobre } \\
\text { mudanças que são feitas? }\end{array}$ \\
\hline $\begin{array}{l}\text { Controle de } \\
\text { Interface }\end{array}$ & $\begin{array}{l}\text { Como gerenciar o efeito causado por alterações externas ao } \\
\text { sistema? }\end{array}$ \\
\hline $\begin{array}{l}\text { Controle de } \\
\text { Subcontratados e } \\
\text { Fornecedores }\end{array}$ & $\begin{array}{l}\text { Como garantir que módulos do sistema construídos por terceiros } \\
\text { estejam corretos e coerentes com o restante do sistema? }\end{array}$ \\
\hline
\end{tabular}


Alguns órgãos certificadores de qualidade de software (quadro 1.2) exigem o gerenciamento de configuração de software como requisito básico para que uma empresa inicie a melhoria de qualidade do processo de desenvolvimento de software.

Quadro 1.2 - Padrões de Qualidade

\begin{tabular}{|l|l|}
\hline \multicolumn{1}{|c|}{ Padrões de Qualidade } & \multicolumn{1}{|c|}{ Recomendação } \\
\hline ANSI/IEEE 983-1986 & $\begin{array}{l}\text { Exige gerenciamento de configuração de software como } \\
\text { providência para garantia de qualidade. }\end{array}$ \\
\hline $\mathrm{CMM}^{1} / \mathrm{SEI}$ & $\begin{array}{l}\text { Exige gerenciamento de configuração de software para uma } \\
\text { empresa sair do nível de maturidade 1, denominado caótico. }\end{array}$ \\
\hline
\end{tabular}

Quando se fala em gerenciamento de configuração de software em pequenas empresas, geralmente o pessoal da área de informática reage de duas maneiras: desconhecem o assunto ou o associam com uma tarefa burocrática que apenas "atrasa o serviço".

A primeira reação não se justifica, pois gerenciamento de configuração vem sendo estudado desde os anos sessenta [Berlack, 1992]. Inicialmente, era aplicado da mesma forma para software e hardware, sendo que no final dos anos setenta já havia padrões de gerenciamento de configuração específicos para software.

A segunda reação é resultado de uma visão distorcida, pois os ganhos em tempo e qualidade pela aplicação do gerenciamento de configuração são comprovados e mensuráveis. Esses ganhos podem ser reconhecidos constatando-se que o uso de gerenciamento de configuração de software

1 CMM=Capability Maturity Model desenvolvido pelo Software Engeneering Institute (SEI) para a melhoria da qualidade do processo de desenvolvimento de software. Este modelo classifica as organizações em cinco estágios seqüenciais de maturidade (caótico, repetitível, definido, gerenciado e otimizado) e descreve os passos necessários para evolução [Paulk,1993]. 
facilita a comunicação entre as equipes de desenvolvedores relatando a situação do software a cada momento, assim como as alterações que foram efetuadas. Isso traz como conseqüência a redução no esforço necessário para efetuar alterações e a redução no número de erros. O resultado final é melhor cumprimento dos cronogramas, redução nos custos e melhora na qualidade do software [Berlack, 1992].

Essas reações podem não ocorrer se as tarefas de gerenciamento de configuração de software forem esclarecidas e orientadas através de um Plano de Gerenciamento de Configuração e apoiadas por ferramentas que automatizem algumas dessas tarefas.

No entanto, os padrões de planos de gerenciamento de configuração de software existentes (IEEE Std 828-1990, NASA-Sfw-DID-04, DoD-DID) se apresentam apenas como uma lista de tópicos que devem ser abordados na implantação das tarefas de gerenciamento de configuração de software. Essa lista é pouco esclarecedora e não é destinada especificamente para as necessidades de uma empresa de pequeno porte.

O mesmo ocorre com as ferramentas de gerenciamento de configuração de software existentes no meio acadêmico e no mercado (SCCS, RCS, Aide-de-Camp, AllChange, Continuus, CCC, ClearCase, CMSDigital, CMCV-IBM, CMZ, CVS, MKS Source Integrity, Perforce, PMCS, PVCS, SCLM, SMS, Source Code Manager, VCS-UX [CMFAQ, 1996]). Essas ferramentas geraimente são dispendiosas e necessitam computadores de grande porte ou estações de trabalho para serem executadas. Isso se deve ao fato de serem construídas para serem usadas em grandes projetos. Outro obstáculo para que essas ferramentas sejam usadas é a dificuldade para instalá-las e utilizá-las, pois seus manuais são vagos e a operação complexa. Esses obstáculos colocam as ferramentas além do alcance das pequenas empresas de desenvolvimento de software, que geralmente trabalham com orçamentos reduzidos, projetos pequenos e pessoal inexperiente em gerenciamento de configuração de software. 


\subsection{Objetivos}

As pequenas empresas que desenvolvem software geralmente produzem produtos que, ao longo do tempo, são adaptados às necessidades de cada nova situação. A administração das diversas versões liberadas poderia ser bastante auxiliada através de gerenciamento de configuração de software. Porém, esta solução não é viável devido aos altos custos para aquisição das ferramentas existentes e às dificuldades de implantação de um plano de gerenciamento de configuração de software.

Assim, o objetivo deste trabalho é executar um levantamento empírico das características de uma típica pequena empresa de desenvolvimento de software para, a partir desses dados, estudar quais tarefas de gerenciamento de configuração de software são essenciais para essas empresas e, então, apresentar um plano de gerenciamento de configuração de software específico para as mesmas. Faz parte desse plano a indicação de ferramentas existentes que sirvam de apoio às tarefas de gerenciamento de configuração de software consideradas importantes para uma empresa de pequeno porte.

\subsection{Organização do Trabalho}

Este trabalho está dividido em seis capítulos. Neste capítulo apresentam-se o contexto e os objetivos principais do trabalho.

A revisão bibliográfica compreende os capítulos 2 e 3 .

No capítulo 2 - Gerenciamento de Configuração de Software apresentam-se as principais tarefas de gerenciamento de configuração de software.

Os aspectos administrativos da implantação do gerenciamento de configuração de software apresentam-se no capítulo 3 - Planos de Gerenciamento de Configuração de Software. 
No capítulo 4 - A Determinação de um Típico Processo de Gerenciamento de Configuração de Software em Empresas de Pequeno Porte - é apresentada uma pesquisa empírica realizada em empresas de pequeno porte e são analisados os resultados obtidos.

No capítulo 5 - A Elaboração do Plano de Gerenciamento de Configuração de Software - é apresentado um plano de implantação de gerenciamento de configuração de software em empresas de pequeno porte.

No capítulo 6 - Conclusões e Trabalhos Futuros - são apresentadas as conclusões deste trabalho, bem como propostas para futuras pesquisas que podem ser desenvolvidas, na área de gerenciamento de configuração de software. 


\section{Gerenciamento DE CONFIGURAÇÃO DE SOFTWARE}

Este capítulo inicia com a apresentação do processo de desenvolvimento de software e de um conceito fundamental para o Gerenciamento de configuração de software: a linha de referência (baseline). Posteriormente, serão vistas as tarefas de gerenciamento de configuração de software: Identificação da Configuração, Controle de Versão, Controle de Mudanças, Auditoria de Configuração, Relato de Situação, Controle de Interface e Controle de Subcontratados e Fornecedores.

\subsection{Conceitos Fundamentais de Gerenciamento de Configuração de Software}

O desenvolvimento de um software pode ser organizado de várias formas. A cada uma dessas formas de organização dá-se o nome de um paradigma de ciclo de vida. Os paradigmas mais estudados são o clássico, a prototipação, o modelo espiral e as técnicas de quarta geração [Pressman, 1995].

Um processo de desenvolvimento de software, independente do paradigma de ciclo de vida adotado, inclui as fases de engenharia de sistemas, análise de requisitos, projeto de software, codificação, testes e manutenção [Pressman, 1995]. O quadro 2.1 apresenta uma descrição resumida de cada uma dessas fases. 
Quadro 2.1- Fases do Desenvolvimento de Software

\begin{tabular}{|l|l|}
\hline \multicolumn{1}{|c|}{ Fases } & \multicolumn{1}{c|}{ Descrição } \\
\hline $\begin{array}{l}\text { Engenharia de } \\
\text { Sistemas }\end{array}$ & $\begin{array}{l}\text { Coleta dos requisitos em nível do sistema, com uma pequena } \\
\text { quantidade de projeto e análise de alto nível. }\end{array}$ \\
\hline Análise de Requisitos & $\begin{array}{l}\text { Compreensão do domínio da informação através dos requisitos } \\
\text { coletados na fase anterior. }\end{array}$ \\
\hline Projeto de Software & $\begin{array}{l}\text { Desenvolvimento de quatro atributos distintos do software: } \\
\text { estrutura de dados, arquitetura de software, detalhes } \\
\text { procedimentais e caracterização de interfaces. }\end{array}$ \\
\hline Codificação & $\begin{array}{l}\text { Tradução do projeto de software numa forma legível para a } \\
\text { máquina. }\end{array}$ \\
\hline Testes & $\begin{array}{l}\text { Realização de testes dos programas. Esses testes concentram-se } \\
\text { nos aspectos lógicos internos do software e nos aspectos } \\
\text { funcionais externos. }\end{array}$ \\
\hline Manutenção & $\begin{array}{l}\text { Modificações após o software ser liberado. Essas mudanças } \\
\text { ocorrem por erros, adaptações, novos ambientes e novas } \\
\text { funcionalidades. }\end{array}$ \\
\hline
\end{tabular}

Durante o processo de desenvolvimento de um software, é produzida uma grande quantidade de itens de informação. Esses itens são chamados itens de configuração de software e o conjunto dos mesmos compõem uma configuração de software.

A criação e as alterações de cada item de configuração de software devem ser acompanhadas e controladas pelo gerente do projeto. Para isso, é necessário o estabelecimento de pontos bem definidos dentro do processo de desenvolvimento do software: as Linhas de Referência (baselines). Esses pontos podem ocorrer ao final de cada uma das fases do processo de desenvolvimento de software, ou de algum outro modo definido pela gerência.

Nos pontos estabelecidos pelas linhas de referência, os itens de configuração devem ser identificados, analisados, corrigidos, aprovados e armazenados ("congelados") como uma configuração de software. Os itens aprovados são armazenados em um local sob controle de acesso, 
denominado repositório dos itens de configuração. Esses itens só poderão ser alterados após uma solicitação de alteração formalmente aprovada pelo gerente de configuração. Essa é uma forma de prover controle sobre a situação de cada um dos itens de configuração, evitando inconsistências.

O método utilizado para trabalhar com itens de configuração que já estão no repositório é chamado de Check In/Check Out [Bersoff, 1979; Harter, 1989], ou seja, conferência na entrada e conferência na saída. Quando for desejada uma alteração em algum item de configuração do repositório, uma cópia do item é colocada numa área de trabalho do desenvolvedor ("check out"). A partir desse momento, nenhum outro desenvolvedor poderá alterar o mesmo item: a isso dá-se o nome de controle de concorrência. Dentro de sua área, o desenvolvedor tem total liberdade de trabalho. Após o final das alterações no item de configuração, ele será revisado e recolocado no repositório ("check in"). Nesse momento, uma nova linha de referência deverá ser traçada, de modo que uma nova configuração contendo o item alterado seja formada e congelada no repositório (Figura 2.1).

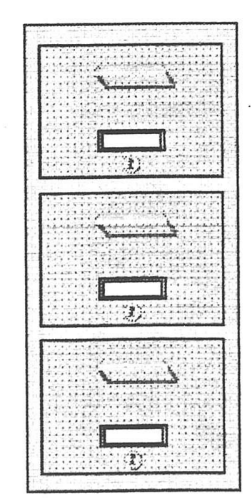

Repositório

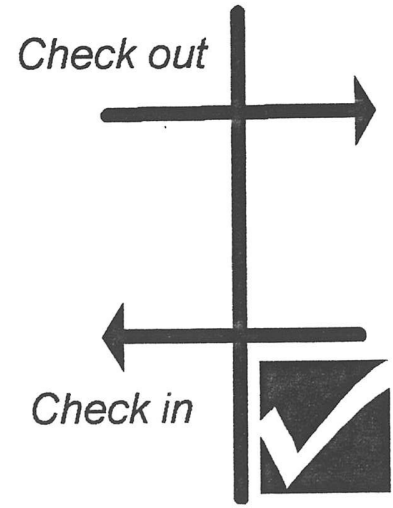

Linha de Referência

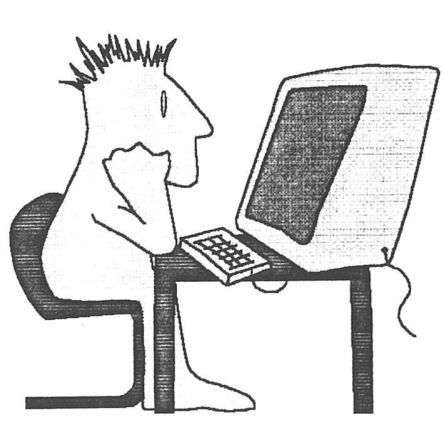

Área de trabalho do desenvolvedor

Figura 2.1 - Linha de Referência / Controle de concorrência 
Depois do congelamento, o acesso é liberado, permitindo que outros desenvolvedores também executem alterações sobre esse item de configuração.

\subsection{Tarefas de Gerenciamento de Configuração de Software}

As tarefas de gerenciamento de configuração de software, que respondem às questões apresentadas no quadro 1.1 são descritas a seguir.

\subsection{1 - Tarefa 1- Identificação da Configuração de Software}

O primeiro passo para a identificação é selecionar os itens a serem gerenciados. Como exemplo, apresentamos no quadro 2.2 uma série de itens sugeridos por Pressman [Pressman, 1995]:

Quadro 2.2- Hierarquia dos itens de configuração

1. Especificação do Sistema

2. Plano de Projeto de Software

3. Especificação de Requisitos do Software

4. Manual Preliminar do Usuário

5. Especificação do Projeto

a) Descrição do Projeto de Dados

b) Descrição do Projeto Arquitetural

c) Descrições do Projeto Modular

d) Descrições do Projeto de Interface

e) Descrições de Objetos (se forem usadas técnicas orientadas a objetos)

6. Listagem do código-fonte

7. Planos, Procedimentos, Casos de Testes e Resultados Registrados

8. Manuais Operacionais e de Instalação

9. Programa Executável e Módulos Interligados

10. Descrição do Banco de Dados

a) Esquema e estrutura de arquivo

b) Conteúdo inicial

11. Manual do Usuário

12. Documentos de Manutenção

a) Relatórios de problemas de software

b) Solicitações de manutenção

c) Pedidos de mudança

13. Padrões e procedimentos para engenharia de software

14. Ferramentas de produção de software (editores, compiladores, CASE, etc.)

É importante que seja efetuada uma seleção dos itens relevantes, porque uma superdocumentação torna o gerenciamento de configuração muito oneroso. Geralmente, devem sofrer gerenciamento de configuração os 
itens mais usados no ciclo de vida, os mais genéricos, os mais importantes para a segurança, os itens projetados para reuso e os que podem ser modificados por vários desenvolvedores ao mesmo tempo [Bersoff, 1992]. Somente os itens selecionados serão controlados, sendo que os outros itens poderão ser alterados livremente.

Após a seleção, deve-se descrever como esses itens se relacionam. Consideram-se cinco classes de relacionamento: equivalência (ex: BD em disco e em fita magnética), dependência (ex: a descrição do projeto modular é dependente da especificação do projeto), derivação (ex: código objeto é derivado do código fonte), sucessão (ex: a versão 1.2 é sucessora da versão 1.1) e variante (ex: versão para DOS ou para UNIX). A identificação desses relacionamentos é muito importante para a manutenção, pois permite que se localize rapidamente os itens afetados por cada alteração.

Depois de escolhidos os itens e estabelecidos os relacionamentos, deve-se criar um esquema de identificação dos itens com a atribuição de nomes únicos a cada um dos componentes, de forma que seja possivel reconhecer a evolução de cada uma das versões dos componentes e a hierarquia existente entre componentes, a partir de seus nomes [Bersoff, 1979; Karakas, 1992]. Um exemplo simples para um pequeno programa cuja sigla é "AA" é apresentado no quadro 2.3. O esquema de identificação utiliza a combinação de nome do projeto, tipo de item, nome do item e versão.

Quadro 2.3 -Identificação dos itens de configuração

\begin{tabular}{|l|lll|l|l|l|}
\hline \multicolumn{1}{|c|}{ Item } & Projeto & Tipo & Nome & Versão & Nome completo \\
\hline Especificação do Sistema & AA & ES & & 1.1 & AAES & v1.1 \\
Plano de Projeto & AA & PP & & 1.1 & AAPP & v1.1 \\
Especificação de Requisitos & AA & ER & & 1.1 & AAER & v1.1 \\
do Software & & & & & & \\
Especificação de Projeto & AA & EP & & 1.1 & AAEP & v1.1 \\
Programa Fonte & AA & PF & Prin & 1.1 & AAPFPrin & v1.1 \\
Programa Fonte (sub-rotinas) & AA & PF & Rot & 1.1 & AAPFRot & v1.1 \\
Plano e Casos de Testes & AA & TT & & 1.1 & AATT & v1.1 \\
Nova versão das sub-rotinas & AA & PF & Rot & 1.2 & AAPFRot & v1.2 \\
\hline
\end{tabular}


Após o estabelecimento do esquema de identificação, devem ser planejadas as linhas de referência dentro do ciclo de vida do projeto. Geralmente, cria-se uma linha de referência ao final de cada fase do ciclo de vida do projeto e, periodicamente, depois de cada manutenção. Deve-se especificar quais itens serão revisados e armazenados em cada uma das linhas de referência planejadas. O último passo da identificação é descrever a maneira como os itens serão arquivados e recuperados do repositório.

\subsection{2 - Tarefa 2 - Controles de Mudança e de Versões}

Dois controles básicos são instituídos no processo de gerenciamento de configuração de software: Controle de Mudanças e Controle de Versões.

\section{a) Controle de Mudanças}

Durante 0 processo de desenvolvimento de software, mudanças descontroladas podem levar rapidamente ao caos [Presmann, 1995]. Assim, deve ser instituído na organização um processo que combine procedimentos humanos e ferramentas automatizadas para proporcionar um mecanismo de controle das mudanças. Esse processo deve ser implementado depois que uma linha de referência for fixada - antes disso somente um controle de mudanças informal precisa ser aplicado [Bersoff, 1979; Bersoff, 1984; Bersoff, 1992; Presmann, 1995]. A figura 2.2 ilustra um processo de controle de mudanças que pode ser implementado para os itens que já passaram por uma linha de referência.

De acordo com esse processo de controle de mudanças, quando um pedido de mudança é solicitado, primeiramente ele deve ser analisado, gerando um relatório de mudanças. Esse relatório é encaminhado para avaliação; se aprovado, o relatório de mudança segue para o gerente de configuração. O Gerente de configuração controla o acesso aos itens no repositório, liberando-os para a equipe de desenvolvimento para que a mudança seja efetuada, e recebendo os itens, quando atualiza o repositório. 
Caso o pedido de mudança não seja aprovado, o relatório e o pedido são arquivados e é dado um retorno ao solicitante.

Esse controle possibilita que as mudanças sejam efetuadas, comunicadas e incorporadas de um modo disciplinado. Entretanto, para que esse controle ocorra de forma satisfatória, qualquer mudança que ocorra nos itens de configuração de software, após o estabelecimento de uma linha de referência, deve seguir efetivamente sempre o mesmo caminho [Bersoff, 1992].

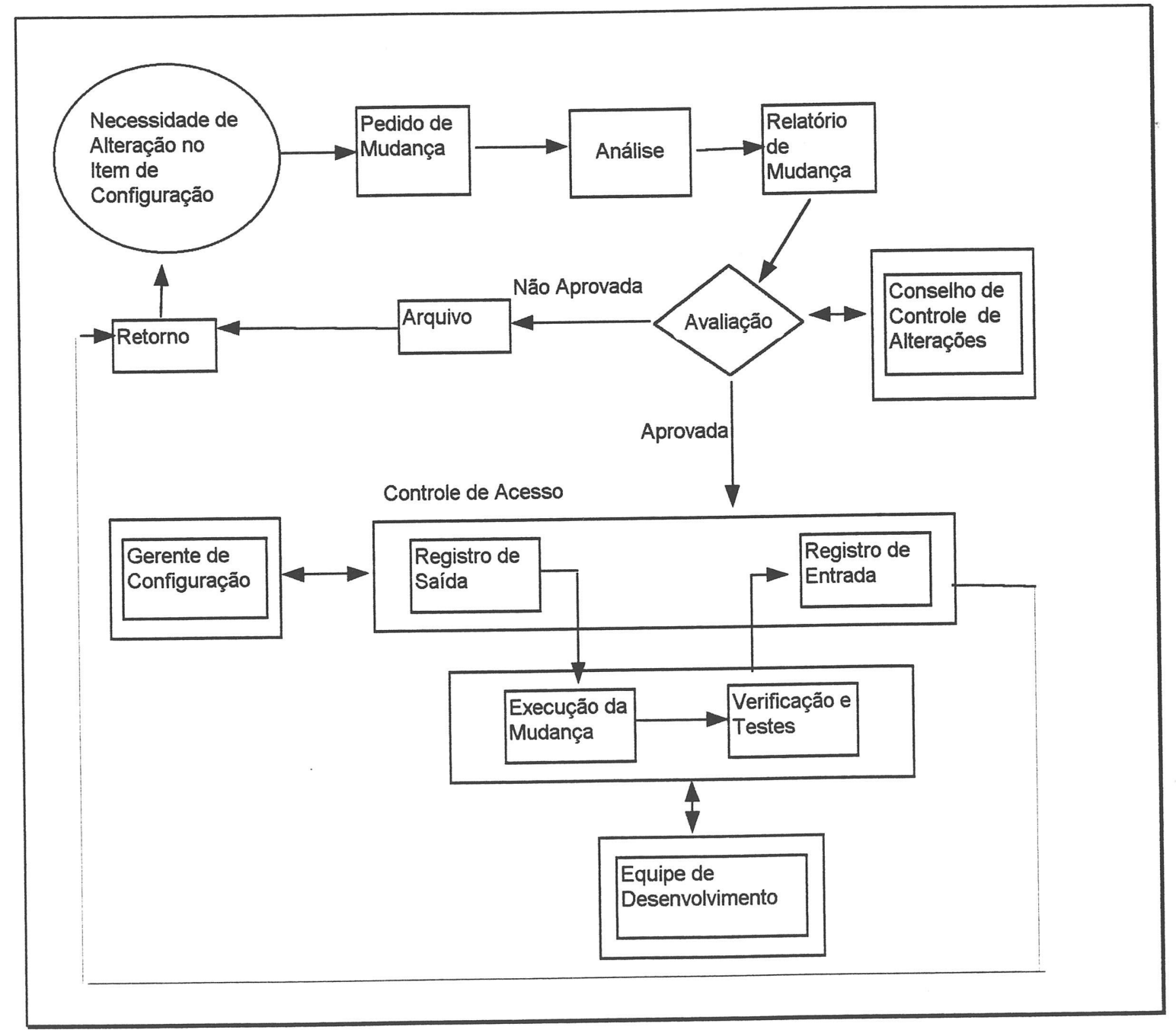

Figura 2.2 - Processo de Controle de Mudanças

No processo de controle de mudanças, as alterações aprovadas são efetuadas de maneira sincronizada. O objetivo dessa sincronização é evitar que duas pessoas efetuem, ao mesmo tempo, mudanças incompatíveis em 
um mesmo item, criando inconsistências [Bersoff, 1992]. O método mais utilizado para evitar inconsistências é controlar o acesso ao repositório, de forma que, quando um desenvolvedor retira um item para alterações, ele bloqueia o acesso de escrita no item para os outros desenvolvedores (vide seção 2.1).

Os procedimentos de controle das mudanças asseguram que as mudanças em um software sejam feitas de modo controlado, permitindo-se prever o efeito das mesmas em todo o sistema. Procedimentos formais de organização e de controle das mudanças no sistema permitem que os pedidos de alteração possam ser considerados em conjunto com outros pedidos. Desse modo, os pedidos similares podem ser agrupados, e os pedidos incompatíveis entre si ou com os objetivos do sistema identificados. Também podem ser atribuídas prioridades aos pedidos e, de acordo com essas prioridades, pode-se gerar um cronograma.

\section{b) Controle de Versões}

Um item, ao ser desenvolvido, evolui até que atinja um estado em que atenda aos propósitos para o qual foi criado. Isso implica em diversas alterações, gerando uma versão (revisão) do item a cada estado. Para estabelecer o controle sobre as diversas versões, todas as versões devem ser armazenadas e identificadas. Isso, geralmente, é feito com o auxílio de uma ferramenta.

A versão do item pode ser incluída no esquema de identificação ou ser acessivel a partir de uma tabela à parte (vide seção 2.2.1). É conveniente que o esquema de identificação das versões dos itens seja feito em forma de árvore, pois ao mesmo tempo em que mantém um histórico das versões dos itens, permite identificação única e ramificações a partir de qualquer versão (Figura 2.3).

Quando um item existe simultaneamente em duas ou mais formas diferentes que atendam a requisitos similares, temos variantes do item, 
representados por ramificações na árvore. Um exemplo seria o de duas subrotinas para retornar a data do sistema operacional: uma para Unix e outra para OS/2 (versões 2.1 .1 e 2.2.1 na Figura 2.3).

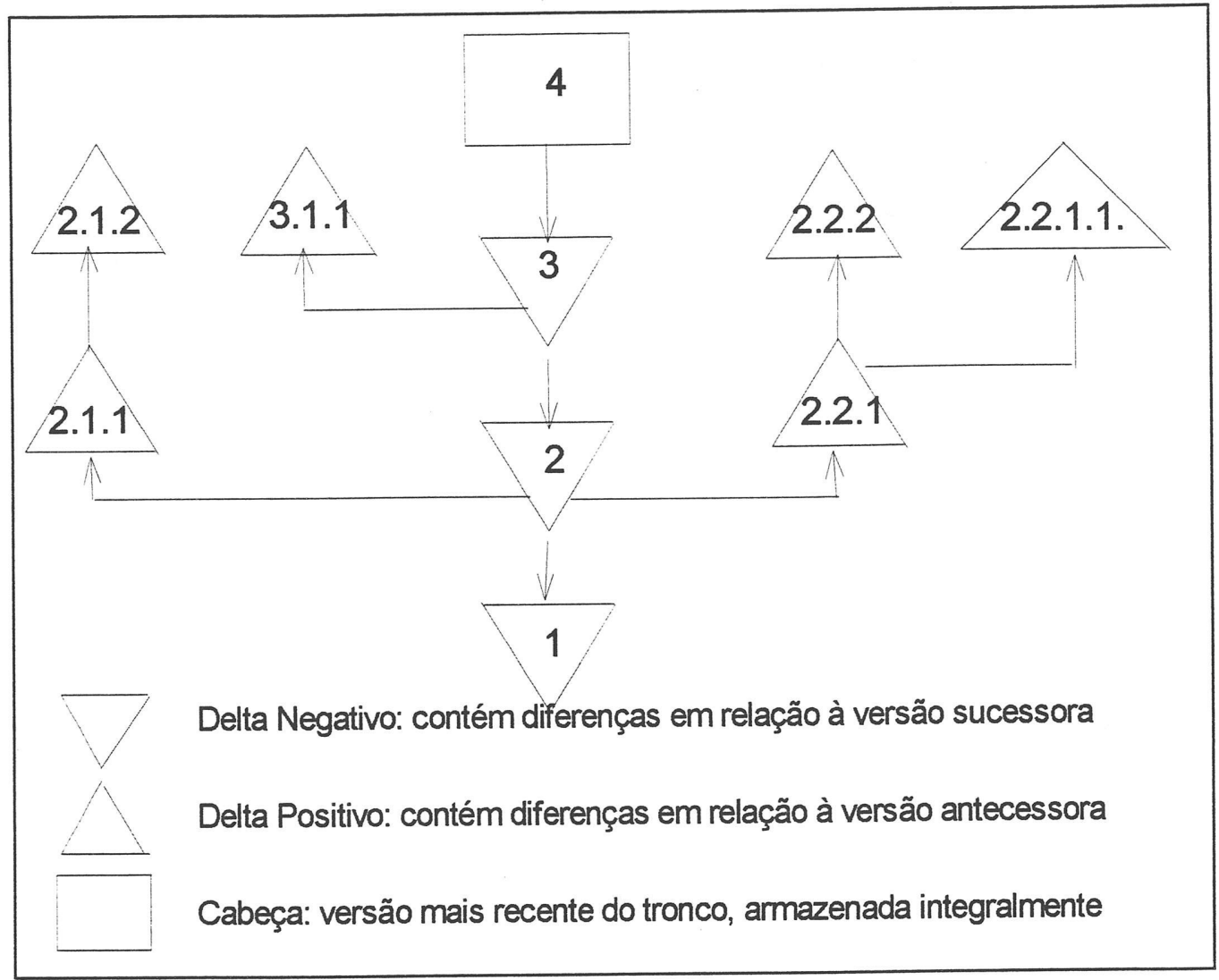

Figura 2.3- Árvore de revisões em um item de configuração, usando delta negativo.

Para minimizar o espaço de armazenamento das versões utiliza-se o conceito de delta, ou seja, são armazenadas uma versão completa e as diferenças entre as versões [Ambriola, 1990; Boas, 1994; Brown, 1991; Dart, 1991; Humphrey, 1989]. Há duas variações desse conceito: delta negativo e delta positivo. Com o delta negativo, armazena-se integralmente a versão mais recente e as diferenças (deltas) existentes até então. Com o delta positivo, armazena-se a versão mais antiga e, para montar as versões mais recentes, processam-se as diferenças (deltas) armazenadas.

Os sistemas atuais de gerenciamento de versões utilizam o conceito de delta negativo no tronco, por ser mais comum a utilização de versões mais recentes do item de configuração [Boas, 1994]. A figura 2.3 representa um 
caso em que se utiliza delta negativo. A única versão armazenada integralmente é a 4. As outras versões são construídas, quando solicitadas, a partir da 4 e das diferenças armazenadas. Utilizam-se deltas negativos no tronco da árvore, que representa o caminho principal de evolução do item. As raificações representam as variantes dos itens e são obtidas pela utilização de delta positivo.

\subsection{3 - Tarefa 3 - Auditoria da Configuração}

A identificação e controle das alterações ajudam a manter ordem mas, para assegurar que a alteração foi implementada apropriadamente, há necessidade de auditorias na configuração do software [Sommerville, 1989].

Existem dois tipos de auditoria de configuração de software que são pré-requisitos para o estabelecimento das linhas de referência no ciclo desenvolvimento de software: a Auditoria Funcional e a Auditoria Física.

A auditoria funcional preocupa-se com aspectos internos dos arquivos, compreendendo uma verificação técnica formal na configuração de software, que deve ser realizada ao ser fixada uma linha de referência. Esta verificação é uma atividade de controle de qualidade que tenta descobrir omissões ou erros na configuração, que degradam os padrões de construção do software [Capretz, 1992; Capretz, 1994; Pressman, 1995].

A auditoria física é um processo administrativo que ocorre no final de cada fase do ciclo de vida do software e consiste em verificar se a configuração, a ser congelada pela linha de referência, está composta da versão mais recente dos itens de configuração, determinados para a fase do ciclo de vida específica [Bersoff, 1979; Bersoff, 1984; Capretz, 1992] e se os procedimentos e padrões foram devidamente aplicados.

\subsection{4 - Tarefa 4 - Relato da Situação}

O objetivo dessa tarefa de gerenciamento de configuração é relatar a todas as pessoas envolvidas no desenvolvimento e na manutenção do 
software as seguintes informações sobre as alterações na configuração de software:

a) O que aconteceu?

b) Quem o fez?

c) Quando aconteceu?

d) O que mais será afetado?

Para isso, deve ser criado um banco de dados sobre as ocorrências no gerenciamento de configuração. Esse banco de dados deve estar disponível aos desenvolvedores com acesso através de palavras-chave. Além disso, deve ser gerado regularmente um relatório de situação para informar as alterações mais importantes. O acesso rápido às informações sobre a configuração agiliza o processo de desenvolvimento e melhora a comunicação entre as pessoas, o que é uma maneira de eliminar muitos problemas relativos à modificação do mesmo item de informação, com intenções diferentes e conflitantes.

\subsection{5 - Tarefa 5 - Controle de interface}

As atividades de controle de interface (ou fronteira) coordenam as mudanças nos itens de configuração que são afetados por itens que não estejam sendo controlados. Equipamentos, sistemas de software, software de suporte, assim como outros projetos devem ser examinados na busca por possiveis interfaces com o projeto sob controle.

Para cada interface o plano deve descrever:

a) O tipo de interface.

b) As unidades organizacionais afetadas.

c) Como será feito o controle sobre a interface.

d) Como os documentos de controle da interface serão aprovados. 


\subsection{6 - Tarefa 6 - Controle de subcontratados e fornecedores}

As atividades de controle de subcontratados e fornecedores coordenam a forma como os itens que foram desenvolvidos por solicitação a outras empresas ou foram adquiridos já prontos são testados e incorporados ao repositório do projeto.

Para itens subcontratados o plano deve descrever:

a) Os requisitos de gerenciamento de configuração de software a serem satisfeitos pelo subcontratado.

b) Como será feito o monitoramento sobre o subcontratado.

c) Como o código, documentação e dados externos serão testados, aceitos e adicionados ao projeto.

d) Como serão tratadas as questões de propriedade do código produzido, como direitos autorais e royalties.

Para itens adquiridos prontos o plano deve descrever:

a) Como serão recebidos, testados e colocados sob controle de gerenciamento de configuração.

b) Como as mudanças no software do fornecedor serão tratadas.

c) Se e como o fornecedor participará no processo de gerenciamento de mudança do projeto.

Itens de configuração poderão ser adquiridos de fornecedores, subcontratados, clientes, outros projetos ou outras fontes.

\subsection{Considerações Finais}

Neste capítulo, foram apresentados conceitos gerais e as principais tarefas de gerenciamento de configuração de software. Um estudo detalhado das necessidades específicas de cada ambiente de desenvolvimento de software, no que diz respeito ao gerenciamento de configuração de software, é necessário para que seja possível a execução das tarefas de forma mais 
adequada a cada situação. O documento gerado após esse estudo é chamado Plano de Gerenciamento de Configuração de Software. No próximo capítulo, planos de gerenciamento de configuração de software são estudados em maiores detalhes. 


\section{Plano de Gerenciamento de CONFIGURAÇÃO DE SOFTWARE}

Um plano representa um método através do qual tarefas podem ser definidas e executadas. Este capítulo apresenta elementos organizacionais que influenciam a preparação do plano de gerenciamento de configuração de software e alguns padrões de planos de gerenciamento de configuração de software. O padrão IEEE Std 828-1990 é estudado em detalhes. No final do capítulo são apresentadas recomendações para a elaboração de um plano de gerenciamento de configuração de software.

\subsection{Elementos envolvidos no Plano de Gerenciamento de Configuração}

O plano de gerenciamento de configuração de software é um documento que descreve quais atividades devem ser efetuadas na implantação e na administração do processo de gerenciamento de configuração de software. Neste plano também é descrito como e quando as atividades serão efetuadas, quem serão os responsáveis por elas e que recursos serão necessários [Whitgifh, 1991, IEEE Std 828-1990]. O plano de gerenciamento de configuração de software é desenvolvido de acordo com as peculiaridades de cada empresa, ou seja, ele depende das metas e soluções alternativas específicas a cada ambiente.

Dez elementos estão envolvidos no plano de gerenciamento de configuração de uma organização [Bounds, 1993]. Sete deles referem-se à etapa de preparação do plano e três à etapa de implantação. 


\section{Preparação do Plano:}

1. Projeto do plano: determinar a estrutura do plano de gerenciamento de configuração. Neste passo é recomendado que sejam estudados alguns padrões internacionais de gerenciamento de configuração de software.

2. Processo: descrever as tarefas de gerenciamento de configuração que serão implementadas e os controles que serão efetuados nas mesmas.

3. Pessoas: relacionar pessoas às funções, tarefas e responsabilidades envolvidas no gerenciamento de configuração.

4. Ambiente: analisar o tipo de cultura que existe na organização a fim de buscar uma solução de gerenciamento de configuração que seja apropriada a esta cultura.

5. Sistema: determinar os sistemas ou partes de sistemas que serão colocados sob o controle do gerenciamento de configuração e determinar os itens de informação que são relevantes para compor a configuração de software desses sistemas.

6. Automatização: decidir os requisitos mínimos que uma ferramenta de gerenciamento de configuração de software deverá apresentar em termos de funcionalidade, custo, plataforma necessária, facilidade de uso, etc.

7. Decisões Gerenciais: identificar como a gerência encara a utilização de ferramentas de gerenciamento de configuração de software que já existem no mercado e o desenvolvimento parcial ou integral de ferramentas de gerenciamento de configuração de software na própria organização.

Implantação do Plano:

1. Elaboração do plano: escrever o plano de forma a atender todos os requisitos identificados nas sete fases da etapa de preparação.

2. Implantação de ferramentas de gerenciamento de configuração de software: implantar as ferramentas adquiridas ou desenvolvidas para 
auxiliar o gerenciamento de configuração. Este passo pode incluir treinamento.

3. Elaboração da estratégia de implantação: desenvolvimento de um roteiro para auxiliar a implantação do processo de gerenciamento de configuração na organização e para institucionalizar este processo. A institucionalização ocorre após intensiva realização das tarefas e utilização das ferramentas e a identificação de necessidades de alterações e complementações neste processo.

Os elementos relacionados ao plano de gerenciamento de configuração de software são representados na figura 3.1.

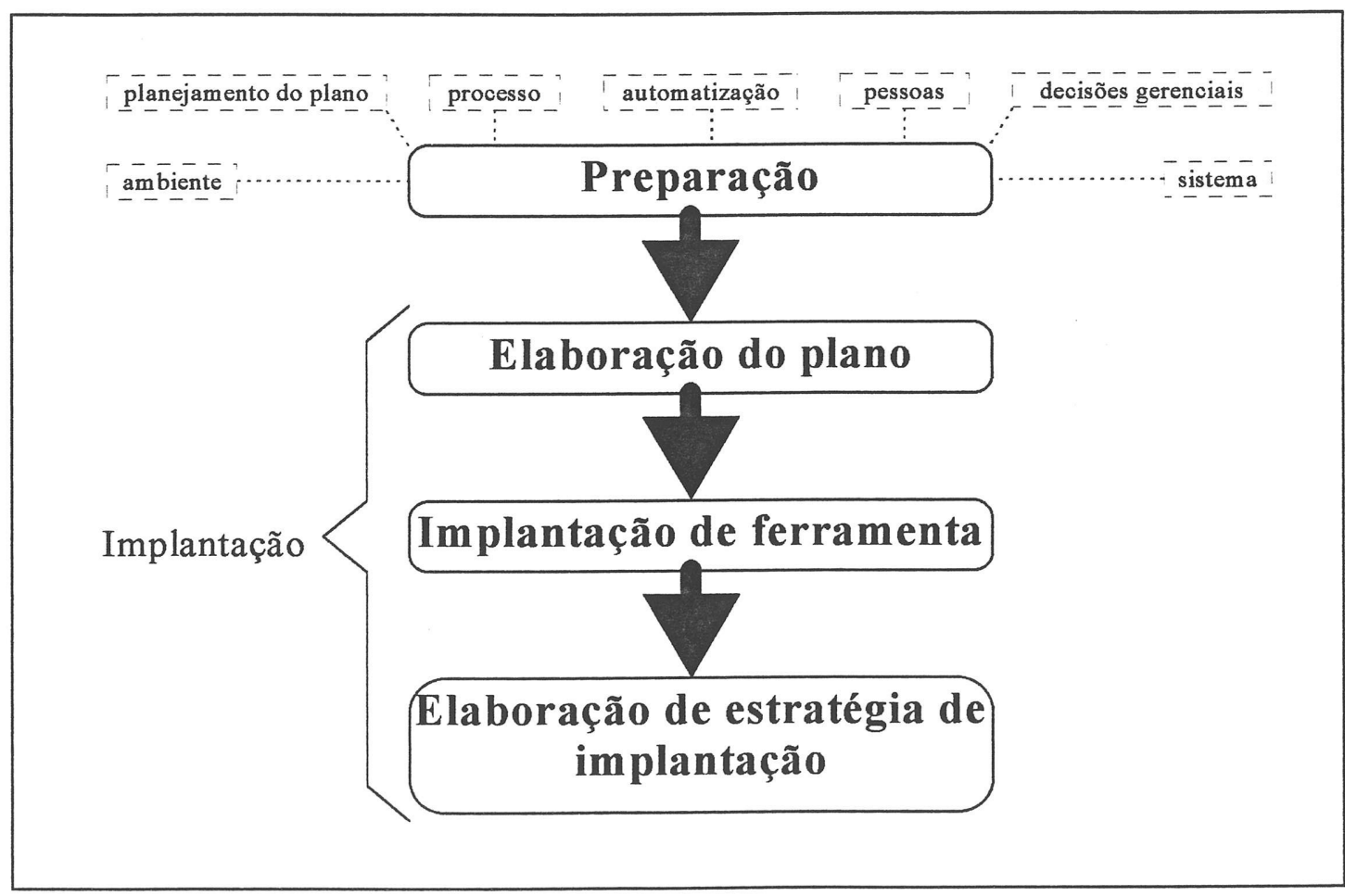

Figura 3.1 - Elementos relacionados ao plano de gerenciamento de configuração

A elaboração do plano é um dos três fatores chave para o sucesso em gerenciamento de configuração. Em muitos casos, o gerenciamento de configuração faz parte de um projeto de melhoria de toda a empresa e, neste caso, o plano deve estar em concordância com os outros planos relacionados com o esforço geral de melhoria.[Bounds, 1993] 


\subsection{Alguns Padrões de Planos de Gerenciamento de Configuração de Software}

Ao iniciar o desenvolvimento de um plano de gerenciamento de configuração de software, é natural a dúvida sobre como começar e qual a forma mais adequada de apresentação das informações. É recomendado que sejam estudados alguns dos padrões internacionais de planos de gerenciamento de configuração e que seja escolhido como base aquele que tenha maior compatibilidade com o projeto para o qual o plano esteja sendo escrito [Buckley, 1993].

Alguns dos padrões mais amplamente utilizados são:

- IEEE Standard for Configuration Management Plans (IEEE Std 828-1990): Deve ser analisado juntamente com o IEEE Std 1042-1986, um guia de gerenciamento de configuração, e o IEEE Std 610.12-1990, um glossário de termos de engenharia de software. 0 grande valor deste padrão é que ele registra o consenso, entre os profissionais da área, sobre o que deve ser feito.

- Configuration Management Practices for Systems, Equipment, Munitions, and Computer Programs (MIL-STD-483A-1979): Especifica o formato e o conteúdo necessário para um plano de gerenciamento de configuração. 0 nível de detalhes é superficial e requer ampliação se software ou firmware forem incluídos.

- NASA Software Configuration Management Plan Item Description (NASASfw-DID-04): Foi escrito para um segmento específico de indústria e é muito bem organizado, o que o torna fácil de usar. Os capítulos sobre controle de mudanças e documentação merecem destaque, porém o seu maior problema é que pede ao usuário que crie um plano para cada item de configuração, o que é trabalhoso e cria redundâncias. Outro problema é a sua superficialidade. 
- DoD Software Development Plan Data Item Description juntamente com DoD-STD-2167A (DI-MCCR-80030A): A abordagem utilizada é introduzir as informações de planejamento de gerenciamento de configuração de software no próprio plano de desenvolvimento de software. O problema é que desta maneira as informações de gerenciamento de configuração ficam dispersas no plano de desenvolvimento, não sendo possível identificá-las separadamente. Se o contrato forçar o uso desta abordagem, o problema pode ser contornado colocando-se o plano de gerenciamento de configuração de software como um apêndice do plano de desenvolvimento de software.

Bounds e Dart [Bounds, 1993] analisaram três desses padrões (quadro 3.1) utilizando os critérios facilidade de uso, completitude, adaptabilidade, correção, consistência e adequação ao ciclo de vida do software.

- Facilidade de uso é medida pelo tempo e pelo esforço realizado para aprender como usar um padrão, e pelo esforço realizado para executar o plano. Atenção especial é dada àqueles que estão escrevendo um plano pela primeira vez.

- Completitude é conseguida quando o usuário do padrão não tem que procurar informações em outros lugares além do padrão para escrever um plano, ou seja, apenas com o padrão em mãos é possível escrever o plano.

- Adaptabilidade é a medida do quanto o padrão pode ser modificado de forma a atender às necessidades de cada projeto e com que facilidade isso pode ser feito.

- Correção é a medida em que o padrão contém apenas informações corretas, sem contradições ou informações inúteis ou impraticáveis.

- Consistência é obtida se o padrão é bem estruturado e se há uniformidade através de todo o documento, especialmente na nomenclatura.

- Adequação ao ciclo de vida do software só pode ser conseguida por um bom padrão e representa o quanto o padrão de gerenciamento de 
configuração e as tarefas de gerenciamento de configuração se encaixam no ciclo de vida do projeto.

O padrão IEEE obteve melhores resultados nos quatro primeiros critérios, empatando nos dois últimos. Essas características fazem com que o padrão IEEE seja o mais adequado para desenvolvimento de planos de gerenciamento de configuração de software de uso geral.

Quadro 3.1- Comparação entre padrões de planos de gerenciamento de configuração

\begin{tabular}{|l|r|r|r|}
\hline \multicolumn{1}{|c|}{ Critério } & IEEE & NASA & DoD \\
\hline Facilidade de Uso & 3 & 1 & 1 \\
\hline Completitude & 2 & 1 & 0 \\
\hline Adaptabilidade & 3 & 1 & 1 \\
\hline Correção & 3 & 1 & 1 \\
\hline Consistência & 3 & 3 & 3 \\
\hline Adequação ao ciclo de vida & 1 & 1 & 1 \\
\hline
\end{tabular}

$0=$ não satisfaz requisitos mínimos

1 =satisfaz os requisitos para um padrão regular

$2=$ satisfaz os requisitos para um bom padrão

3=satisfaz os requisitos para um ótimo padrão

Outras características de destaque do padrão IEEE são:

- Não é um padrão específico para determinado ramo da indústria (o que ocorre com os da NASA e DoD), e ainda permite adaptações;

- Não exige grande experiência anterior para que um plano seja escrito;

- É aplicável a todo o ciclo de vida do software;

- Abrange o controle sobre empresas subcontratadas ou fornecedoras de itens e as informações necessárias a este controle;

- Provê uma lista de interfaces possíveis, e as informações mínimas necessárias em cada uma.

$\mathrm{Na}$ próxima seção será apresentada a estrutura do plano de gerenciamento de configuração proposto pelo padrão IEEE Std 828-1990. 


\subsection{O Padrão IEEE Std 828 1990}

Este padrão foi escrito pelo subcomitê de engenharia de software do Instituto dos Engenheiros Eletro-Eletrônicos dos Estados Unidos, para estabelecer o conteúdo mínimo necessário em um plano de gerenciamento de configuração de software e para definir as atividades e requisitos de gerenciamento de configuração de software necessários durante o desenvolvimento do software.

Este padrão é uma atualização do padrão do ano de 1983, ocorrida devido às novas práticas de engenharia de software e ao novo padrão de gerenciamento de configuração: IEEE Std 1042-1987. Os usuários do padrão poderão ser todos os envolvidos no planejamento das atividades de gerenciamento de configuração ou na execução de auditorias de gerenciamento de configuração de software.

O plano resultante da adoção deste padrão tem a estrutura apresentada no quadro 3.2 .

Quadro 3.2 - Estrutura do Plano de Gerenciamento de Configuração

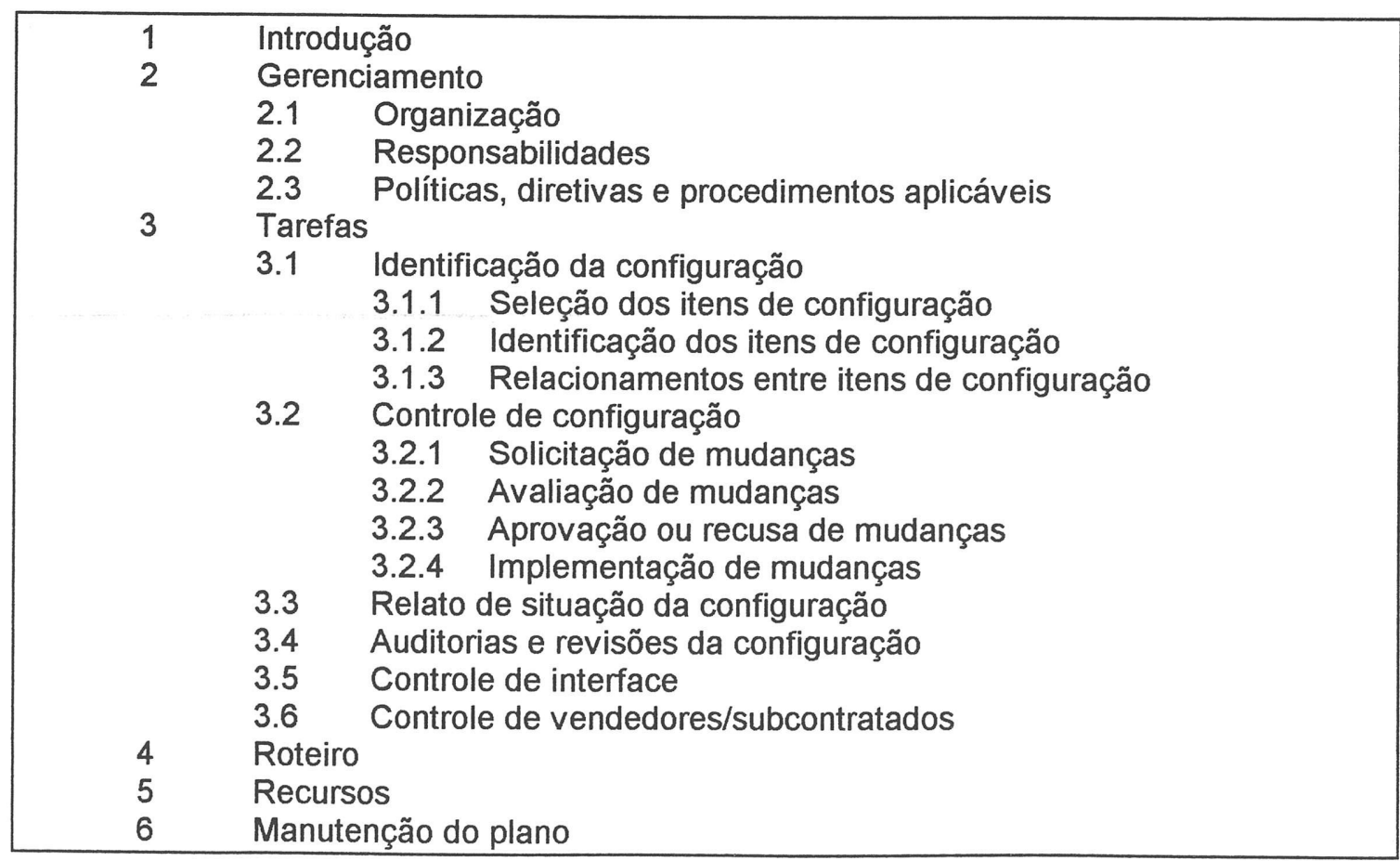




\subsection{1 - Introdução do Plano}

Esta seção descreve o propósito do plano, as possiveis aplicações, termos-chave e referências. Deve ser apresentado um resumo bem simplificado dos conceitos das tarefas de gerenciamento de configuração que serão efetuadas, para que as pessoas que tenham que interagir com gerenciamento de configuração o compreendam melhor. Quatro tópicos são importantes:

- Propósito: as primeiras necessidades de quem lê o plano são saber por que ele existe e quem deve lê-lo. Também é interessante que se faça uma análise de riscos da implantação do gerenciamento de configuração.

- Escopo: deve ser descrito onde o gerenciamento de configuração será aplicado, e as limitações e suposições sobre as quais o plano está baseado. Podem ser incluídas também previsões de custo e prazos, descrição do projeto onde será aplicado, participações dos clientes, ferramentas disponíveis, etc.

- Termos-chave: devem ser definidos para que se tenha uma terminologia única entre todos os usuários do plano.

- Referências: todas as referências que o plano fizer a políticas, padrões, procedimentos, terminologias ou outros documentos devem ser identificadas, para que os usuários possam ter acesso.

\subsection{2 - Gerenciamento}

Esta seção identifica os responsáveis e as autoridades que devem acompanhar as atividades planejadas. Devem ser descritas as unidades organizacionais envolvidas com gerenciamento da configuração e as responsabilidades de cada unidade. Cada uma das tarefas de gerenciamento de configuração deve ter uma unidade responsável. É recomendável que se registrem os atributos necessários e desejáveis para o ocupante de cada cargo. 
Para grandes organizações, é geralmente necessário criar departamentos, cada um responsável por determinada tarefa para um único projeto, algumas vezes com hierarquias entre esses departamentos. Para projetos e/ou organizações menores, um departamento pode executar determinada tarefa para vários projetos ou um departamento pode ser composto de uma única pessoa ou mesmo podem ser atribuídas várias tarefas a uma única pessoa, desde que seja feita uma análise cuidadosa sobre os possíveis resultados dessa acumulação de tarefas. Não seria aconselhável, por exemplo, permitir que alguém fosse programador e gerente de configuração do mesmo projeto.

Whitgifh [Whitgifh, 1991] apresenta, em seu livro sobre métodos e ferramentas para gerenciamento de configuração de software, um organograma para um projeto de médio porte com aproximadamente quinze membros na equipe de projeto [figura 3.2].

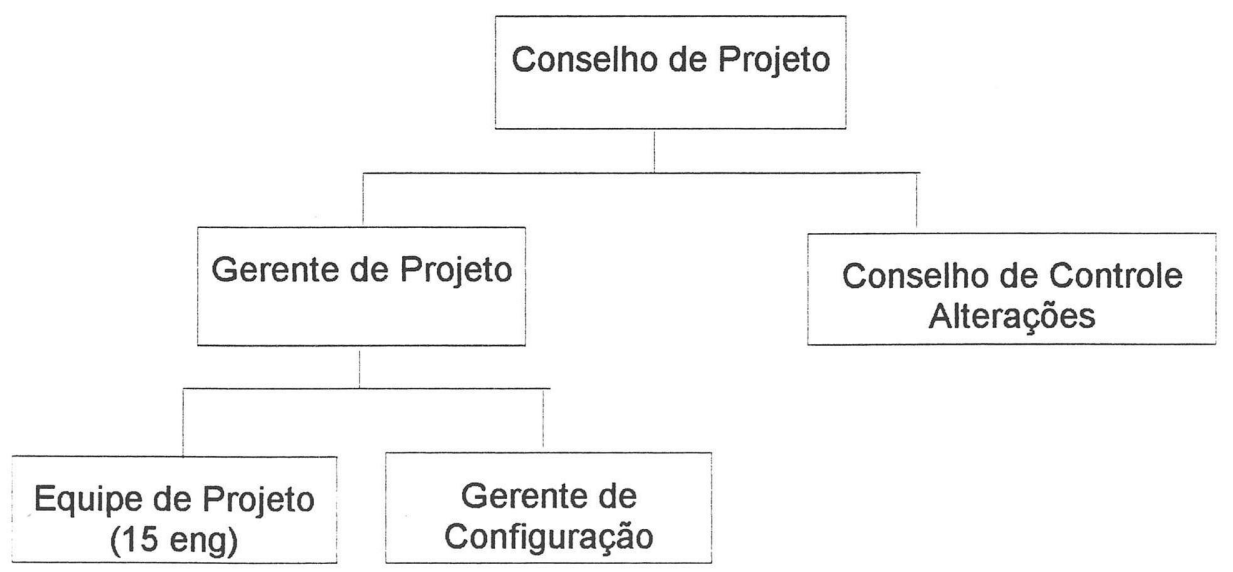

Figura 3.2- Exemplo de organograma para gerenciamento de configuração

Cada unidade neste organograma possui diversas tarefas. Apenas as tarefas associadas ao gerenciamento de configuração serão apresentadas.

O conselho de projeto é responsável pelos objetivos gerais do projeto e pela alocação dos recursos necessários. É composto por três membros: um executivo chefe, o gerente do projeto e um representante experiente do 
cliente. O gerente do projeto e o representante do cliente são indicados especialmente para cada projeto cuja configuração de software é colocada sob controle. Assim, esse conselho difere de projeto a projeto. $O$ conselho deve revisar e aprovar todos os planos do projeto, inclusive o plano de gerenciamento de configuração.

O gerente de projeto é responsável por garantir que o software seja executado no prazo, dentro do orçamento, e com o devido padrão de qualidade. Deve estar atento a desvios que estejam ocorrendo em relação aos planos, prevendo os problemas, e comunicando-os ao conselho de projeto. O gerente de projeto envia o plano de gerenciamento de configuração ao conselho de projeto para aprovação e garante que ele seja executado.

A equipe de projeto projeta e implementa o sistema de software, sob a coordenação do gerente de projeto. A equipe deve executar as tarefas de gerenciamento de configuração, de acordo com o plano. Solicitações de alteração na configuração de software podem ser feitas por qualquer membro da equipe, ou pelo gerente de projeto, e são submetidas à aprovação do conselho de controle de alterações.

O gerente de configuração deve, primeiramente, escrever o plano de gerenciamento de configuração, junto com o gerente do projeto e, a partir de então, torna-se responsável pela implementação das tarefas rotineiras do plano. São tarefas do gerente de configuração:

- Criar a estrutura do repositório de itens de configuração de modo que ele atenda o esquema de identificação previsto no plano.

- Garantir a segurança e a integridade do repositório através de controle de acesso e cópias de segurança.

- Implementar as rotinas para criar novos itens de configuração para retirar (check out) e armazenar (check in) itens no repositório. 
- Gerar os relatórios de situação da configuração, quando necessários.

- Gerenciar a liberação de versões de sistemas para os clientes.

O conselho de controle de alterações é responsável pela integridade do software produzido pelo projeto. É composto por três membros: o gerente do projeto, um representante do cliente e um coordenador de garantia de qualidade. Trabalhando com os relatórios de situação da configuração, o conselho é auxiliado por engenheiros da equipe de projeto sempre que necessário. O conselho de controle de alterações aprova ou rejeita as solicitações de alteração para itens congelados e monitora a execução das alterações que foram aprovadas. Se o impacto da alteração solicitada excede certos limites definidos, a solicitação de alteração deve ser aprovada também pelo conselho de projeto. Assim, o conselho de projeto atua como um conselho de controle de alterações de alto nível para o projeto.

\subsection{3 - Tarefas}

Tanto as tarefas técnicas quanto as tarefas administrativas devem ser identificadas e descritas detalhadamente.

As tarefas de gerenciamento de configuração de software propostas pelo plano IEEE estão de acordo com as descritas no capítulo 2 desta minidissertação e, desse modo, não serão aqui reapresentadas. As tarefas de gerenciamento de configuração são tradicionalmente classificadas em: identificação da configuração, controle da configuração, relato de situação e auditorias e revisões, controle de interfaces e controle de vendedores e subcontratados.

\subsection{4 - Roteiro}

Esta seção descreve como será a coordenação temporal entre as tarefas de gerenciamento de configuração e as outras atividades do projeto.

As tarefas de gerenciamento de configuração ocorrem em diferentes momentos do ciclo de vida do software. Algumas tarefas são constantes no 
decorrer de todo o projeto, algumas ocorrem em determinados momentos particulares e outras surgem durante o projeto.

O ponto mais importante do roteiro é definir quando o controle de mudanças começa a existir, ou seja, quando as linhas de referências serão estabelecidas. É muito importante que o início do controle de mudanças não seja nem muito precoce nem muito tardio.

A forma para a especificação da seqüência e coordenação das tarefas de gerenciamento de configuração de software pode ser a mesma utilizada para determinar cronogramas de projetos, ou seja, através de um gráfico de Gantt, Pert ou Timeline. A determinação das datas pode ser feita utilizandose datas absolutas, ou datas relativas a eventos a ocorrer.

\subsection{5 - Recursos}

Esta seção descreve os recursos que serão necessários para executar as tarefas de gerenciamento de configuração descritas no capítulo 2. São identificados ferramentas de software, pessoal, treinamento e equipamentos necessários.

O gerenciamento de configuração pode ser feito com uma combinação entre ferramentas de software e manual de procedimentos. As ferramentas tanto podem ser específicas para o gerenciamento de configuração como podem ser ferramentas genéricas. Também podem ser padronizadas para todos os projetos ou pode haver ferramentas específicas para cada projeto.

As ferramentas podem apoiar as seguintes funções:

- Manutenção da estrutura do repositório;

- Controle de acesso;

- Desenvolvimento de documentação;

- Controle de versões do código fonte;

- Geração de linhas de referências; 
- Processamento, comunicação e autorização de mudanças;

- Relato de situação;

- Relacionamento entre problemas e alterações;

- Arquivamento, bloqueio e recuperação de itens controlados;

- Criação do plano de gerenciamento de configuração.

Para cada tipo de tarefa de gerenciamento de configuração, o plano deve identificar quais ferramentas, técnicas, equipamentos, pessoas e treinamento são necessários e como cada recurso será obtido.

Para cada ferramenta de software, seja ela adquirida externamente ou desenvolvida juntamente com o projeto, o plano deve descrever ou referenciar suas funções e deve identificar o controle de configuração que deve ser feito sobre a ferramenta.

\subsection{6 - Manutenção do Plano}

Esta seção descreve como manter o plano sempre atualizado. Isso envolve a identificação das atividades e responsabilidades necessárias para manter um controle contínuo sobre a execução do plano.

As seguintes informações devem estar presentes:

- Quem é responsável por monitorar o plano?

- Com que freqüências serão feitas as atualizações?

- Como as atualizações serão avaliadas e aprovadas?

- Como as alterações serão efetivadas e comunicadas?

O plano deve ser revisto no início de cada fase do projeto. Se as alterações propostas forem aprovadas, então todos os participantes da equipe devem ser informados. 
O plano pode ser construído de forma que os detalhes de cada tarefa fiquem em documentos à parte ou em apêndices. Se esta forma for adotada, deve ser descrito como será feita a manutenção nesses outros documentos.

Como parte do projeto, o próprio plano pode ser colocado sob controle do gerenciamento de configuração.

\subsection{Recomendações para a elaboração do Plano de Gerenciamento de Configuração de Software}

Algumas pessoas acham que devem escrever um plano de gerenciamento de configuração apenas se isso for requisitado pelo cliente. Com isso perdem a oportunidade de estabelecer métodos uniformes para desenvolver sistemas de software. O momento da criação do plano de gerenciamento de software é excelente para que o gerente de configuração vislumbre os problemas, antes que eles afetem os custos ou prazos do projeto [Berlack, 1992].

Escrever um plano de gerenciamento de configuração de software não é uma tarefa difícil; o mais difícil é determinar como executar o gerenciamento de configuração e quais tarefas serão implementadas [Bounds, 1993]. Para que o plano seja bem sucedido, é necessário que haja a colaboração da equipe de desenvolvimento, tanto na elaboração quanto na implementação.

A estrutura do plano deve seguir o padrão adotado pela empresa. Novamente vale salientar que o padrão IEEE é bastante adequado para empresas de desenvolvimento de software de pequeno porte. Se a empresa não faz gerenciamento de configuração e está elaborando um plano pela primeira vez, é recomendado que sejam lidos livros, padrões e, se possível, planos escritos para projetos semelhantes. Convém salientar que, como 0 plano apresenta características muito peculiares e valiosas da forma de trabalho da organização, é bastante difícil obter um plano de outra 
empresa ${ }^{2}$. Geralmente, a aquisição dos conhecimentos para elaboração da estrutura do plano deve ser feita em poucos dias. Quando o material mais interessante já estiver separado, um esboço do plano poderá ser escrito. Este esboço conterá apenas uma descrição sobre o que escrever em cada seção do plano.

O passo seguinte, no qual as tarefas de gerenciamento de configuração que serão implementadas são descritas, deve ser feito em conjunto com todos os grupos envolvidos com o gerenciamento de configuração. Será definido como fazer o controle de versões, qual será o esquema de identificação, como serão feitas as auditorias e revisões, como será efetuado o relato de situação, como será feito o controle de interface e o controle de subcontratadas e vendedores. Este é, na verdade, o passo mais difícil e mais importante do plano.

Os procedimentos detalhados para cada uma das tarefas são então escritos no plano, e é feita uma análise para verificar se nada foi esquecido. Caso falte algo, deve-se retornar ao passo anterior até que o processo esteja completo. Geralmente, os procedimentos não estão perfeitos em sua primeira descrição, mas, com o uso, pode-se aperfeiçoá-los. Um bom plano não precisa ser alterado freqüentemente e é fácil de entender. Além disso, um bom plano faz com que os participantes do projeto se interessem em seguilo, e com que a gerência o apoie e custeie.

O plano de gerenciamento de configuração de software geralmente é bastante utilizado pelos desenvolvedores até que se acostumem com as tarefas de gerenciamento de configuração, momento em que o plano deixa de ser consultado com freqüência. Outros usuários do plano podem ser, por exemplo, as equipes de controle de qualidade (para fazer auditorias), e os líderes de projeto (na seleção de pessoal).

2 Boas, A.V. (CPqD - Telebrás) - Comunicação pessoal. (1996) 
Em pequenos projetos, o plano de gerenciamento de configuração de software pode suprimir algumas das tarefas ou passos do gerenciamento de configuração presentes para grandes projetos. Por exemplo, o controle de subcontratados e fornecedores - suprimido caso o software seja completamente desenvolvido na própria empresa - e outros tópicos, podem ser simplificados, como o controle de interface em ambientes bem estáveis. Nos pequenos projetos, o essencial é estabelecer os processos de controle de mudanças de versões, o esquema de identificação dos itens e políticas de liberação de versões. [CMFAQ, 1996]

É interessante notar que uma boa ferramenta de controle de versões já representa um grande benefício para o gerenciamento de configuração de software, por dispensar o controle manual sobre arquivos em diferentes diretórios. Se for possível automatizar também a composição da configuração dos sistemas, a produtividade aumentará bastante [Bounds, 1993; CMFAQ, 1996]. Quanto mais complexo o software em desenvolvimento e mais sofisticada a dinâmica de desenvolvimento, mais elaboradas devem ser as ferramentas de gerenciamento de configuração de software. 


\section{A DeterminaçÃo De UM TÍPICO Processo De Gerenciamento DE CONFIGURAÇÃo DE SOFTWARE EM EMPResas De PeQueno PORTE}

\subsection{Considerações Iniciais}

Para a determinação de um típico processo de Gerenciamento de Configuração de Software, foi elaborada uma pesquisa empírica em empresas de pequeno porte.

Primeiramente descreve-se o método de pesquisa utilizado e, através de cada um dos passos desse método, efetua-se uma descrição completa da pesquisa efetuada e resultados obtidos.

\subsection{O Método de Pesquisa}

O método utilizado neste trabalho denomina-se "Goal/Question/Metric" (GQM) [Basili e Weiss, 1984] e já foi aplicado em muitos projetos de pesquisa em engenharia de software [Rombach, 1990; Shepperd, 1990; Rombach, 1987; Basili, 1990; Basili et alii, 1986; Basili e Rombach, 1988; Rombach e Ulery, 1989; Gallagher e Lyle, 1991].

Esse método fornece um mecanismo que orienta a determinação dos objetivos da pesquisa e o refinamento de cada objetivo em um conjunto de questões, com o propósito de quantificar os mesmos. Tais questões definem o conjunto específico dos dados a serem coletados. 
O método GQM consiste de 6 passos básicos, apresentados resumidamente no Quadro 4.1.

QUADRO 4.1 - O Método de Pesquisa GQM (Goal/Question/Metric)

\begin{abstract}
PASSO 1: Estabelecer os Objetivos da Coleta de Dados
Focaliza o trabalho a ser realizado.

O Objetivo é definido em termos do:

Objeto de Estudo: um processo ou um produto.

Propósito: determinar, entender, melhorar, caracterizar, avaliar, prever, motivar ou controlar algum aspecto de qualidade do objeto de medida.

Perspectiva: identifica a quem interessa os resultados da pesquisa.

Ambiente: fornece o contexto para a interpretação dos resultados.
\end{abstract}

\title{
PASSO 2: Desenvolver uma Lista de Questões de Interesse
}

As questões devem permitir uma caracterização do objeto de pesquisa e dos aspectos de interesse do mesmo.

\section{PASSO 3: Estabelecer as Métricas}

Colocar como cada questão será avaliada, de modo que se possa saber quais dados devem ser coletados.

\section{PASSO 4: Projetar e Testar o Formulário de Coleta de Dados}

Se necessário, as alterações devem ser efetuadas antes que a coleta de dados comece.

\section{PASSO 5: Coletar e Validar os Dados}

Os dados são coletados através do preenchimento do questionário.

A validação consiste em verificar os formulários quanto à consistência, completitude e não ocorrência de erros.

\section{PASSO 6: Analisar os Dados}

Analisar e interpretar os dados coletados no contexto das questões colocadas no passo 2 e com as quais os dados estão associados. 


\subsection{A Pesquisa Efetuada}

Nas seis sessões que seguem será apresentado como foram utilizados os seis passos do método GQM, para determinação de um típico processo de Gerenciamento de Configuração de Software em empresas de pequeno porte.

\subsection{1- Passo 1 - Objetivos da Coleta de Dados}

Esse passo focaliza o trabalho a ser realizado.

a) Objeto da Pesquisa: O que se pretende analisar é o processo de Gerenciamento de Configuração de Software e características da empresa que se relacionam com esse processo.

b) Propósito: Identificar um processo típico de Gerenciamento de Configuração de Software.

c) Perspectiva: Do desenvolvedor de software.

d) Ambiente: Empresas de pequeno porte.

\subsection{2- Passo 2 - Lista de Questões de Interesse}

Neste passo é criada uma lista de questões que caracterizam o objeto em estudo.

As questões para caracterização do típico processo de Gerenciamento de Configuraçã̃o de Software foram divididas em dois grupos. As questões do grupo 1 se relacionam com a forma como são aplicadas as seis tarefas básicas de Gerenciamento de Configuração de Software; as questões do grupo 2 envolvem informações sobre características da empresa que se relacionam com o Gerenciamento de Configuração de Software.

As tarefas de Gerenciamento de Configuração de Software, aqui consideradas, são aquelas apresentadas no capítulo 2 deste trabalho e as características da empresa que se relacionam com Gerenciamento de 
Configuração de Software são as apresentadas no capítulo 3. Desse modo, o objetivo deste estudo pode ser detalhado na lista de questões apresentadas no Quadro 4.2.

Quadro 4.2 - Lista de Questões a Serem Respondidas pela Pesquisa

\begin{tabular}{|c|c|}
\hline Tarefas & Questões \\
\hline $\begin{array}{l}\text { Identificação da } \\
\text { Configuração } \\
\text { - } \quad \text { seleção } \\
\text { - } \text { relacionamento } \\
\text { - identificação } \\
\text { - linhas de referência }\end{array}$ & $\begin{array}{l}\text { 1. Como é feita a identificação e atualização dos itens de } \\
\text { informação que são produzidos durante o desenvolvimento do } \\
\text { software? } \\
\text { - Que informações são produzidas e atualizadas durante o } \\
\text { desenvolvimento do software? } \\
\text { - Existe um descrição de como os itens se relacionam? } \\
\text { - Para quais itens de informação produzidos, existe um } \\
\text { esquema de identificação? } \\
\text { - Existe algum momento a partir do qual os itens da } \\
\text { configuração são armazenados e, para serem alterados, } \\
\text { precisam de autorização? Quais momentos? }\end{array}$ \\
\hline $\begin{array}{l}\text { Controles } \\
\text { - Controle de } \\
\text { Mudanças } \\
\text { - Controle de Versões }\end{array}$ & $\begin{array}{l}\text { 2. Como é feito o controle da configuração? } \\
\text { - Como é feito o controle de mudanças nos itens de } \\
\text { informação? } \\
\text { - Como é feito o controle de versões dos itens de informação? }\end{array}$ \\
\hline $\begin{array}{l}\text { Auditoria da } \\
\text { Configuração }\end{array}$ & 3. Que auditorias são efetuadas nos itens de informação? \\
\hline Relato da Situ & lato de situação? \\
\hline Cont & 5. Como é feito o controle de interface? \\
\hline $\begin{array}{l}\text { Controle de } \\
\text { Subcontratados e } \\
\text { Fornecedores } \\
\text { - Subcontratados } \\
\text { - Fornecedores } \\
\end{array}$ & $\begin{array}{l}\text { - Como é feito o controle de subcontratados? } \\
\text { - Como é feito o controle de fornecedores? }\end{array}$ \\
\hline
\end{tabular}

\begin{tabular}{|c|c|}
\hline $\begin{array}{c}\text { Características da } \\
\text { Empresa }\end{array}$ & Questões \\
\hline Pessoas & $\begin{array}{l}\text { Qual o tamanho e a capacidade da equipe de desenvolvimento } \\
\text { para executar Gerenciamento de Configuração de Software? }\end{array}$ \\
\hline Ambiente & $\begin{array}{l}\text { A cultura das equipes de desenvolvimento permite que seja } \\
\text { aplicado Gerenciamento de Configuração de Software? }\end{array}$ \\
\hline Sistema & $\begin{array}{l}\text { Qual o tipo de sistema produzido? } \\
\text { Quais os itens de informação mais relevantes? }\end{array}$ \\
\hline Automatização & $\begin{array}{l}\text { Quais os equipamentos e sistemas operacionais disponíveis? } \\
\text { Qual a possibilidade de investimentos em equipamentos e } \\
\text { ferramentas de software? }\end{array}$ \\
\hline Decisões Gerenciais & $\begin{array}{lllll}\text { Qual a capacitação e e } & \text { disponibilidade da equipe } & \text { de } \\
\text { desenvolvimento para desenvolver ferramentas de software? }\end{array}$ \\
\hline
\end{tabular}




\subsection{3- Passo 3 - Métricas}

As métricas são definidas para descrever os dados que devem ser coletados para responder as questões.

\subsubsection{1- Grupo 1 - Tarefas de Gerenciamento de Configuração de Software}

Este grupo contém seis questões, especificamente uma questão sobre cada uma das atividades de Gerenciamento de Configuração de Software.

Questão 1 - Como é feita a identificação e atualização dos itens de informação que são produzidos durante o desenvolvimento do software?

A atividade de identificação da configuração pode ser dividida em quatro atividades básicas: seleção dos itens de configuração, especificação do relacionamento entre os itens de configuração, criação de um esquema de identificação e planejamento das linhas de referência. É proposta uma subquestão para cada uma dessas tarefas básicas.

Sub-questão 1-a) Que informações são produzidas e atualizadas durante $o$ desenvolvimento do software?

Através dessa questão procura-se medir a abrangência da configuração de software produzida durante o ciclo de vida. A existência de uma maior variedade de tipos de itens de configuração denota um maior amadurecimento do processo de engenharia de software, assim como implica em maiores esforços para a atualização desses itens. Pressman 
[Pressman;1995] sugere uma lista com os itens de configuração de software mais utilizados, que servem como base para o questionário.

Apenas os itens de informação que sejam mantidos atualizados pela maioria dos entrevistados são considerados itens que a empresa típica selecionou para fazer parte de seu repositório. A coluna "produz" servirá como referência, caso poucos entrevistados atualizem os itens produzidos.

1-a) Que itens de informação são produzidos durante o desenvolvimento do software e quais itens estão sempre atualizados? (marque com X)

Item

Especificação de requisitos do sistema

Plano de projeto do software

Especificação dos requisitos de software

Manual preliminar do usuário

Descrição do projeto de dados

Descrições do projeto modular

Descrições do projeto de interfaces

Descrições de objetos

Código fonte

Plano e procedimentos de testes

Casos de testes e resultados registrados

Manuais de operação e instalação

Esquema e estrutura de arquivos do banco de dados

Conteúdo inicial dos arquivos

Manual feito de acordo com o usuário

Relatórios de problemas de software

Solicitações de manutenção

Pedidos de mudança de engenharia

Padrões e procedimentos para engenharia de software

$\begin{array}{cl}\begin{array}{c}\text { Produz } \\ ()\end{array} & \text { Atualiza } \\ (\text { ) } & (\text { ) } \\ (\text { ) } & (\text { ) } \\ (\text { ) } & (\text { ) } \\ (\text { ) } & (\text { ) } \\ (\text { ) } & (\text { ) } \\ (\text { ) } & (\text { ) } \\ (\text { ) } & (\text { ) } \\ (\text { ) } & (\text { ) } \\ () & (\text { ) } \\ () & (\text { ) } \\ () & (\text { ) } \\ () & (\text { ) } \\ () & (\text { ) } \\ () & (\text { ) } \\ () & ()\end{array}$

Sub-questão 1-b) Existe um descrição de como os itens se relacionam? Se sim, relacione:

Através dessa questão procura-se especificar os relacionamentos existentes entre os itens de informação selecionados como importantes. São apresentados os itens de informação sugeridos por Pressman [Pressman,1995] em duas colunas para que o usuário estabeleça os relacionamentos existentes.

Serão considerados para a empresa típica os relacionamentos citados pela maioria dos entrevistados. 
1-b) Existe uma descrição de como os itens de informação se relacionam?

$\operatorname{SIM}($ ) NÃO ( )

Se existe, relacione ligando uma coluna à outra:

Especificação de requisitos do sistema Plano de projeto do software

Especificação dos requisitos de software

Manual preliminar do usuário

Descrição do projeto de dados

Descrições do projeto modular

Descrições do projeto de interfaces

Descrições de objetos

Código fonte

Plano e procedimentos de testes

Casos de testes e resultados registrados

Manuais de operação e instalação

Esquema e estrutura de arquivos do banco

de dados

Conteúdo inicial dos arquivos

Manual feito de acordo com o usuário

Relatórios de problemas de software

Solicitações de manutenção

Pedidos de mudança de engenharia

Padrões e procedimentos para engenharia de software

Especificação de requisitos do sistema

Plano de projeto do software

Especificação dos requisitos de software

Manual preliminar do usuário

Descrição do projeto de dados

Descrições do projeto modular

Descrições do projeto de interfaces

Descrições de objetos

Código fonte

Plano e procedimentos de testes

Casos de testes e resultados registrados

Manuais de operação e instalação

Esquema e estrutura de arquivos do banco de dados

Conteúdo inicial dos arquivos

Manual feito de acordo com o usuário

Relatórios de problemas de software

Solicitações de manutenção

Pedidos de mudança de engenharia

Padrões e procedimentos para engenharia de software

Sub-questão 1-c) Para quais itens de informação, que sejam produzidos, existe um esquema de identificação?

Através dessa questão procura-se saber para quais tipos de itens de informação utiliza-se algum tipo de esquema de identificação. Um esquema de identificação reflete a estrutura do software e define nomes únicos a cada item de informação [Bennett, 1991; Dart, 1991]. A lista de itens de informação apresentada é a mesma das questões anteriores.

Serão considerados como típicos os itens citados pela maioria dos entrevistados. 
1-c) Para quais itens de informação, que seja produzido, existe um esquema de identificação? (marque com X)

Item

Especificação de requisitos do sistema

Plano de projeto do software

Especificação dos requisitos de software

Manual preliminar do usuário

Descrição do projeto de dados

Descrições do projeto modular

Descrições do projeto de interfaces

Descrições de objetos

Código fonte

Plano e procedimentos de testes

Casos de testes e resultados registrados

Manuais de operação e instalação

Esquema e estrutura de arquivos do banco de dados

Existe esquema de identificação

Conteúdo inicial dos arquivos

Manual feito de acordo com o usuário

Relatórios de problemas de software

Solicitações de manutenção

Pedidos de mudança de engenharia

Padrões e procedimentos para engenharia de software

Arquivos de Dados

Arquivos de Programas

Aplicativos

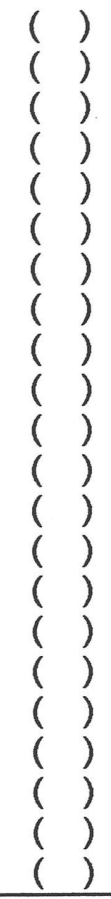

Sub-questão 1-d) Existe algum momento, a partir do qual os itens da configuração são armazenados e, para serem alterados, precisam de autorização? Quais momentos?

Através dessa questão procura-se saber quando são aplicadas linhas de referência. Segundo Bersoff [Bersoff,1979], os momentos mais comuns são no final de cada fase do ciclo de vida do software. As opções oferecidas aos entrevistados neste questionário estão baseadas nessa afirmativa.

Serão considerados como típicos os momentos citados pela maioria dos entrevistados. 


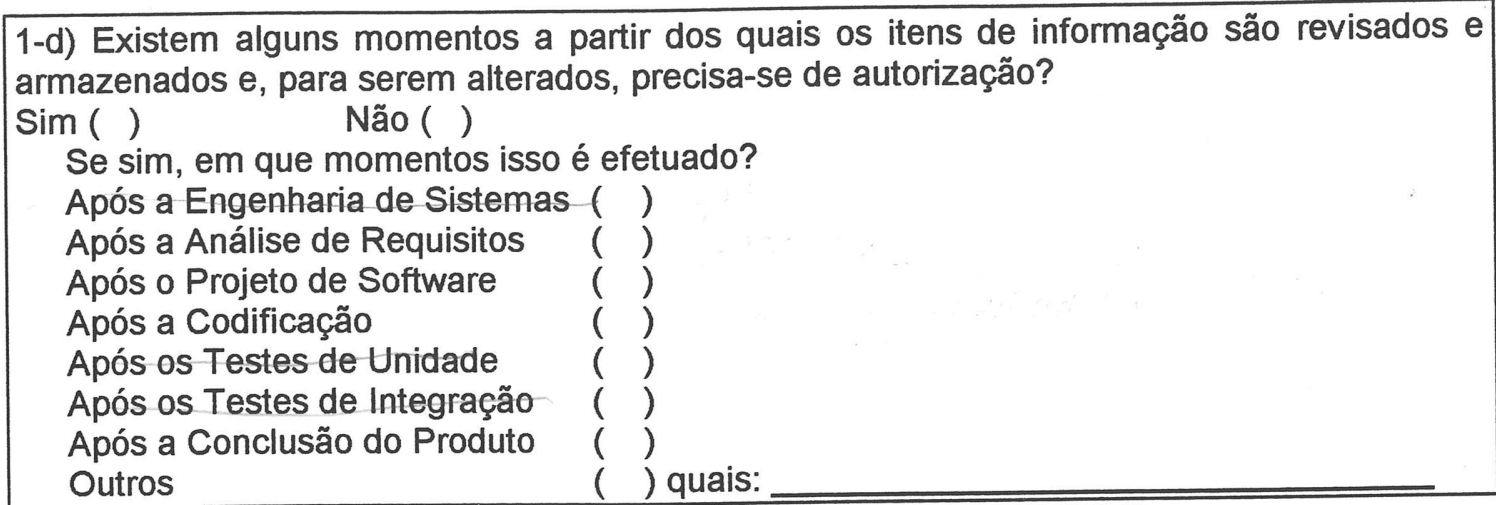

\section{Questão 2 - Como é feito o controle da configuração?}

O controle da configuração é dividido em dois controles básicos: controle de mudanças e controle de versões.

Sub-questão 2-a) Como o controle de mudanças nos itens de informação é efetuado?

Através dessa questão procura-se identificar, dentre as atividades de um processo básico de controle de mudanças [fig. 2.2], quais são as atividades realizadas. $\mathrm{O}$ controle de mudanças instaura um formalismo que evita que mudanças desorganizadas levem o software ao caos.

Serão consideradas atividades típicas aquelas citadas pela maioria dos entrevistados.

\begin{tabular}{|c|c|c|}
\hline \multicolumn{3}{|l|}{ 2-a) Como o controle de mudanças dos itens de informação é efetuado? } \\
\hline Atividade & Sim & Não \\
\hline Existe formulário de controle de alteração? & & \\
\hline $\begin{array}{l}\text { As solicitações de alteração são encaminhadas a um responsável } \\
\text { pelo recebimento das solicitacões de alteração? }\end{array}$ & & \\
\hline $\begin{array}{l}\text { pelo recebimento das solicitações de alteração? } \\
\text { É feita uma análise prévia da alteração? }\end{array}$ & & \\
\hline $\begin{array}{l}\text { É feita uma análise prévia da alteração? } \\
\text { Existe um responsável pela aprovação da alteração? }\end{array}$ & & \\
\hline $\begin{array}{l}\text { Existe um responsável pela aprovação da alteração? } \\
\text { Um item de informação que está sendo alterado fica bloqueado para }\end{array}$ & & \\
\hline $\begin{array}{l}\text { outras alterações? } \\
\text { As alterações no item d }\end{array}$ & & ( ) \\
\hline $\begin{array}{l}\text { As alterações no item de informação e nos itens relacionados sáo } \\
\text { documentadas? }\end{array}$ & & \\
\hline Existe uma verificação (auditoria) sobre as alterações efetuadas & & \\
\hline
\end{tabular}


Sub-questão 2-b) Como o controle de versões dos itens de informação é efetuado?

Através dessa questão procura-se identificar como a atividade de controle de versões é efetuada. O controle de versões gerencia o histórico de itens produzidos.

São consideradas típicas as respostas dadas pela maioria dos entrevistados.

\begin{tabular}{|c|c|}
\hline $\begin{array}{l}\text { 2-b) Como o controle de versões dos itens de informação é efetuado? } \\
\text { É mantido histórico da evolução das versões dos itens de informação? } \\
\text { Existe um esquema de identificação das versões? } \\
\text { Versões anteriores de itens são necessárias freqüentemente? } \\
\text { Um mesmo sistema pode conter módulos que são substituiveis para } \\
\text { ambiente diferente? } \\
\text { É utilizada alguma ferramenta de software para controle de versões? }\end{array}$ & 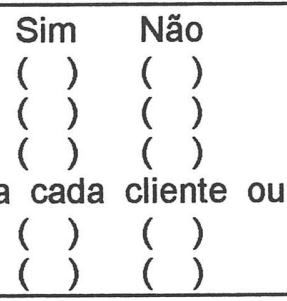 \\
\hline
\end{tabular}

$$
\begin{gathered}
\text { Questão } 3 \text { - São feitas as auditorias nos itens de } \\
\text { informação? }
\end{gathered}
$$

Através dessa questão procura-se saber se existe uma preocupação em verificar se as alterações nos itens de informação foram implementadas apropriadamente. Existem dois tipos de auditorias: auditorias funcionais (buscam omissões ou erros no software) e auditorias físicas (buscam falhas na aplicação dos procedimentos) [Capretz, 1992; Bersoff, 1994].

São consideradas típicas as respostas efetuadas pela maioria dos

\begin{tabular}{|c|c|}
\hline $\begin{array}{l}\text { 3- Como são efetuadas as auditorias nos itens de informação? } \\
\text { São efetuadas auditorias que busquem omissões ou erros no software? } \\
\text { São efetuadas auditorias que procurem falhas na aplicação dos p } \\
\text { controle dos itens de informação? }\end{array}$ & $\begin{array}{l}\text { Sim } \\
(\stackrel{\text { Não }}{()}() \\
\text { orocedimentos de } \\
(\quad)(r)\end{array}$ \\
\hline
\end{tabular}
entrevistados. 
São considerados típicos os controles efetuados pela maioria dos entrevistados.

\begin{tabular}{|lll|}
\hline 6- Como é feito o controle de subcontratados e fornecedores? & Sim & Não \\
Para subcontratados: & & \\
Módulos de software são subcontratados para serem produzidos & $($ ) & $($ ( ) \\
por terceiros? & $($ ) & $($ ) \\
Se sim : As empresas subcontratadas são monitoradas? & & \\
Para fornecedores: & $($ ) & $($ ( ) \\
Módulos prontos são adquiridos? & $($ ) & $($ ) \\
\hline
\end{tabular}

\subsubsection{2- Grupo 2 - Características da Empresa}

Este grupo é dividido em duas questões abaixo: infra-estrutura e ambiente cultural.

\section{Questão 7 - Qual a infra-estrutura da empresa?}

Através dessa questão obtêm-se informações sobre a infra estrutura da empresa, número e função de funcionários, principais usuários, produtos, equipamentos disponiveis e sistemas operacionais utilizados.

As informações obtidas nesse grupo serão de grande valia no capítulo 5 , onde serão utilizados para a elaboração de um Plano de Gerenciamento de Configuração de Software.

A quantidade de funcionários que trabalham em desenvolvimento e suporte é importante para que se possa estabelecer um organograma adequado. A quantidade típica de funcionários será obtida pelo cálculo da média das quantidades encontradas.

O tipo de usuário é interessante para analisar se as empresas estão fornecendo software para empresas que podem exigir Gerenciamento de Configuração de Software (exterior/governamentais). Os usuários típicos serão aqueles citados pela maioria dos entrevistados. 
A quantidade e tipo de equipamentos disponíveis, assim como sistemas operacionais utilizados são importantes para que se possa encontrar ferramentas de apoio ao Gerenciamento de Configuração de Software adequadas aos equipamentos e sistemas operacionais existentes. Serão considerados típicos aqueles citados pela maioria dos entrevistados.

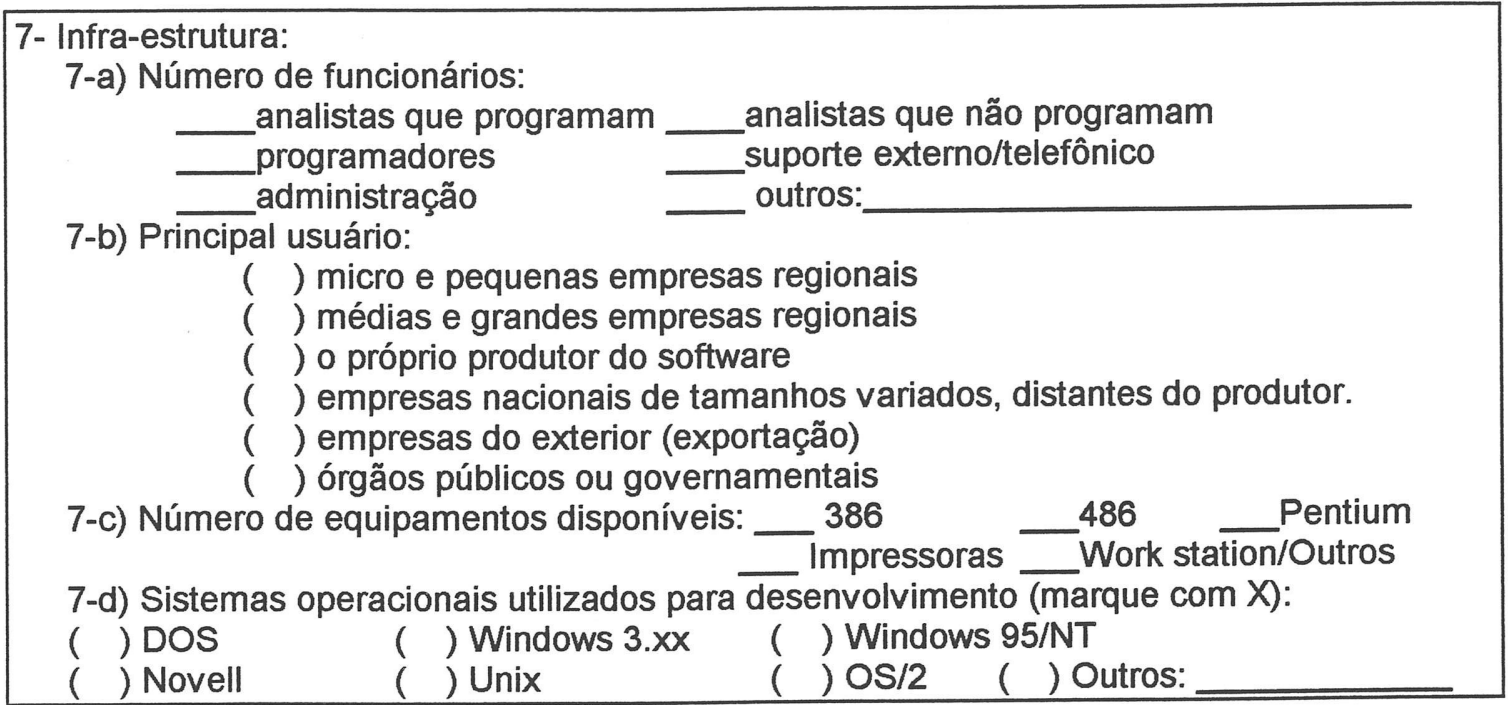

Questão 8- Ambiente Cultural

Através dessa questão obtêm-se informações sobre o ambiente e a cultura da empresa, ou seja:

- capacidade da equipe de desenvolvimento para executar Gerenciamento de Configuração de Software e adequação da sua cultura.

- principais problemas existentes, que se relacionam com Gerenciamento de Configuração de Software.

- possibilidade de investimentos em equipamentos e ferramentas de software.

- capacitação e disponibilidade da equipe de desenvolvimento para desenvolver ferramentas de software. 
Essas informações são importantes porque influenciam o Plano de Gerenciamento de Configuração de Software (capítulo 3).

Será considerado um ambiente cultural típico aquele obtido através das respostas dadas pela maioria dos entrevistados.

8- Perspectiva Gerencial

A respeito das afirmações abaixo sobre sua empresa, responda se são absolutamente falsas $(F)$, mais falsas que verdadeiras $(f)$, mais verdadeiras que falsas $(v)$ ou absolutamente verdadeiras $(\mathrm{V})$.

Assinale sobre a letra $\mathrm{M}$ nos pontos em que sua empresa mais precisa melhorar.

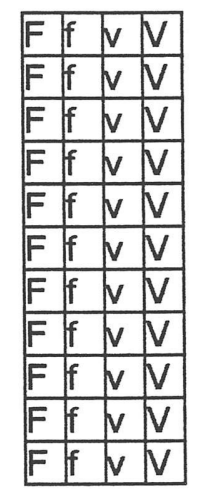

Estamos implantando um programa de qualidade total.

Nossos clientes procuram por qualidade, mesmo que por um maior custo. Nossos funcionários têm facilidade no aprendizado de novas tecnologias. São seguidos os métodos e procedimentos indicados pela gerência.

Trabalhamos sempre com o que há de mais moderno.

Fazemos cursos de atualização.

Nossa equipe técnica é muito competente.

Desenvolvemos nossas ferramentas de desenvolvimento de sistemas.

Investimos em equipamentos.

Investimos em ferramentas de desenvolvimento.

Trabalhamos visando o lucro a longo prazo.

\subsection{4- Passo 4 - Projeto e Teste do Formulário de Coleta dos}

\section{Dados}

Nesta pesquisa, o questionário representa apenas um instrumento de orientação para as entrevistas realizadas. Como ele é preenchido pelo próprio autor, não houve uma preocupação maior com o esclarecimento das questões no questionário.

O questionário utilizado na pesquisa resumiu-se em 115 tópicos distribuídos em 8 questões e 2 partes. No anexo 1 é apresentada a versão final do questionário já preenchido com as resposta de uma típica empresa de desenvolvimento de software de pequeno porte.

\subsection{5- Passo 5 - Coleta e Validação dos Dados}

A coleta de dados foi efetuada no período de março a agosto de 1997 através de visitas a 7 empresas do noroeste do estado de São Paulo. Outras 
empresas foram contatadas, porém não responderam ou não se enquadraram nas características desejadas.

\subsection{6- Passo 6 - Análise dos Dados}

Após a coleta e validação dos dados, fez-se a análise dos mesmos para a caracterização de um típico processo de gerenciamento de configuração de software em empresas de pequeno porte, seguindo os critérios apresentados no passo 3.

Uma primeira análise sobre os resultados obtidos mostra que o gerenciamento de configuração de software não vem sendo aplicado nas empresas de desenvolvimento de software de pequeno porte:

- praticamente não há atualização dos poucos itens de informação produzidos;

- é pouco utilizado o conceito de linhas de referência;

- não é feito o controle de versões.

A seguir serão analisadas mais detalhadamente as respostas obtidas.

\section{Identificação da configuração}

Geralmente são produzidos poucos itens de informação que documentam o sistema. Os itens produzidos quase nunca são atualizados e não possuem esquema de identificação. Os resultados obtidos são apresentados:

\begin{tabular}{|l|c|c|c|}
\hline Itens de informação & criados & atualizados & $\begin{array}{c}\text { esquema de } \\
\text { identificação }\end{array}$ \\
\hline Especificação de requisitos do sistema & $71 \%$ & $40 \%$ & $40 \%$ \\
\hline Plano de projeto do software & $71 \%$ & $20 \%$ & $40 \%$ \\
\hline Especificação dos requisitos de software & $43 \%$ & $33 \%$ & $66 \%$ \\
\hline Manual preliminar do usuário & $29 \%$ & $0 \%$ & $50 \%$ \\
\hline Descrição do projeto de dados & $71 \%$ & $40 \%$ & $40 \%$ \\
\hline Descrições do projeto modular & $57 \%$ & $0 \%$ & $50 \%$ \\
\hline Descrições do projeto de interfaces & $43 \%$ & $0 \%$ & $66 \%$ \\
\hline Descrições de objetos & $43 \%$ & $0 \%$ & $33 \%$ \\
\hline Código fonte & $43 \%$ & $0 \%$ & $33 \%$ \\
\hline Plano e procedimentos de testes & $29 \%$ & $50 \%$ & $50 \%$ \\
\hline
\end{tabular}




\begin{tabular}{|l|c|c|c|}
\hline Casos de testes e resultados registrados & $29 \%$ & $50 \%$ & $50 \%$ \\
\hline Manuais de operação e instalação & $14 \%$ & $0 \%$ & $100 \%$ \\
\hline Esquema e estrutura arq. do banco de dados & $100 \%$ & $71 \%$ & $43 \%$ \\
\hline Conteúdo inicial dos arquivos & $14 \%$ & $0 \%$ & $0 \%$ \\
\hline Manual feito de acordo com o usuário & $14 \%$ & $0 \%$ & $0 \%$ \\
\hline Relatórios de problemas de software & $14 \%$ & $0 \%$ & $0 \%$ \\
\hline Solicitações de manutenção & $57 \%$ & $0 \%$ & $25 \%$ \\
\hline Pedidos de mudança de engenharia & $0 \%$ & $0 \%$ & $0 \%$ \\
\hline
\end{tabular}

Os itens mais produzidos são aqueles utilizados para 0 estabelecimento do contrato de fornecimento, algumas descrições de projeto e principalmente a estrutura de arquivos do banco de dados. Como regra geral, não são identificados os relacionamentos existentes entre os itens de informação.

Quase um terço das empresas (29\%) disseram que utilizam o conceito de linha de referência, mas de uma forma muito discreta e pouco convencedora. As revisões para criação das linhas de referência, quando feitas, são feitas em dois momentos: após os testes e na liberação do produto.

\section{Controle de mudanças}

\begin{tabular}{|l|c|}
\hline Tópico & Afirmações \\
\hline Existe formulário de controle de alterações? & $57 \%$ \\
\hline As solicitações de alteração são encaminhadas a um responsável? & $57 \%$ \\
\hline É feita uma análise prévia? & $85 \%$ \\
\hline Existe um responsável pela aprovação? & $71 \%$ \\
\hline Itens sendo alterados são bloqueados contra alteração simultânea? & $57 \%$ \\
\hline As alterações são documentadas? & $29 \%$ \\
\hline É feita uma verificação sobre as alterações efetuadas? & $14 \%$ \\
\hline
\end{tabular}

O controle de mudanças é efetuado de forma bastante informal. Geralmente não existe formulário de controle de alteração, e não existe um funcionário responsável pelo recebimento de todas as solicitações de alteração. A alteração em cada sistema, ou subsistema, é quase sempre feita pelo programador que o criou (cada sistema tem um responsável). Esse programador analisa a alteração, executa e testa. Não é feito um bloqueio 
formal dos itens sendo utilizados nas alterações, mas como há uma divisão natural da "propriedade" de cada item entre os componentes da equipe de trabalho, não são notados problemas de alterações simultâneas.

Essa divisão de trabalho, onde cada módulo é alterado por apenas uma pessoa, e onde não há documentação das alterações efetuadas é justificada por seus seguidores pelo fato de ser bastante ágil (não são necessários documentos, reuniões, cronogramas, etc.) e por aproveitar o conhecimento "de memória" que o "proprietário" do subsistema tem de seus detalhes internos. Essa agilidade e simplicidade reduz custos a curto prazo mas leva a empresa a situações indesejadas como: dependência da "memória" do funcionário, que não poderá sair da empresa ou tirar férias sem causar sérios transtornos; possibilidade de "stress" pela sobrecarga de memorizações necessárias; dificuldades para a integração de funcionários em projetos existentes; dificuldades para análise de problemas de software.

\section{Controle de Versões}

\begin{tabular}{|l|c|}
\hline Tópicos & Afirmações \\
\hline É mantido histórico da evolução das versões dos itens de informação? & $0 \%$ \\
\hline Existe um esquema de identificação das versões? & $0 \%$ \\
\hline É utilizada alguma ferramenta de software para controle de versões? & $0 \%$ \\
\hline $\begin{array}{l}\text { Um mesmo sistema pode conter módulos que são substituíveis para cada } \\
\text { cliente ou ambiente diferente? }\end{array}$ & $43 \%$ \\
\hline Versões anteriores de itens são necessárias freqüentemente? & $29 \%$ \\
\hline
\end{tabular}

Geralmente não é efetuado qualquer tipo de controle de versões. Uma necessidade de controle de versões ocorre em sistemas que possuem módulos que são substituíveis para o cliente. A estratégia adotada é tratar as diferenças manualmente durante a link-edição de cada sistema. Outra necessidade de controle de versões ocorre com clientes que utilizam versões mais antigas do sistema. Nesse caso o problema é contornado atualizandose a versão do sistema ao cliente, mesmo contra sua vontade (ou conhecimento), toda vez que for necessária qualquer alteração no sistema. 
Alguns dos entrevistados mantêm algumas cópias de versões anteriores, geralmente as últimas duas versões.

\section{Auditorias}

\begin{tabular}{|l|c|}
\hline Tópicos & Afirmações \\
\hline São efetuadas auditorias que busquem omissões ou erros no software? & $14 \%$ \\
\hline $\begin{array}{l}\text { São efetuadas auditorias que procurem falhas na aplicação dos } \\
\text { procedimentos de controle dos itens de informação? }\end{array}$ & $0 \%$ \\
\hline
\end{tabular}

Os entrevistados fazem auditorias nos itens de informação. Os erros não encontrados durante a fase de testes poderão ser encontrados pelos usuários ou pelos desenvolvedores durante o uso normal do sistema. Geralmente não há um método para análise das causas dos erros, o que permitiria que a redução da quantidade de erros. O gerente utiliza a "intuição" como ferramenta de trabalho de análise dos erros encontrados.

\section{Relato de Situação}

\begin{tabular}{|l|c|}
\hline Tópicos & Afirmações \\
\hline Alterações feitas no software são informadas aos membros da equipe? & $29 \%$ \\
\hline A situação do software está disponível aos membros da equipe? & $85 \%$ \\
\hline É mantido um histórico das alterações efetuadas? & $43 \%$ \\
\hline
\end{tabular}

O fato de não existir um formulário de controle de alterações prejudica bastante o relato de situação, uma vez que não há um documento que registre as alterações efetuadas, datas, autores, razões, tempos gastos, etc. Os poucos recursos de relato de situação existentes são então a comunicação verbal aos membros da equipe (pouco eficiente) e a disponibilização da situação atual do software aos membros da equipe, geralmente feita através do código fonte e escassa documentação. 


\section{Controle de interface}

\section{Tópicos}

Alterações em equipamentos, sistemas operacionais, ou versões do compilador provocam alterações freqüentes nos sistemas?

Se sim, é mantido registro sobre os itens de informação afetados por alterações em equipamentos, sistemas operacionais ou versões de compilador?

Poucos entrevistados acusaram problemas causados por alterações externas aos sistemas $e$, portanto, não estabeleceram procedimentos para controlar o efeito dessas alterações sobre os sistemas.

Controle de subcontratados e fornecedores

\begin{tabular}{|l|c|}
\hline Tópicos & Afirmações \\
\hline $\begin{array}{l}\text { Módulos de software são subcontratados para serem produzidos por } \\
\text { terceiros? }\end{array}$ & $0 \%$ \\
\hline Se sim: b) As empresas subcontratadas são monitoradas? & $0 \%$ \\
\hline Módulos prontos são adquiridos de fornecedores? & $14 \%$ \\
\hline Se sim : São efetuados testes nos módulos adquiridos? & $0 \%$ \\
\hline
\end{tabular}

Os entrevistados não costumam subcontratar módulos para serem produzidos por terceiros ou adquirir módulos prontos e por isso não estabeleceram procedimentos de monitoramento ou testes. 


\section{Infra-estrutura}

Número de funcionários:

\begin{tabular}{ll}
2 analistas que programam & $\frac{1}{1}$ analistas que não programam \\
2 programadores & $\frac{1}{3}$ suporte externo/telefônico \\
\hline 1 administração &
\end{tabular}

Principal usuário:

$14 \%$ micro e pequenas empresas regionais

$57 \%$ médias e grandes empresas regionais

29\% o próprio produtor do software

Número de equipamentos disponíveis:

\begin{tabular}{ll}
3 & 486 \\
\hline 4 & Pentium \\
2 & Impressoras \\
\hline
\end{tabular}

Sistemas operacionais utilizados para desenvolvimento:

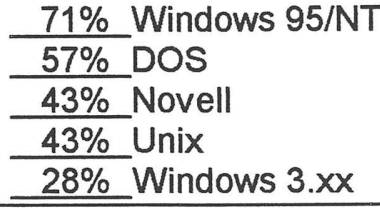

As empresas entrevistadas têm em média sete pessoas trabalhando no desenvolvimento de sistemas, sendo geralmente 1 diretor geral, 1 analista experiente (geralmente trabalhando na análise de requisitos, contato com clientes e definição dos sistemas), quatro desenvolvedores (dois com formação superior e dois técnicos) e uma pessoa fazendo suporte externo a clientes. Outras funções também encontradas são: auxiliar de escritório, "office-boy", recepcionista, técnico em hardware, etc.

Cada pessoa que trabalha no desenvolvimento têm um computador disponivel para si e na maioria das empresas há um servidor de rede. Algumas empresas possuem servidores Unix, mas as estações de trabalho rodam MS-Windows em sua grande maioria. Boa parte das aplicações são desenvolvidas para MS-DOS. 


\section{Ambiente cultural}

\begin{tabular}{|l|c|c|}
\hline Tópicos & Afirmação & Melhorar \\
\hline Nossa equipe técnica é muito competente. & $88 \%$ & $14 \%$ \\
\hline Temos facilidade no aprendizado de novas tecnologias. & $80 \%$ & $14 \%$ \\
\hline Investimos em equipamentos. & $76 \%$ & $28 \%$ \\
\hline São seguidos os métodos e procedimentos indicados pela gerência. & $71 \%$ & $0 \%$ \\
\hline Trabalhamos visando o lucro a longo prazo. & $66 \%$ & $14 \%$ \\
\hline Trabalhamos sempre com o que há de mais moderno. & $61 \%$ & $28 \%$ \\
\hline Fazemos cursos de atualização. & $57 \%$ & $28 \%$ \\
\hline Investimos em ferramentas de desenvolvimento. & $57 \%$ & $14 \%$ \\
\hline Nossos clientes procuram qualidade, mesmo que por um maior custo. & $47 \%$ & $14 \%$ \\
\hline Estamos implantando um programa de qualidade total. & $28 \%$ & $28 \%$ \\
\hline $\begin{array}{l}\text { Desenvolvemos nossas próprias ferramentas de desenvolvimento de } \\
\text { sistemas. }\end{array}$ & $24 \%$ & $0 \%$ \\
\hline $\begin{array}{l}\text { Procuramos manter a documentação dos sistemas completa e } \\
\text { atualizada }\end{array}$ & $24 \%$ & $43 \%$ \\
\hline
\end{tabular}

Os pontos em que as empresas entrevistadas julgaram como seus pontos mais fortes são a facilidade no aprendizado, a competência de seu pessoal (apesar de fazerem poucos cursos de atualização) e os seus equipamentos (em sacrifício das ferramentas de desenvolvimento).

Os pontos mais fracos se referem à implantação de programas de qualidade (em conseqüência do desinteresse dos clientes em pagar mais por isso), à elaboração das suas próprias ferramentas de desenvolvimento e à documentação dos sistemas, que foi citada como o ponto em que mais desejam melhorar. Praticamente todas as empresas disseram que não podem "parar para fazer documentação" porque o prazo para a construção dos sistemas é muito curto, mas que uma documentação mais completa seria de grande valia.

\subsection{Conclusões da Pesquisa}

A figura 4.1 apresenta um gráfico que resume os resultados obtidos na entrevista sobre as tarefas e atividades de gerenciamento de configuração mais relevantes. A medida apresentada (percentual de aplicação) refere-se ao grau de adequação da forma como as tarefas e atividades são realizadas 
na empresa (em média) em relação à forma como deveriam ser realizadas para serem consideradas eficazes.

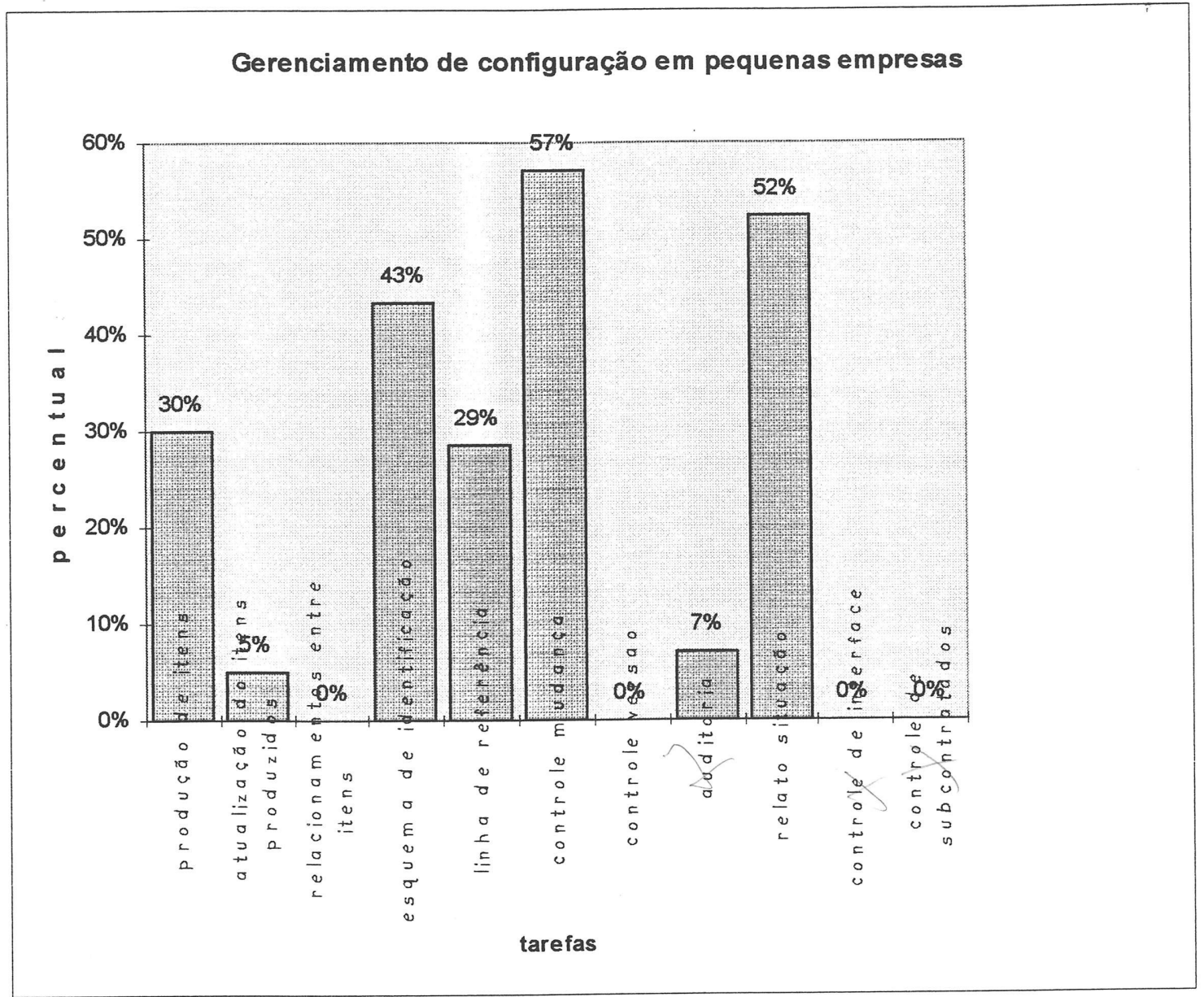

Figura 4.1 - Gerenciamento de configuração em empresas de pequeno porte

O processo típico utilizado pelas empresas de pequeno porte é considerado insuficiente para que a configuração de software possa ser satisfatoriamente mantida de forma atualizada e correta, uma vez que omite atividades básicas, como o controle de versões e não são adequadamente efetuados o controle de mudanças e a identificação dos itens.

Segundo o IEEE [IEEE Std 828-1990], há seis tarefas de gerenciamento de configuração de software: identificação, controle de versões e mudanças, relato de situação, auditoria, controle de interface e controle de subcontratados e fornecedores. 
O resultado da pesquisa apresentada no capítulo 4, porém, mostra que as empresas de pequeno porte não executam adequadamente nenhuma dessas tarefas. As tarefas de identificação e controle de mudanças são executadas apenas parcialmente, e o controle de versões, que não é executado, é considerado importante e desejável. Por isso, o plano propõe a execução da identificação da configuração e do controle de versões e de mudanças.

A maioria das empresas não tem experiência na realização de auditorias, não possuem recursos para contratar consultores externos e dizem que não podem "parar" para procurar falhas em seus procedimentos: a auditoria não será executada e as falhas serão, portanto, corrigidas quando forem "casualmente" encontradas.

O relato de situação também não é executado pelas empresas entrevistadas, porém, se nenhum recurso lhes fosse oferecido, os desenvolvedores poderiam ter dificuldade para saber as principais alterações ocorridas nos itens de configuração, ou para associar determinada versão de um item de configuração a uma versão de um sistema.

As tarefas de controle de interface e controle de subcontratados e fornecedores apresentaram-se desnecessárias, pois as empresas entrevistadas não têm problemas com os aspectos tratados por essas tarefas.

Sendo assim, será considerado, para a elaboração do plano, um processo de gerenciamento de configuração de software com as seguintes atividades: identificação da configuração, controles (de mudanças e de versões) e relato de situação.

\subsection{Considerações Finais}

Neste capítulo, a pesquisa efetuada nas empresas de pequeno porte foi descrita através dos cinco primeiros passos da metodologia de pesquisa GQM, e a "Análise dos Dados", passo 6, serviu para estabelecer um típico 
processo de gerenciamento de configuração de software em empresas de pequeno porte. No capítulo seguinte, os dados obtidos neste capítulo serão utilizados na criação de um Plano de Gerenciamento de Configuração de Software adequado para a realidade dessas empresas. 


\section{A Elaboração do Plano de GERENCIAMENTO DE CONFIGURAÇÃO DE SOFTWARE}

\subsection{Considerações Iniciais}

Neste capítulo é apresentado como foi elaborado um plano de gerenciamento de configuração de software apropriado para as características de uma empresa de desenvolvimento de software, apresentada nas conclusões da pesquisa do capítulo 4 .

\subsection{Preparação do Plano de Implantação de Gerenciamento de Configuração de Software}

O plano de gerenciamento de configuração de software é um documento que descreve quais atividades devem ser efetuadas na implantação e na administração do processo de gerenciamento de configuração de software. No plano também é descrito como e quando as atividades serão efetuadas, quem serão os responsáveis por elas e que recursos serão necessários [Whitgifh, 1991].

Antes de começar a escrever e implantar gerenciamento de configuração de software, devem ser feitas reuniões de conscientização do pessoal e reuniões de preparação do plano.

A maioria das pessoas não sabe o que é gerenciamento de configuração de software, ou sabe apenas que isso aumenta a burocracia a cada alteração, mas poucas pessoas imaginam os benefícios que podem ser obtidos com a sua implantação. Para que as pessoas vejam gerenciamento 
de configuração como um "aliado" e não como um "inimigo", devem ser feitas reuniões de esclarecimento e motivação. Podem ser usadas técnicas como visitar locais que tenham implantado gerenciamento de configuração $e$ assistir a palestras de especialistas, mas o mais importante é estudar gerenciamento de configuração $e$, após analisar as características e necessidades da empresa, preparar um plano adequado.

O estudo mais aprofundado sobre gerenciamento de configuração de software deve ser deixado a cargo de um analista da empresa que futuramente será o gerente de configuração (seção 2.1 do plano). Após o estudo, devem ser organizadas reuniões que tenham como objetivo debater formas de adequar as técnicas e tarefas de gerenciamento de configuração às características e necessidades da empresa. $O$ resultado dessas reuniões não é o plano pronto, mas uma ata onde constam as conclusões obtidas sobre pontos importantes do plano. O plano posteriormente será escrito no formato adequado.

Nessa fase de preparação é concebida a forma como o gerenciamento de configuração será aplicado na empresa. No caso específico deste trabalho, serão utilizados para essa concepção os dados da típica empresa de desenvolvimento de software considerados no capítulo quatro, além dos conceitos de gerenciamento de configuração de software vistos anteriormente.

Os elementos relacionados à fase de preparação do plano de gerenciamento de configuração de software (figura 5.1), são:

- projeto do plano: será utilizado o padrão internacional IEEE Std 828-1990, devido aos resultados obtidos na comparação apresentada no capítulo 3 (seção 3.2).

- processo: as tarefas de gerenciamento de configuração de software que serão consideradas são: identificação de configuração, controles de mudanças e versões e relato de situação. Poderá 
haver simplificações na forma de execução das tarefas descritas na bibliografia especializada.

- pessoas: sempre que possível, serão utilizadas as pessoas já existentes na empresa, distribuindo as tarefas de gerenciamento de configuração de software conforme a competência e a disponibilidade das mesmas. Haverá necessidade de treinamento.

- ambiente: por se tratar de empresa de pequeno porte, há necessidade de que as soluções sejam simples e de baixo custo. $O$ apoio da administração deve ser firme e intransigente em relação ao respeito aos métodos estabelecidos, uma vez que as pessoas geralmente não estão acostumadas com ambientes onde há um método formal de trabalho.

- sistema: o plano será destinado a gerenciamento de configuração de software de sistemas comerciais que utilizam sistemas de banco de dados e que são desenvolvidos segundo o modelo de ciclo de vida clássico (cascata) e com metodologia estruturada de desenvolvimento de software.

- automatização: as ferramentas utilizadas devem possuir boa interface gráfica, facilidade de uso e serem compatíveis com Windows 95. A ferramenta de controle de versões deve prover recursos de check in / check out, histórico de versões, identificação de versões de itens e de configurações.

- decisões gerenciais: a ferramenta de controle de versões será adquirida, e seu custo não pode exceder cem dólares. Qualquer banco de dados necessário será desenvolvido pela própria empresa durante a implantação do plano. 


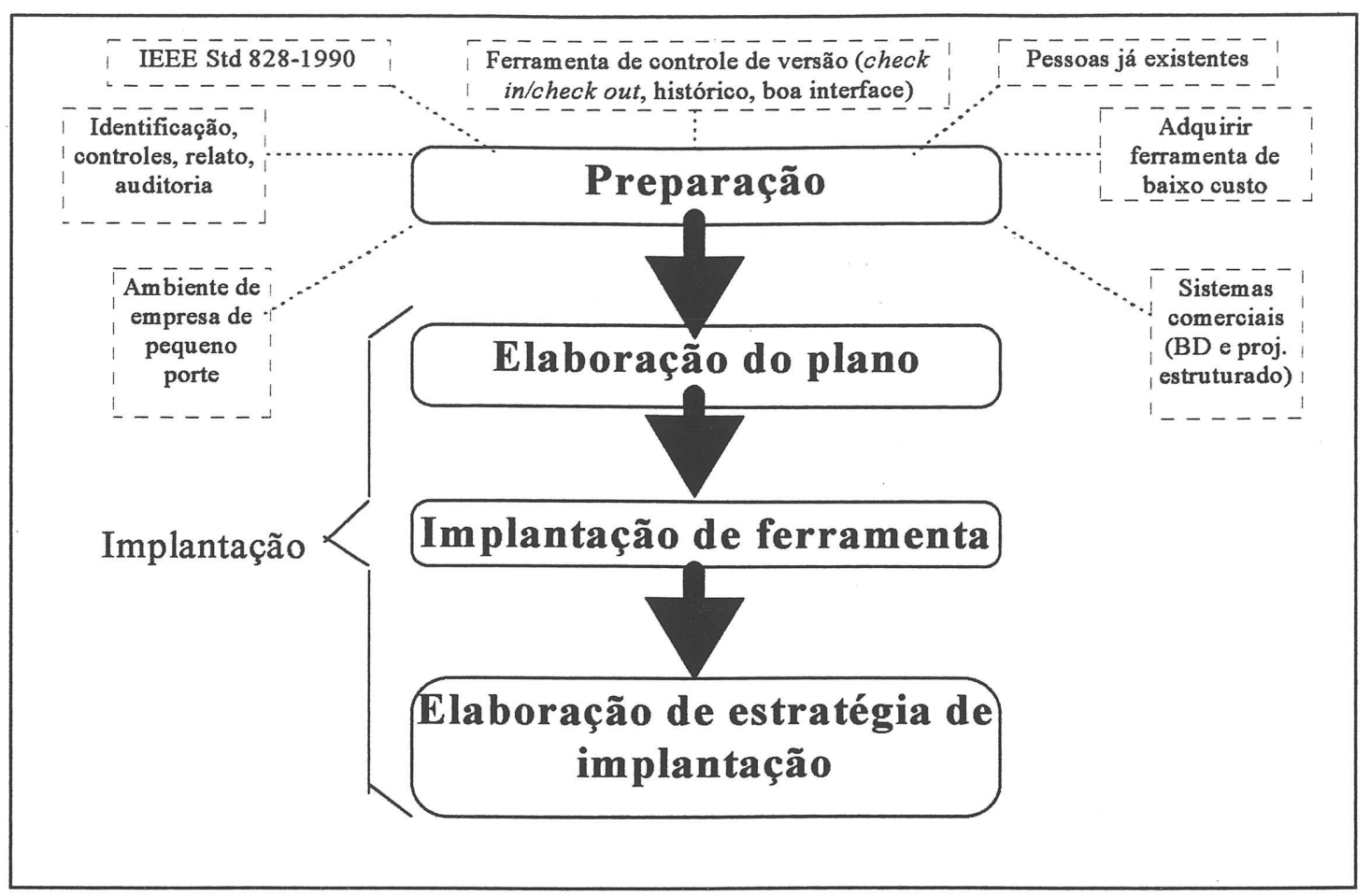

Figura 5.1 - Elementos relacionados ao plano de gerenciamento de configuração

\subsection{Elaboração da Seção 1 do Plano - Introdução}

A seção 1 de introdução do plano é dividida em quatro subseções: propósito, escopo, termos-chave e referências. A subseção de propósito descreve os objetivos gerais do plano. A subseção de escopo inclui algumas limitações e características sobre as quais o plano está baseado. Essas limitações e características da típica empresa de pequeno porte de desenvolvimento de software foram obtidas no capítulo 4. A subseção de termos-chave apresenta um glossário de termos de gerenciamento de configuração utilizados no plano. A subseção de referências apresenta livros e documentos que devem ser consultados por todos que venham a estudar gerenciamento de configuração de software. 


\section{1- Introdução do Plano}

\section{1- PROPÓSITO}

O objetivo deste plano é orientar a implantação de um processo de gerenciamento de configuração de software. Este plano contém instruções sobre as tarefas de gerenciamento de configuração de software, assim como a distribuição das responsabilidades entre os membros da organização, recursos necessários e roteiro de institucionalização do gerenciamento de configuração de software.

Como a implantação do gerenciamento de configuração afeta toda a empresa, inclusive os custos e a estrutura organizacional, deve ser efetuada uma análise de riscos antes de sua implantação, de acordo com as metas e políticas da organização.

\section{2- ESCOPO}

O processo de gerenciamento de configuração proposto é indicado para empresas de desenvolvimento de software que se enquadram nas seguintes características:

- possuem aproximadamente sete pessoas envolvidas com desenvolvimento de sistemas;

- utilizam no mínimo equipamentos da linha IBM-PC (486 ou Pentium) rodando MS-Windows 95 ou NT;

- não dispõem de recursos para adquirir estações de trabalhos UNIX.

- não dispõem de recursos para aquisição de gerenciadores de configuração completos tais como CCC [Softool,1987], Aide-De-Camp[SMDS,1989], etc. que custam algumas dezenas de milhares de dólares ou até mesmo de simples controladores de versões como o PVCS[Brown,1991], que custam aproximadamente mil dólares; 
- produzem alguma documentação de software, mas consideram importante produzir mais e manter a documentação atualizada;

- desejam manter um histórico da situação do software e das solicitações de alteração efetuadas;

- desejam estabelecer um método para controlar o atendimento às solicitações de mudanças;

- desenvolvem sistemas que, embora não tenham a mesma funcionalidade, possuem características de desenvolvimento semelhantes entre si.

\section{3- TERMOS-CHAVE}

árvore de versões - modo de descrever o histórico de versões de cada item de informação.

check in / check out - método de controle de itens de informação armazenados no repositório. Permite que os itens retirados do repositório permaneçam bloqueados (check out) até que sejam novamente armazenados no repositório, mediante revisão (check in).

configuração - conjunto de versões de itens de informação consistentes, correspondente a determinada versão do sistema.

equipe de desenvolvimento - grupo de programadores e analistas que trabalham na execução do sistema, sob coordenação do gerente de projeto.

documentação - conjunto de itens de informação que descrevem características do sistema. Geralmente são diagramas, tabelas, gráficos ou texto.

gerenciamento de configuração de software - área da engenharia de software que procura gerenciar a evolução dos sistemas, desde os estágios iniciais até a fase de manutenção. Para isso estabelece métodos que mantenham o software consistente e a documentação do software atualizada.

item de configuração/ item de informação - qualquer arquivo componente de um sistema, inclusive documentação.

linha de referência ("baseline") - um item de informação passa por uma linha de referência sempre que é revisado e armazenado no repositório. 
ordem de serviço - documento derivado do pedido de alteração, quando de sua aprovação. Contém informações sobre as alterações necessárias, modo de executá-las e responsáveis pela execução.

pedido de alteração - documento que descreve autor, data, motivo e mudanças desejadas em itens de informação.

plano de gerenciamento de configuração de software - documento que descreve a forma como é aplicado o gerenciamento de configuração de software.

repositório - local de acesso controlado, onde se armazenam itens de informação que só podem ser acessados mediante um pedido de alteração aprovado.

versão - situação de um item de informação, após cada alteração.

\section{4- REFERÊNCIAS}

Gerenciamento de Configuração de Software:

-PRESSMAN, R.S. Engenharia de Software. 3.Ed Rio de Janeiro. Makron Books, 1995.

-BERLACK, H.R. Software Configuration Management. 1.Ed. New York, John Wiley, 1992.

-IEEE Standard Glossary of Terminology in Software Engineering. In:IEEE Software Engineering Standard Collection, p.07-83, 1991.

- IEEE/ANSI Standard 1042-1987: IEEE Guide to Software Configuration Management. In: IEEE Software Engineering Standard Collection, 1987.

Plano de Gerenciamento de Configuração de Software:

-IEEE/ANSI Standard 828-1990. Software Configuration Management Plans In: IEEE Software Engineering Standard Collection, 1990.

\subsection{Elaboração da Seção 2 do Plano Gerenciamento}

Neste tópico é apresentada a estrutura organizacional necessária para a implantação do processo de gerenciamento de configuração de software e são alocadas as tarefas a cada unidade envolvida. Na elaboração da seção 2 leva-se em consideração a intenção de distribuir as tarefas de gerenciamento 
de configuração de software às pessoas já existentes na empresa. As tarefas de gerenciamento consideradas são: identificação de configuração, controles de mudanças e versões e relato de situação (essas tarefas são descritas na seção 3 do plano).

Conforme apresentado no final do capítulo 4, a empresa típica possui aproximadamente sete pessoas na área de sistemas, sendo que geralmente há dois ou três sócios, que possuem maior conhecimento e experiência que os outros desenvolvedores. Esses sócios ficarão com os cargos de gerência. Também foi constatado que as pessoas geralmente não estão acostumadas com ambientes onde há um método formal de trabalho. Isso favorece a adoção de um organograma hierárquico e a existência de um gerente de configuração, que exigirá a formalização do método de trabalho.

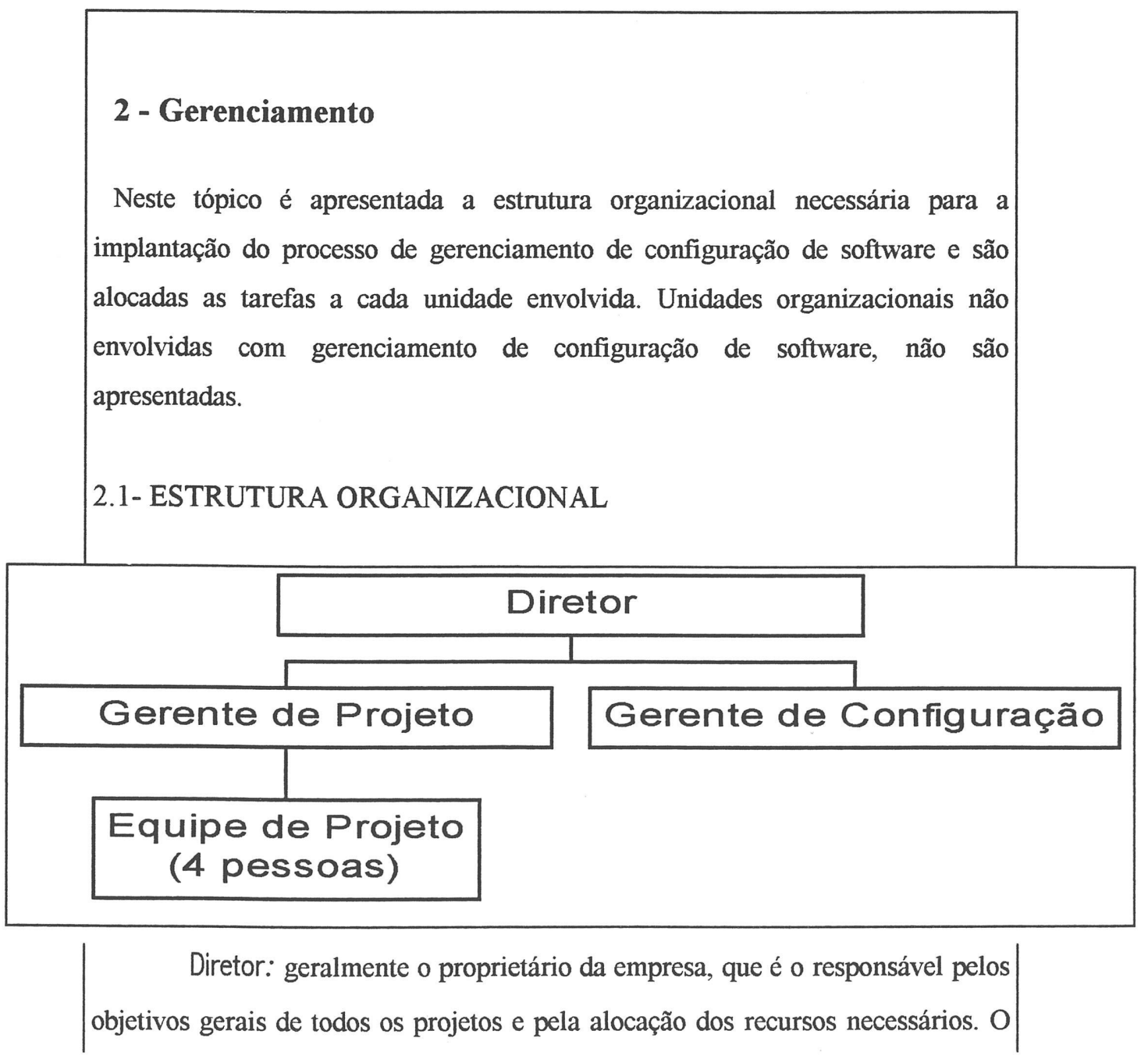


diretor deve revisar e aprovar o plano de gerenciamento de configuração de software. É o diretor quem aprova ou recusa cada alteração nos sistemas.

Gerente de Projeto: é quem mais conhece o projeto, um analista de sistemas experiente, com espírito de liderança. Quando existem dois sócios na empresa, o gerente de projeto pode ser o sócio com perfil mais "técnico" e o diretor o sócio com perfil mais "administrador". Em outras situações, o gerente de projeto pode variar de acordo com o projeto; assim, um membro da equipe de projeto passa a ser o gerente daquele projeto com o qual ele tem maior envolvimento. $\mathrm{O}$ gerente de projeto tem o dever de garantir que o software seja executado no prazo, dentro do orçamento e com o devido padrão de qualidade. Deve estar atento a desvios que estejam ocorrendo em relação aos planos, prevendo os problemas e comunicando-os ao diretor o quanto antes. $O$ gerente de projeto envia o plano de gerenciamento de configuração de software ao diretor para aprovação e garante que ele seja executado. Participa ativamente das alterações, preparando os relatórios de alteração e coordenando o trabalho de alteração.

Gerente de Configuração: devido à importância e complexidade de suas atividades, deve ser um analista experiente e, preferencialmente, sistemático, minucioso e exigente. O gerente de configuração atua como um "bibliotecário" dos itens de informação armazenados no repositório. Suas atividades são:

- escrever o plano de gerenciamento de configuração de software, junto com o gerente do projeto;

- criar a estrutura do repositório para que suporte o esquema de identificação previsto no plano;

- garantir a segurança e a integridade da biblioteca através de controle de acesso e cópias de segurança;

- implementar as rotinas para criar novos itens, para retirar e congelar itens no repositório (check in / check out);

- analisar a documentação atualizada pela equipe de projeto e, se correta, aprová-la e armazená-la;

- gerar os relatórios de situação da configuração, quando necessários; 
- gerenciar a liberação de versões de sistemas para os clientes;

- atuando como um cão de guarda do repositório, impedir que nele sejam feitos acessos ou atualizações sem o devido registro ou autorização.

Equipe de projeto: é composta por programadores e analistas de sistemas que podem trabalhar em vários projetos simultaneamente. A equipe projeta $\mathrm{e}$ implementa o sistema de software sob a coordenação do gerente de projeto. A equipe deve executar as tarefas de gerenciamento de configuração de software de acordo com o plano e com o auxílio do gerente de configuração. Solicitações de alteração podem ser feitas por qualquer membro da equipe, clientes ou pelo gerente de projeto, e são submetidas à aprovação do diretor.

\section{2- RESPONSABILIDADES}

O quadro abaixo detalha, para cada cargo descrito na seção anterior, as responsabilidades com relação às tarefas de gerenciamento de configuração de software (essas tarefas são melhor descritas na seção 3 do plano).

\begin{tabular}{|l|c|c|c|c|}
\hline Atividades de gerenciamento de configuração de software & Diretor & $\begin{array}{c}\text { Gerente } \\
\text { Projeto }\end{array}$ & $\begin{array}{c}\text { Equipe } \\
\text { Projeto }\end{array}$ & $\begin{array}{c}\text { Gerente } \\
\text { Configuração }\end{array}$ \\
\hline Plano de Gerenciamento de Configuração & $\mathrm{A}$ & $\mathrm{C}$ & & $\mathrm{C}$ \\
\hline Alocação de recursos & $\mathrm{E}$ & & & $\mathrm{C}$ \\
\hline Repositório de itens & & & & $\mathrm{C}$ \\
\hline Identificação dos itens & & $\mathrm{A}$ & $\mathrm{E}$ & $\mathrm{C}$ \\
\hline Definir linhas de referência & & $\mathrm{A}$ & & $\mathrm{C}$ \\
\hline Pedido de mudança & $\mathrm{C}$ & $\mathrm{C}$ & $\mathrm{C}$ & $\mathrm{C}$ \\
\hline Relatório de mudança & & $\mathrm{C}$ & & \\
\hline Análise do relatório de mudança & $\mathrm{E}$ & & & \\
\hline Retorno ao solicitante das alteraç̃̃es não aprovadas & $\mathrm{E}$ & $\mathrm{E}$ & & \\
\hline Registro de saída e entrada de itens do repositório & & & & $\mathrm{E}$ \\
\hline Execução da mudança, inclusive documentação & & & $\mathrm{E}$ & \\
\hline Revisão dos itens alterados & & & & $\mathrm{E}$ \\
\hline Liberação de versões a clientes & & $\mathrm{A}$ & & $\mathrm{E}$ \\
\hline Monitoramento do conteúdo das áreas dos desenvolvedores & & & & $\mathrm{E}$ \\
\hline Garantir segurança e integridade do repositório & & & & $\mathrm{E}$ \\
\hline Relato de situação & & & & $\mathrm{E}$ \\
\hline Atualização do Plano de Gerenciamento de Configuração & $\mathrm{A}$ & & & $\mathrm{E}$ \\
\hline Treinamento no uso de ferramentas de Gerenciamento & & & & $\mathrm{E}$ \\
\hline
\end{tabular}

$$
\text { legenda: } \mathrm{C}=\text { Cria } \quad \mathrm{A}=\text { Aprova } \quad \mathrm{E}=\text { Executa }
$$


2.3- Políticas, diretivas e procedimentos aplicáveis

Nesta sessão do plano é colocada toda restrição externa existente devido a outras políticas, diretivas e procedimentos existentes na empresa ou imposta por contrato com terceiros. Para cada restrição, o impacto e efeito sobre o plano deve ser registrado.

\subsection{Elaboração da Seção 3 do Plano Tarefas}

$\mathrm{Na}$ elaboração da seção 3 , de tarefas, leva-se em consideração as conclusões do capítulo 4, que foram baseadas nas determinações do Instituto dos Engenheiros Elétricos e Eletrônicos dos Estados Unidos (IEEE) e as características das empresas de pequeno porte.

O controle de versões é auxiliado pela ferramenta de software chamada QVCS [Voris,1997] que satisfaz os requisitos descritos na preparação do plano.

\section{3- Tarefas}

\section{1- IDENTIFICAÇÃO DA CONFIGURAÇÃO DE SOFTWARE}

Esta tarefa envolve a seleção dos itens de informação que serão controlados, o estabelecimento do momento em que cada item começa a ser controlado e a definição de nomes únicos e significativos para cada item de informação. Além disso, também é descrita a forma como o repositório dos itens é organizado e como os itens no repositório são manipulados.

\subsection{1- Seleção dos itens de informação}

Durante o desenvolvimento e manutenção de um sistema, muitos itens de informação são produzidos. O conjunto de itens de informação a serem controlados é composto de: 
- plano de projeto de software: documento resultante da fase de definição do sistema, onde constam os objetivos gerais do sistema, as principais funcionalidades e estimativas de custo e prazo;

- descrição do banco de dados: documento que descreve a forma como os dados globais ficam armazenados e os relacionamentos existentes entre eles (ex: Modelo Entidade-Relacionamento);

- conteúdo inicial dos arquivos do banco de dados: dados que devem estar armazenados nos arquivos antes da primeira execução do sistema. Pode-se exigir que o arquivo esteja vazio ou que contenha um determinado conjunto inicial de dados;

- especificação dos requisitos do sistema: o modelo de fluxo de dados e o dicionário de dados;

- descrição do projeto modular: documento que descreve os módulos do software e os relacionamentos entre eles;

- casos e resultados de testes: documento que descreve os testes a serem efetuados no software e os resultados esperados;

- código fonte: conjunto de todas as linhas de código do sistema;

- manuais operacionais e de instalação;

- ferramentas de produção de software: ferramentas utilizadas para desenvolvimento do software (ex: compilador).

\subsection{2- Estabelecimento das Linhas de Referência}

As linhas de referência estabelecidas correspondem aos finais de algumas das fases do ciclo de vida do software: de linha de referência de requisitos, linha de referência de projeto, linha de referência de produto e linha de referência de manutenção. 


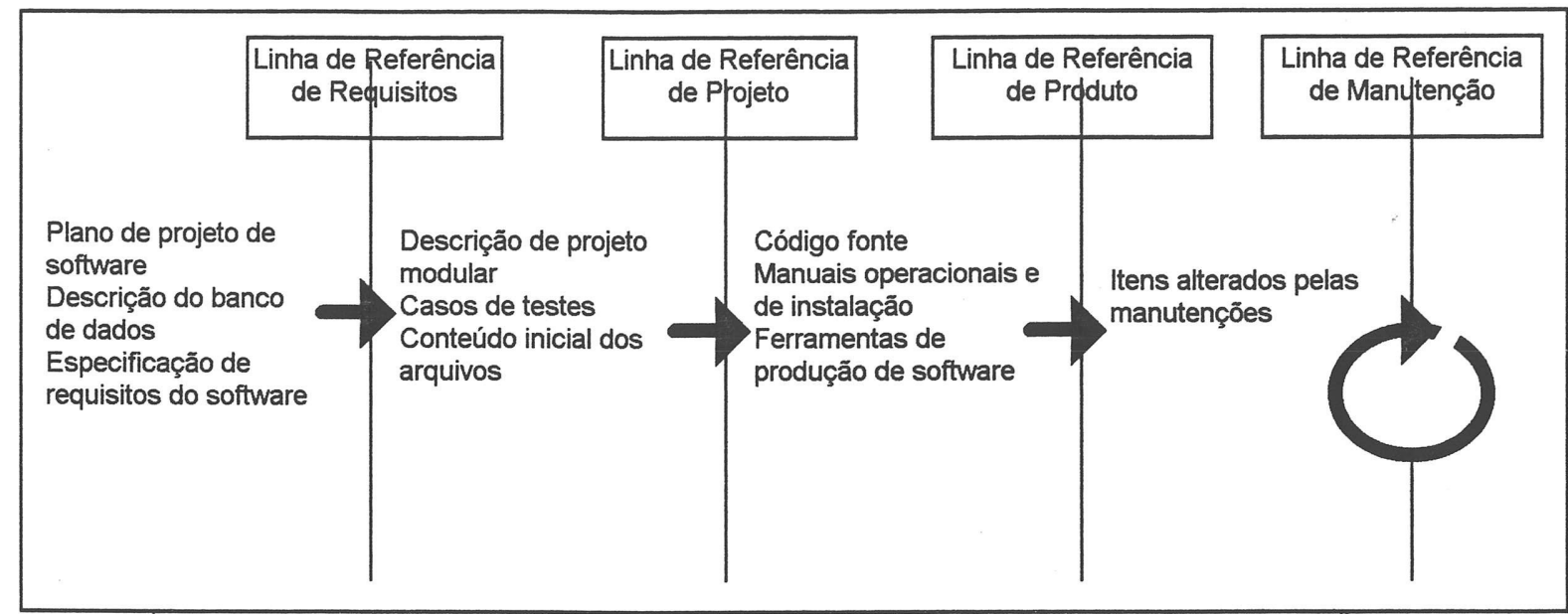

As três primeiras linhas de referência são traçadas apenas uma vez em cada projeto, enquanto que as linhas de referência de manutenção serão traçadas todas as vezes em que for liberada uma nova versão do software.

\subsection{3- Identificação dos itens de informação}

Para que os itens de informação sejam convenientemente manipulados, cria-se um esquema de identificação.

Nesse esquema, os nomes são compostos por até 8 caracteres, mais 3 caracteres de extensão.

\begin{tabular}{|c|c|c|c|c|}
\hline ITEM & $\begin{array}{l}\text { Tipo de } \\
\text { item } \\
\text { (3 letras) }\end{array}$ & $\begin{array}{l}\text { Especificador } \\
\text { do item } \\
\text { ( } 5 \text { letras ou } \\
\text { números ) }\end{array}$ & $\begin{array}{l}\text { Extensão } \\
\text { ( } 3 \text { letras - } \\
\text { conforme } \\
\text { ferramenta de } \\
\text { produção) }\end{array}$ & Exemplo \\
\hline $\begin{array}{l}\text { Plano de Projeto de Software } \\
\text { Descrição do Banco de Dados } \\
\text { Conteúdo Inicial dos Arquivos do Banco de Dados } \\
\text { Dicionário de Dados } \\
\text { Diagrama de Fluxo de Dados } \\
\text { Descrições do Projeto Modular } \\
\text { Listagem do código-fonte } \\
\text { Casos e Resultados de Testes } \\
\text { Manuais Operacionais e de Instalação } \\
\text { Ferramentas de Produção de Software (editores, } \\
\text { compiladores, CASE, etc.) }\end{array}$ & $\begin{array}{l}\text { PPS } \\
\text { DBD } \\
\text { CIA } \\
\text { DIC } \\
\text { DFD } \\
\text { DPM } \\
\text { LCF } \\
\text { CRT } \\
\text { MOI } \\
\text { FPS }\end{array}$ & $\begin{array}{l}\text { CLIEN } \\
10203 \\
10203 \\
10203 \\
\text { TLINK }\end{array}$ & & $\begin{array}{l}\text { PPS.DOC } \\
\text { DBD.ER1 } \\
\text { CIACLIEN.DBF } \\
\text { DIC.DOC } \\
\text { DFD10203.FQP } \\
\text { DPM.DOC } \\
\text { LCF10203.PRG } \\
\text { RCT10203.DOC } \\
\text { MOI.DOC } \\
\text { FPSTLINK.EXE }\end{array}$ \\
\hline
\end{tabular}

O nome de cada um dos itens começa com três caracteres que determinam o tipo do item, e mais cinco caracteres ou números que especificam o item. Todos os itens de informação devem satisfazer ao esquema de identificação proposto. A identificação das versões dos itens é deixado a cargo da ferramenta de controle de versões. 


\subsection{4- Organização do Repositório}

Os itens de informação são criados no diretório de trabalho do projeto, que tem o mesmo nome do projeto (ex: proj1). O repositório dos itens de configuração é um sub-diretório do diretório de trabalho. O nome desse diretório é dado pela ferramenta de controle de versões, e chama-se "qvcs" (Quma Version Control System).

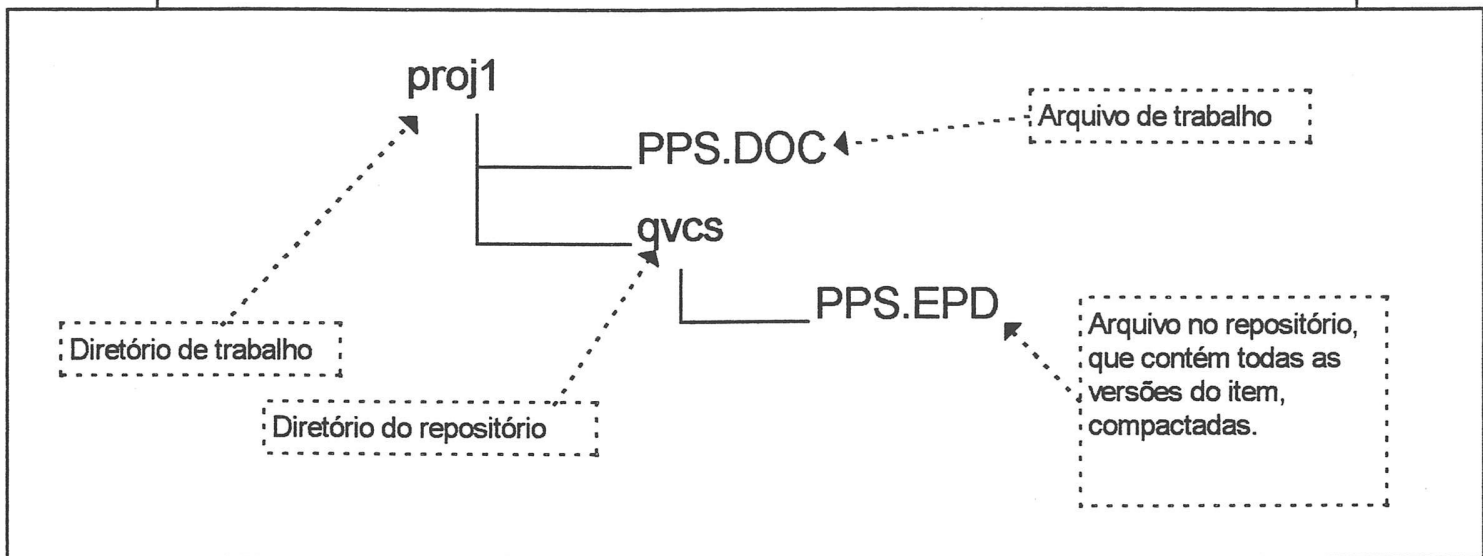

No momento em que um item é armazenado no repositório pela primeira vez , é criado no diretório qvas um arquivo compactado com o mesmo nome do item original, porém com outra extensão. A extensão é montada a partir da extensão original do item, porém com a substituição de cada letra pela letra sucessora ( ex: pps.doc no arquivo de trabalho gera pps.epd no repositório). As novas versões desse item serão também armazenadas no repositório e no mesmo arquivo compactado. A organização interna do arquivo compactado utiliza deltas negativos, para que armazene todas as versões do item sem ocupar muito espaço em disco.

Quando uma versão de um item é recuperada do repositório para a área de trabalho (check out), a ferramenta verifica se já há uma outra versão do item na área de trabalho. Essa verificação serve para evitar que a versão sendo alterada (na área de trabalho) seja sobrescrita por uma versão diferente (vinda do repositório). Se não houver problemas, uma cópia da versão solicitada do item é montada a partir do arquivo compactado e colocada no diretório de trabalho. A mesma versão não poderá mais ser retirada por outros usuários até que seja desbloqueada pelo usuário que a retirou. Dependendo das configurações de proteção do projeto e do item, o arquivo original poderá ser apagado, ou seu atributo alterado para "somente leitura". 
Devido à fragilidade do mecanismo de segurança, serão feitas cópias de segurança freqüentes de todos os arquivos em ambos os diretórios. No disquete ou fita com as cópias de segurança estarão anotadas a data da cópia e o nome do projeto.

\subsection{5- Manipulação de itens de configuração no repositório}

Neste tópico é apresentada a inclusão dos itens de um projeto (chamado Proj1) sob controle de versão, utilizando-se a ferramenta QVCS e os mecanismos utilizados em sua manipulação. $O$ projeto contém arquivos de vários tipos (textos no formato ASCII, documentos do MS-WinWord, diagramas do Flow-chart, modelos entidade-relacionamento no formato do ERWin Open for Model Mart, e arquivos de dados no formato $d b f$.

\section{DIRETÓRIO DO PROJETO}

Inicialmente, os itens são colocados num diretório com o mesmo nome do projeto ( $p r o j l)$ e que será o diretório de onde serão escolhidos os arquivos a serem mantidos sob controle de versão. Este será futuramente o diretório onde serão colocadas as cópias de trabalho das versões dos itens.

O volume da unidade C é DISK1_VOL1

O número de série do volume é DA8C-978E

Diretório de C:Iproj1

\begin{tabular}{|c|c|c|c|c|c|}
\hline \multicolumn{2}{|c|}{$\begin{array}{l}<D I R> \\
<D I R>\end{array}$} & \multicolumn{2}{|c|}{ 12/10/97 13:36. } & & \\
\hline DBD & ER1 & 19.921 & $12 / 10 / 97$ & $13: 46$ & DBD.ER1 \\
\hline CIACLIEN & DBF & 163 & $12 / 10 / 97$ & $13: 48$ & CIACLIEN.DBF \\
\hline PPS & DOC & 13.312 & $12 / 10 / 97$ & $13: 47$ & pps.doc \\
\hline LCF10203 & PRG & 832 & $12 / 10 / 97$ & $14: 54$ & LCF10203.PRG \\
\hline DFD10203 & PDQ & 2.680 & $12 / 10 / 97$ & $14: 03$ & dfd10203.pdq \\
\hline DIC & DOC & 13.312 & $12 / 10 / 97$ & 13:52 & Dic.doc \\
\hline DPM & DOC & 13.824 & $12 / 10 / 97$ & $14: 13$ & DPM.doc \\
\hline $\mathrm{MOI}$ & $\mathrm{DOC}$ & 13.312 & $12 / 10 / 97$ & $14: 51$ & MOl.doc \\
\hline CRT1020 & DOC & 13.824 & $12 / 10 / 97$ & $14: 48$ & CRT10203.doc \\
\hline
\end{tabular}

\section{CRIAÇÃO DO PROJETO}

Para que um projeto seja criado, é inicialmente necessário indicar o nome do projeto, o diretório onde ficam armazenados os itens de informação e os usuários que têm acesso ao repositório. Isso é feito a partir do botão "New" existente na pasta "Projects". 


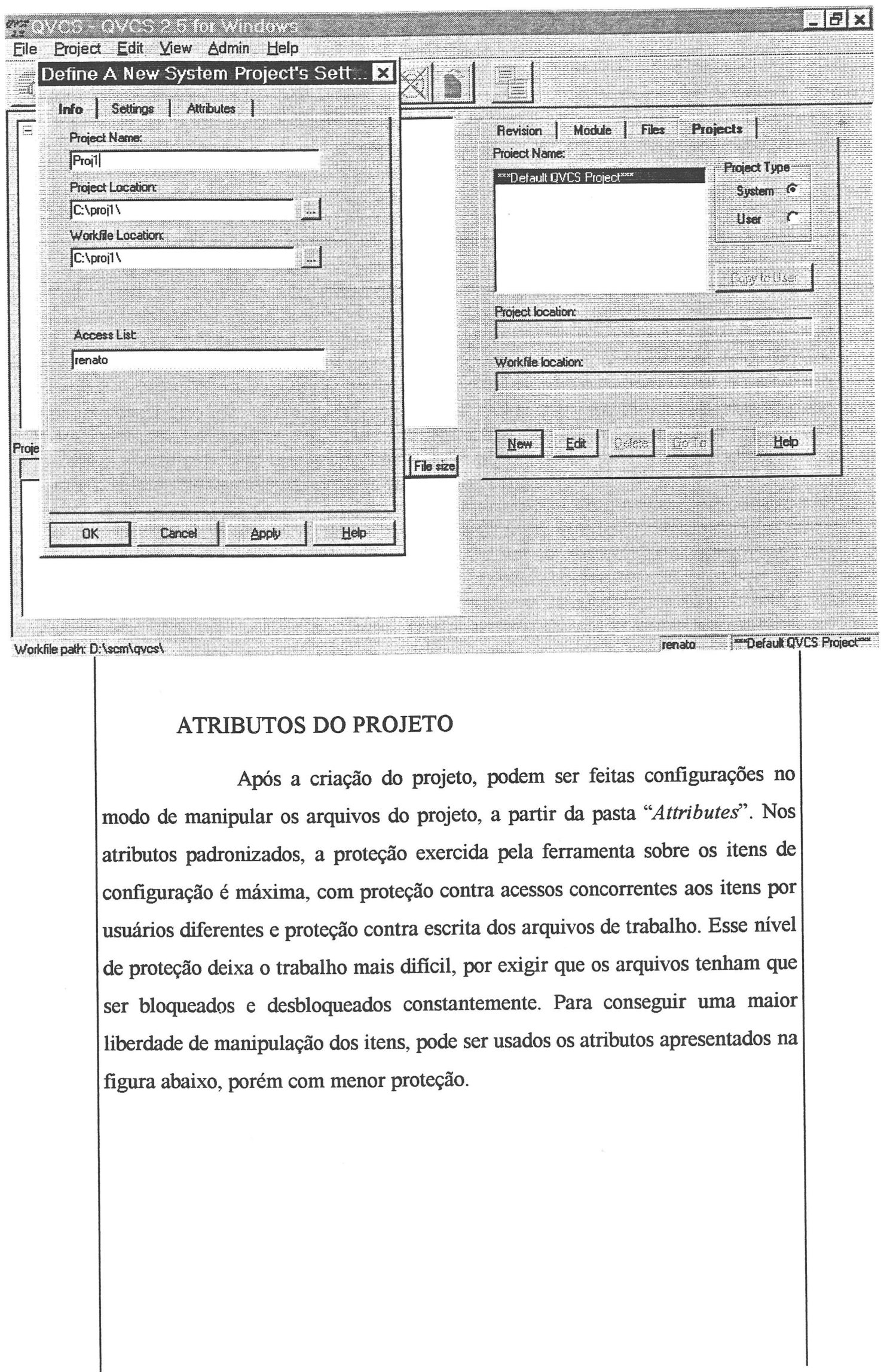




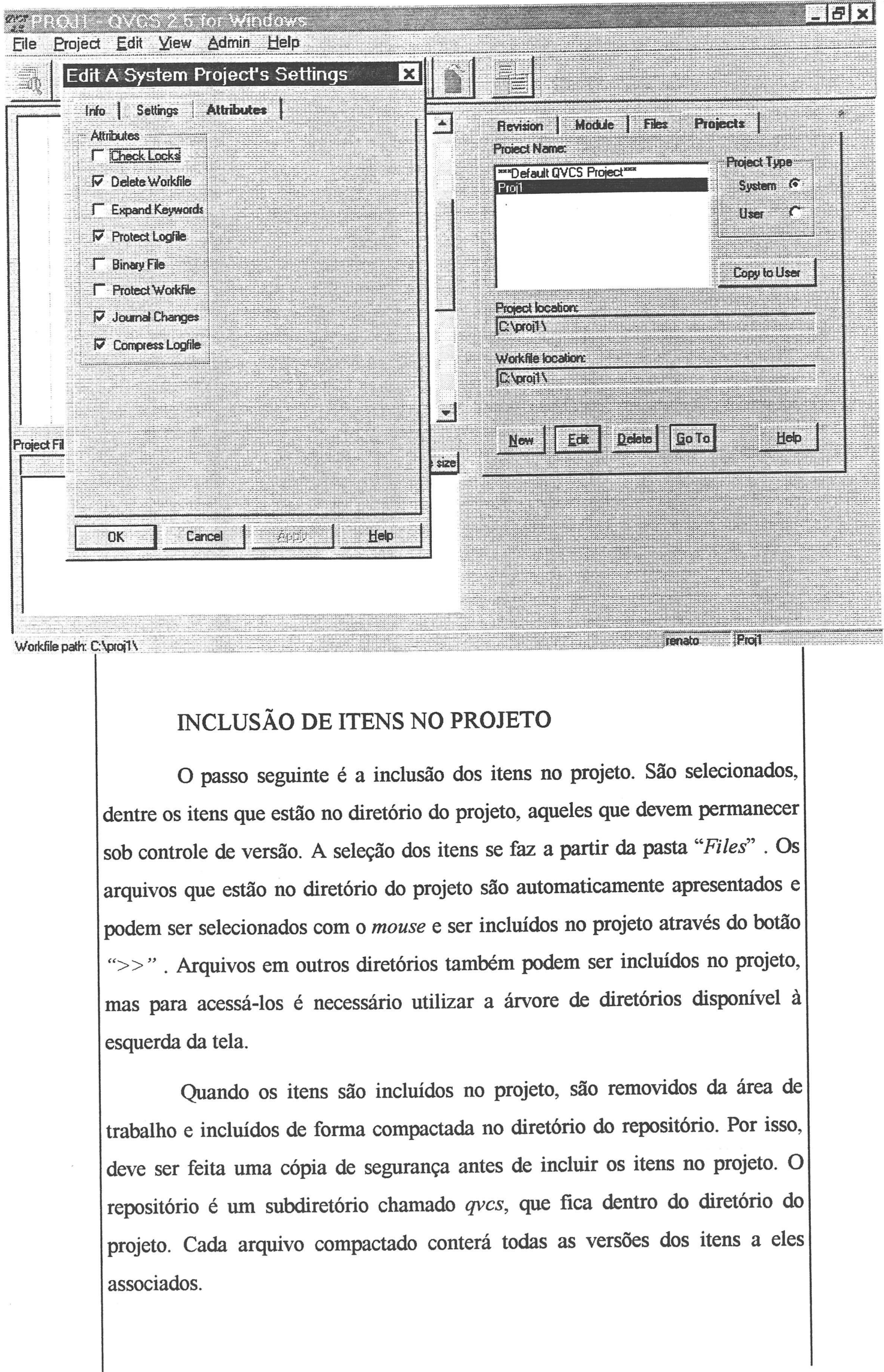




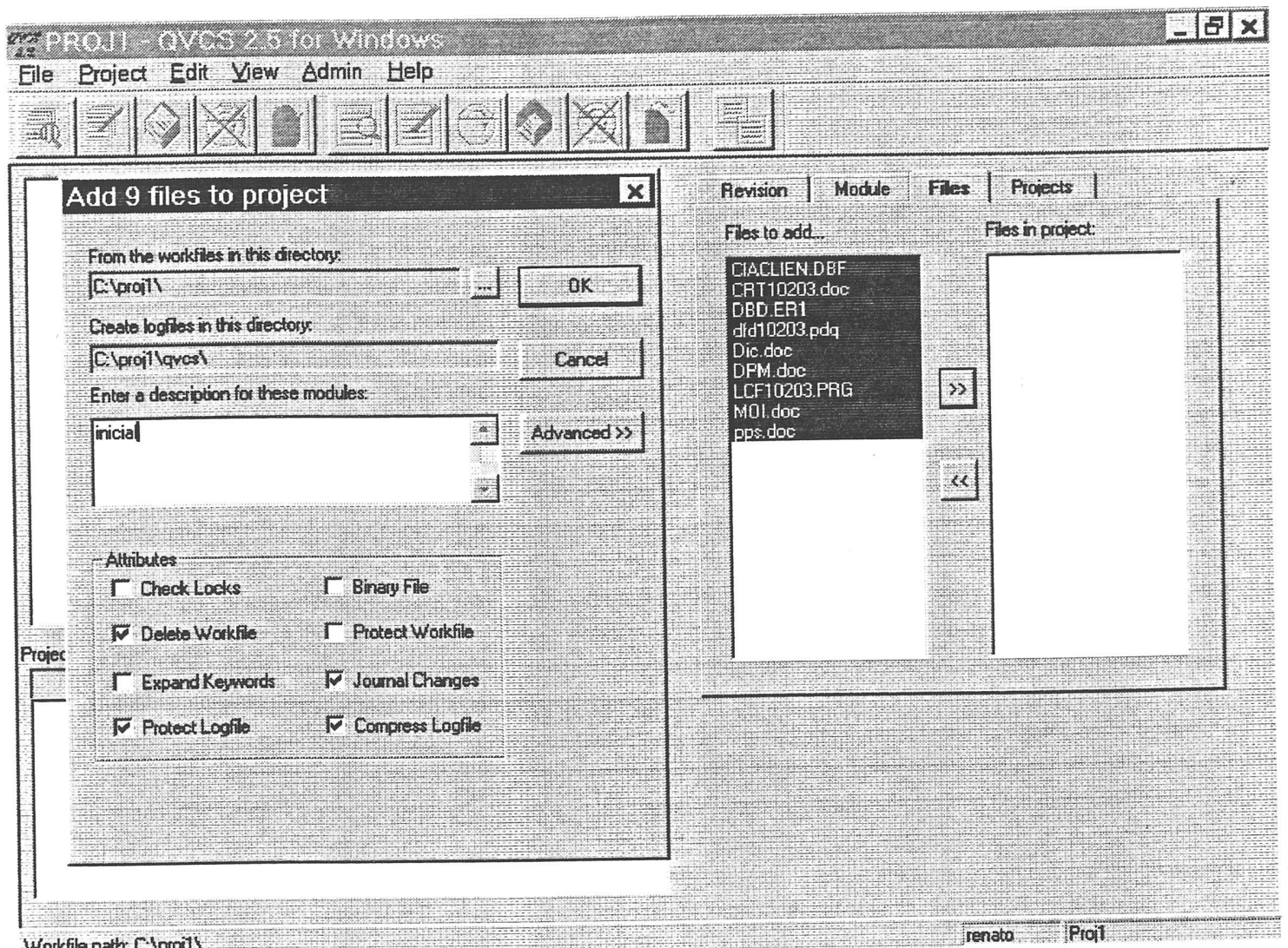

Workfile path C:Lroits

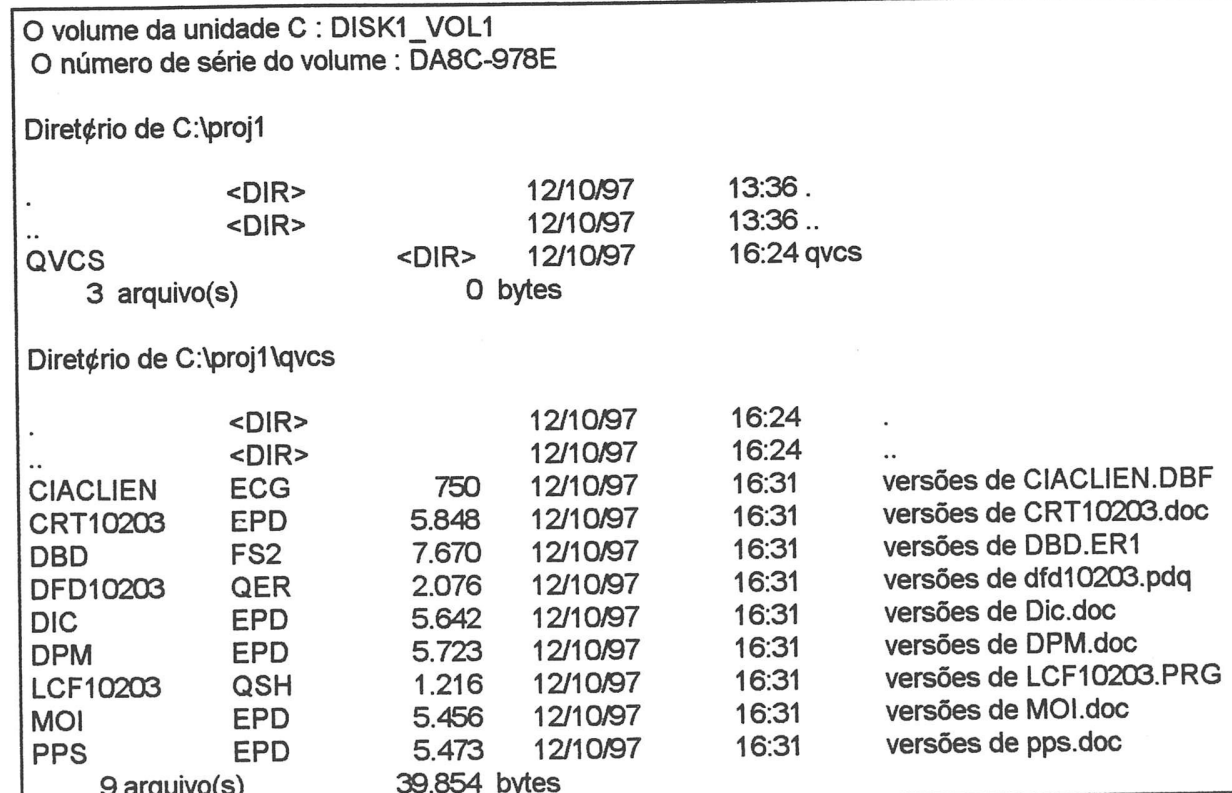

\section{ALTERAÇÃO DE ATRIBUTOS DE ARQUIVOS ESPECÍFICOS}

Inicialmente, os arquivos utilizam os mesmos atributos definidos para o projeto. Alguns arquivos, porém, podem merecer atributos específicos. Um caso relevante é o caso de arquivos binários, cujo método de compactação e de manutenção das diferenças entre versões é diferente do adotado para arquivos 


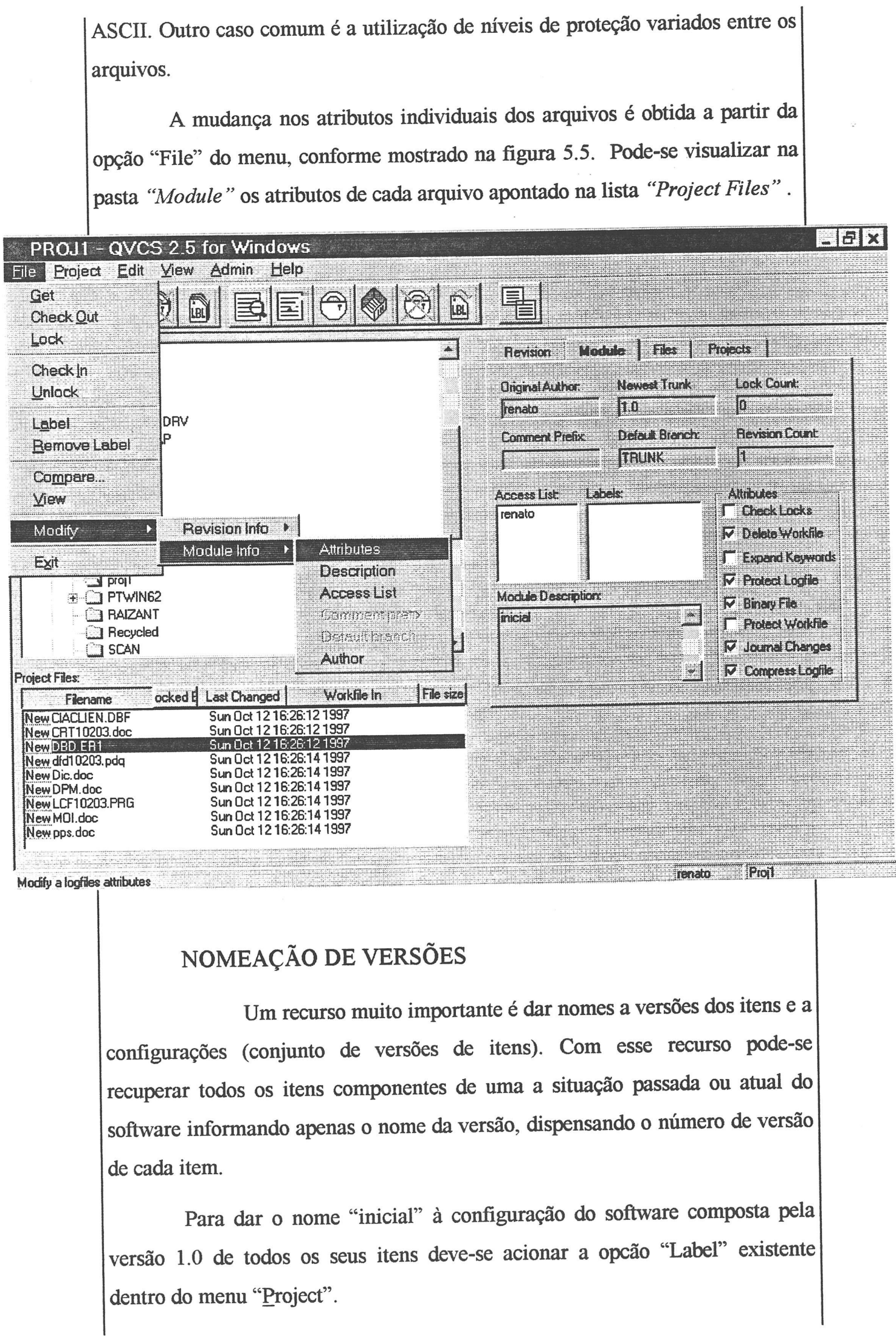




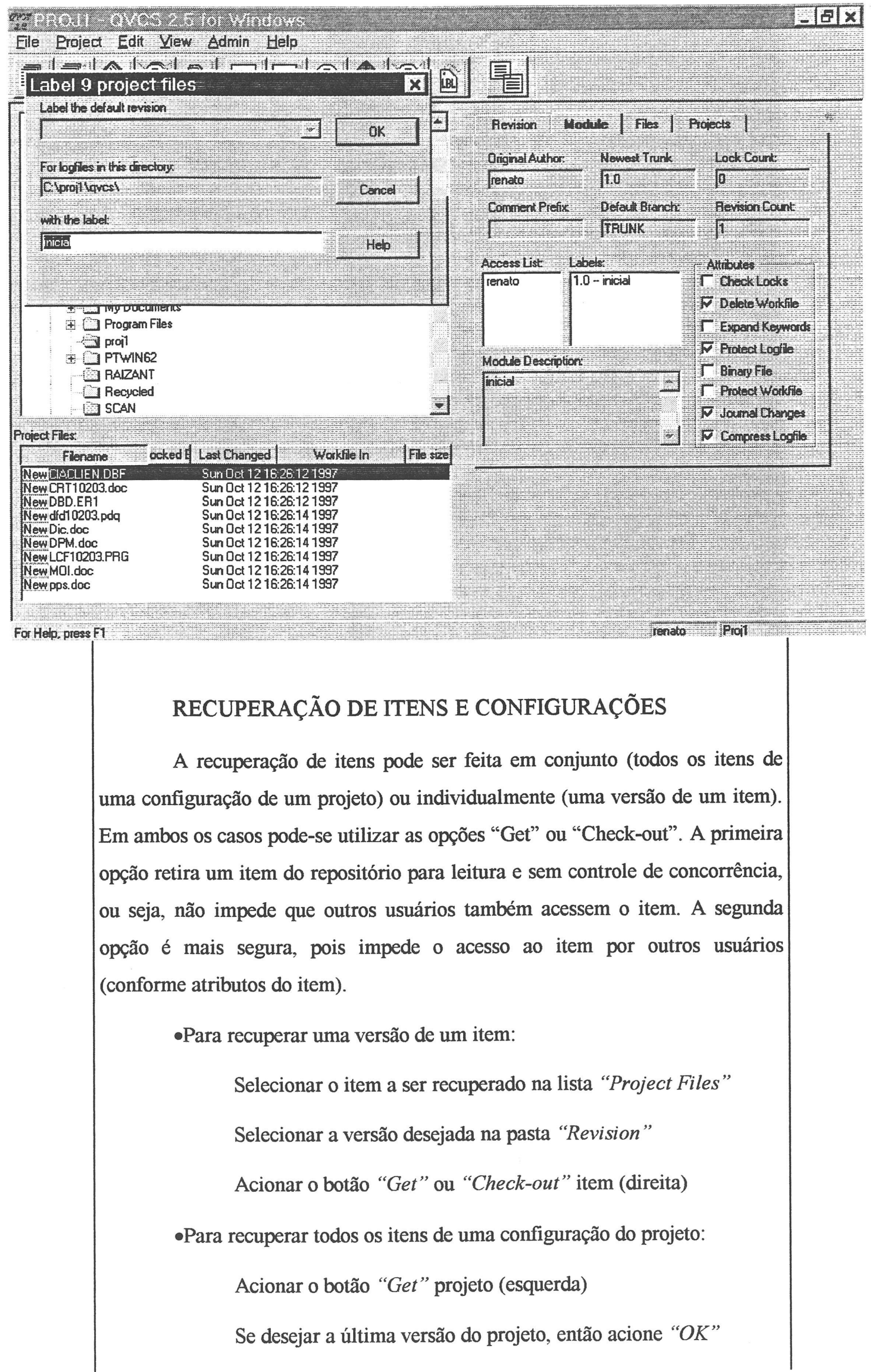




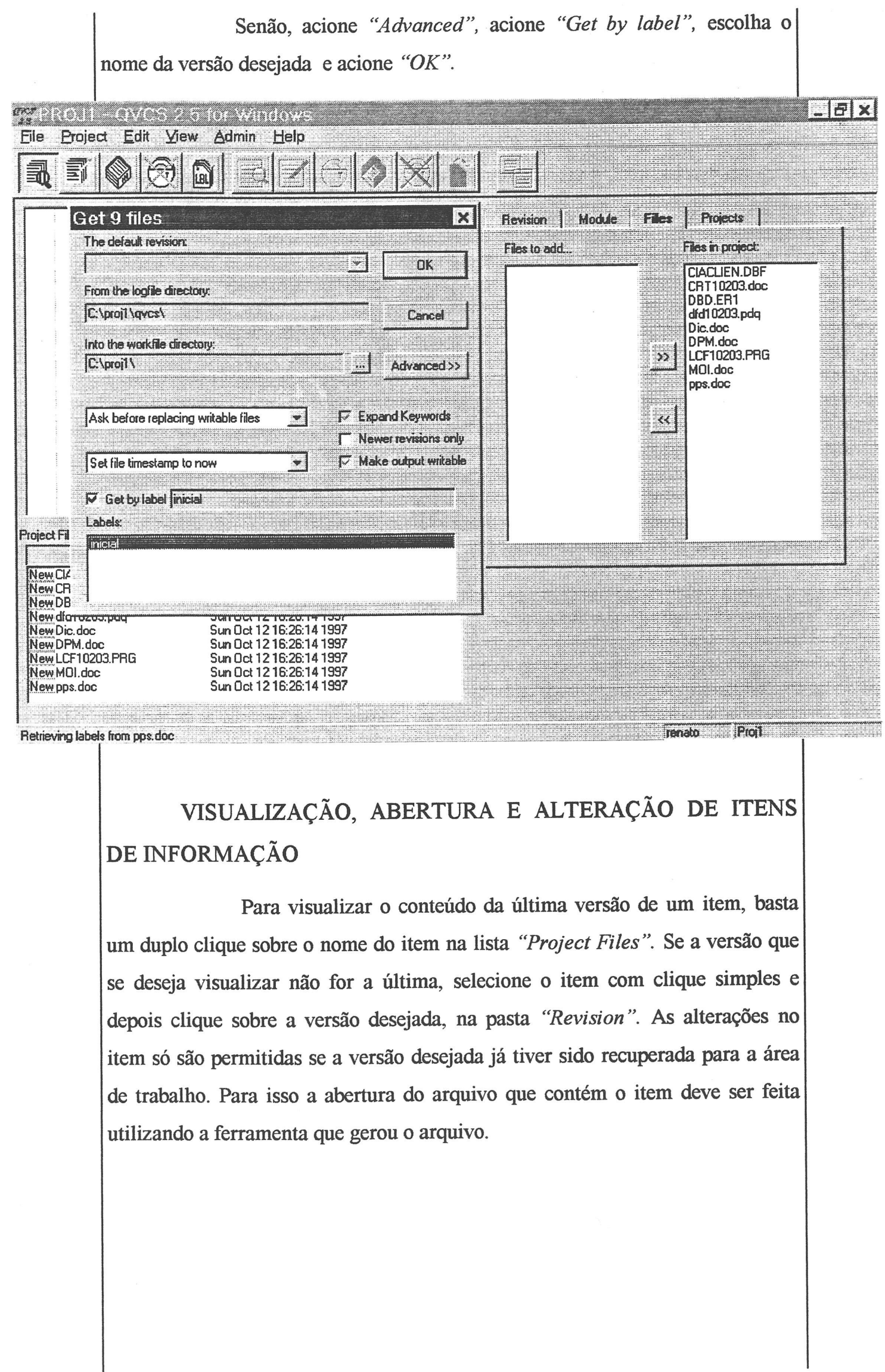




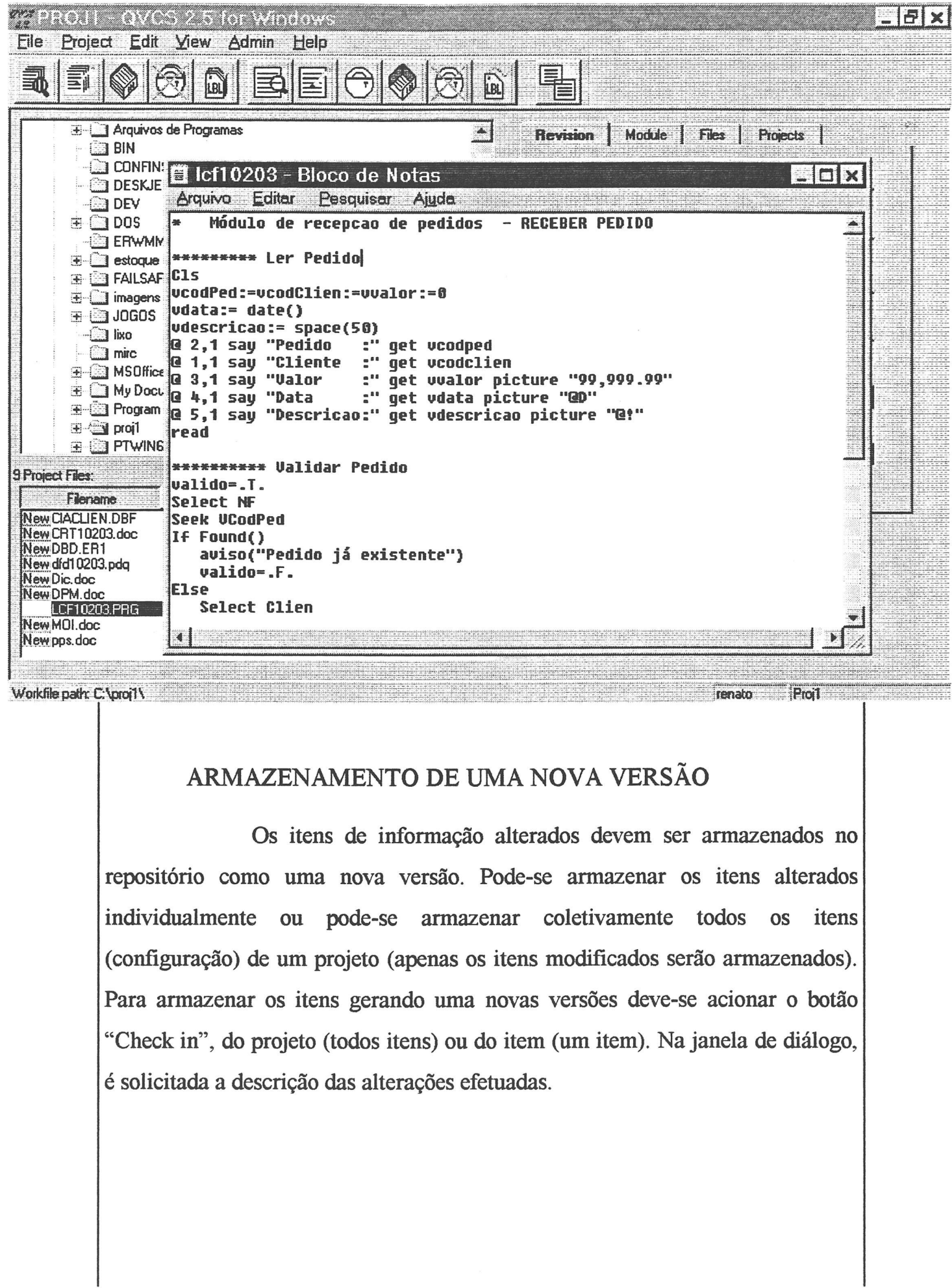




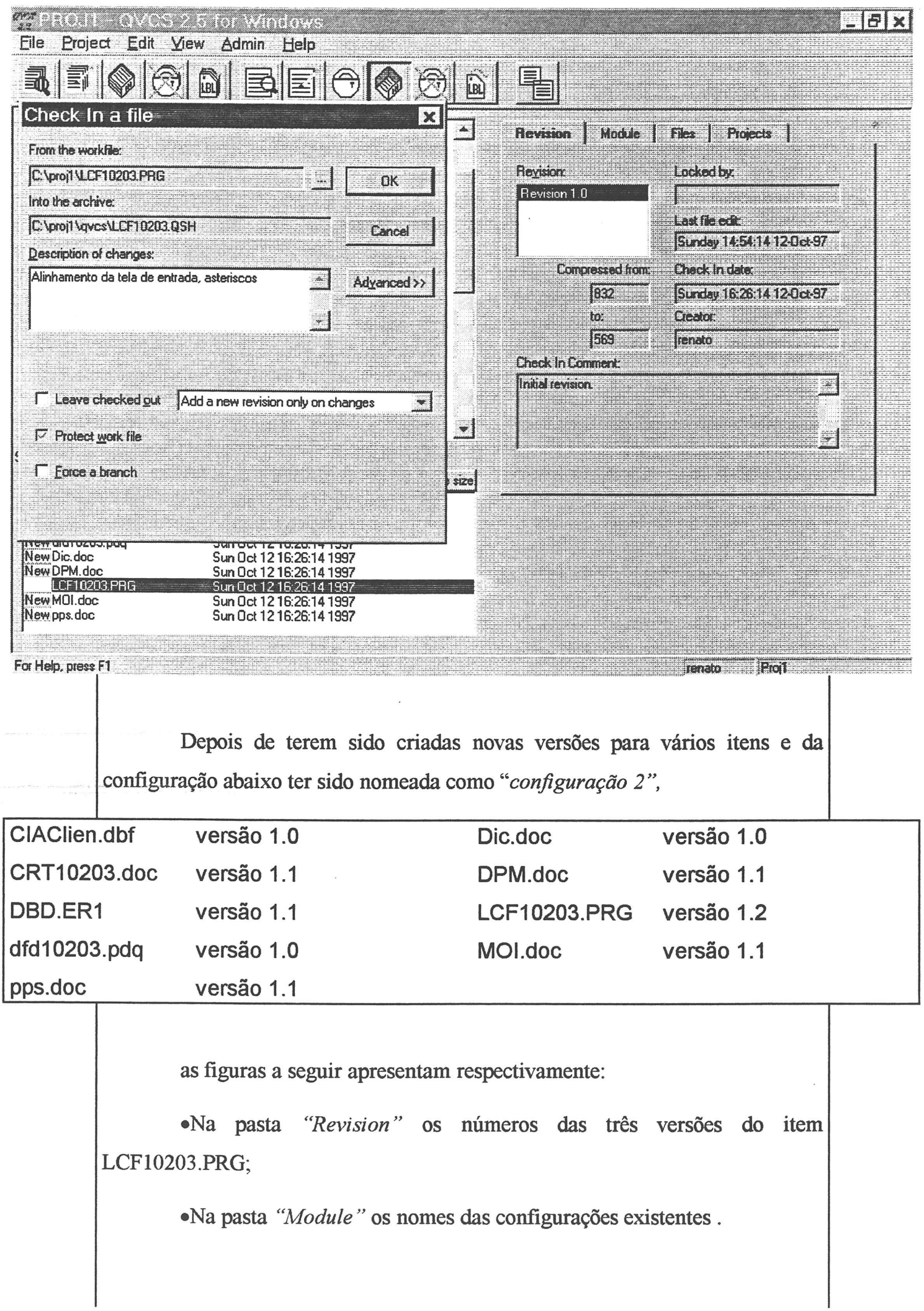


PROJ1 - QVCS 2.5 for Windows

Eile Broject Edit View Admin Help

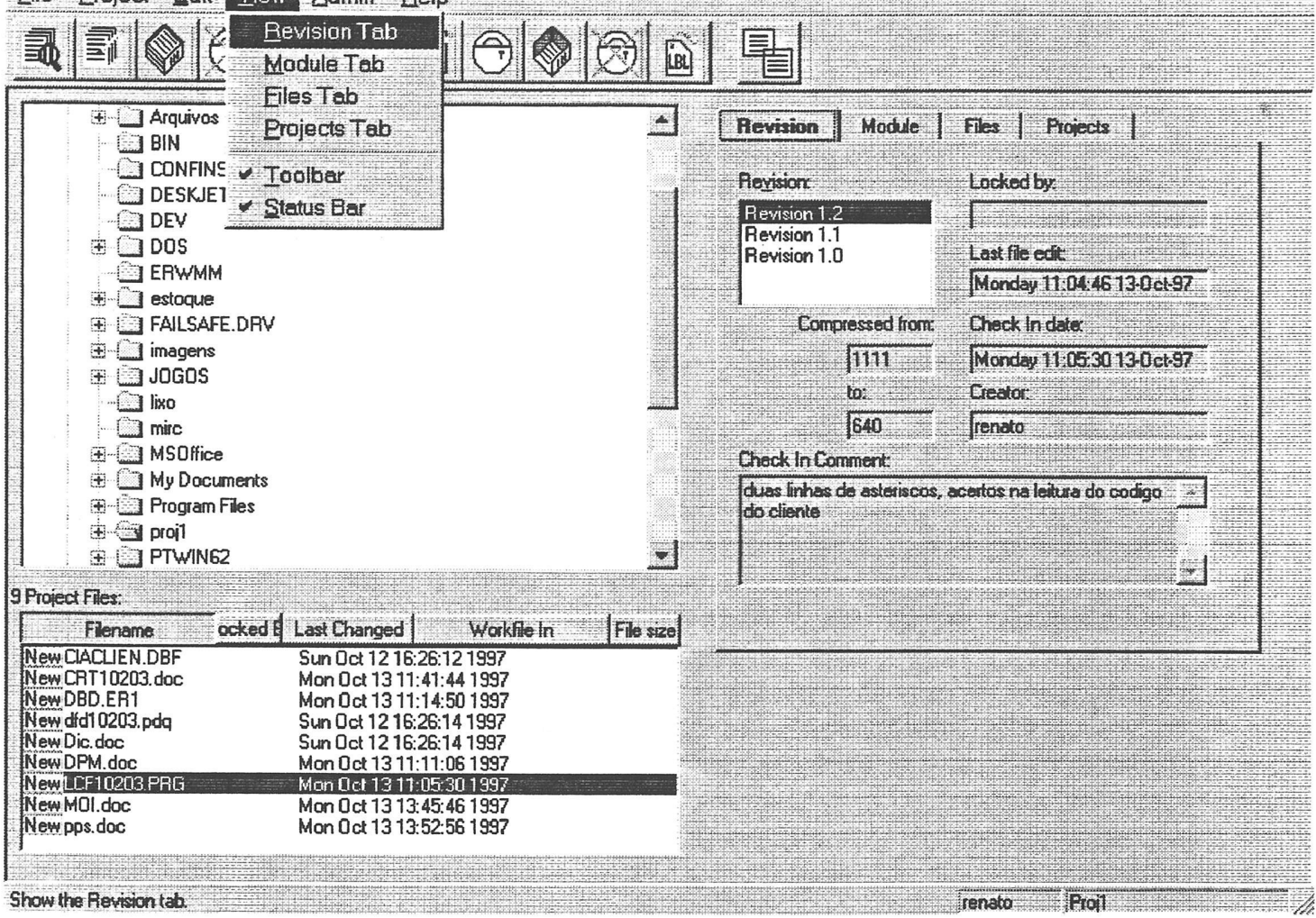

PROJ 1 - QVCS 25 for Windows

$-\mid \vec{x}$

Ele Eroject Endit View Admin Help

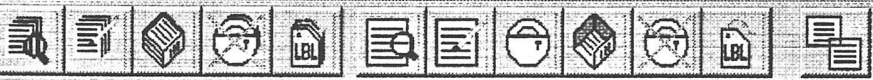

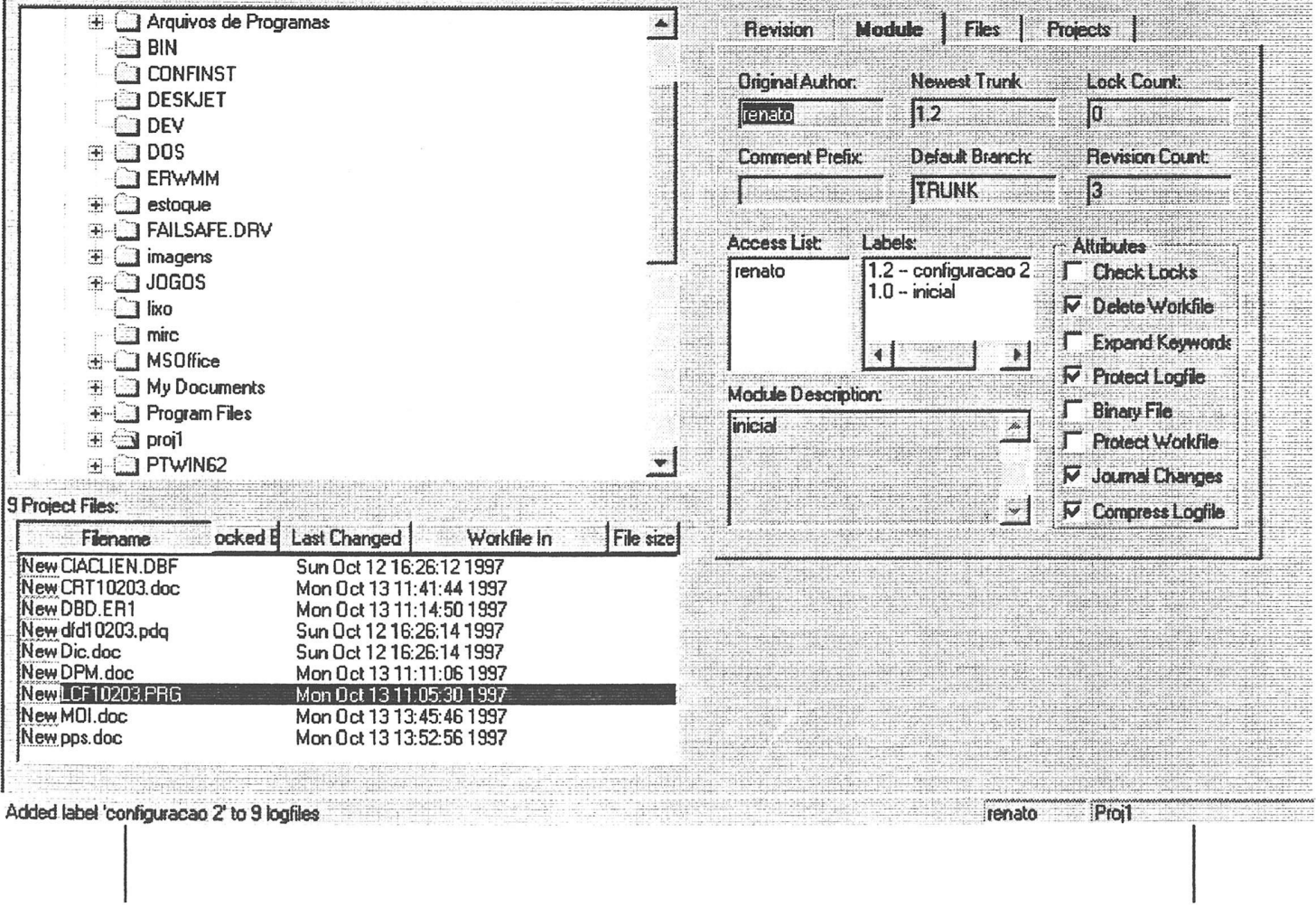




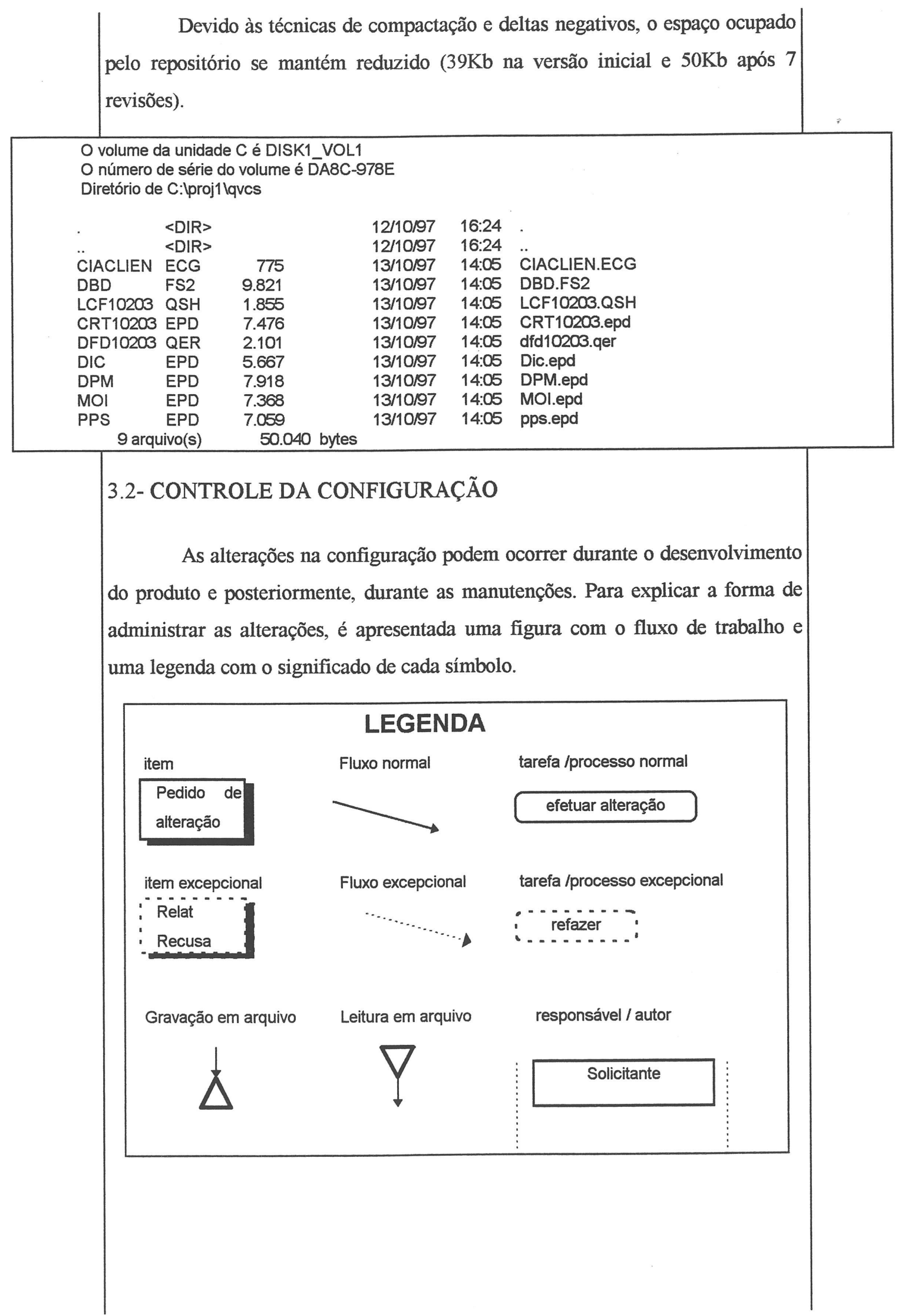




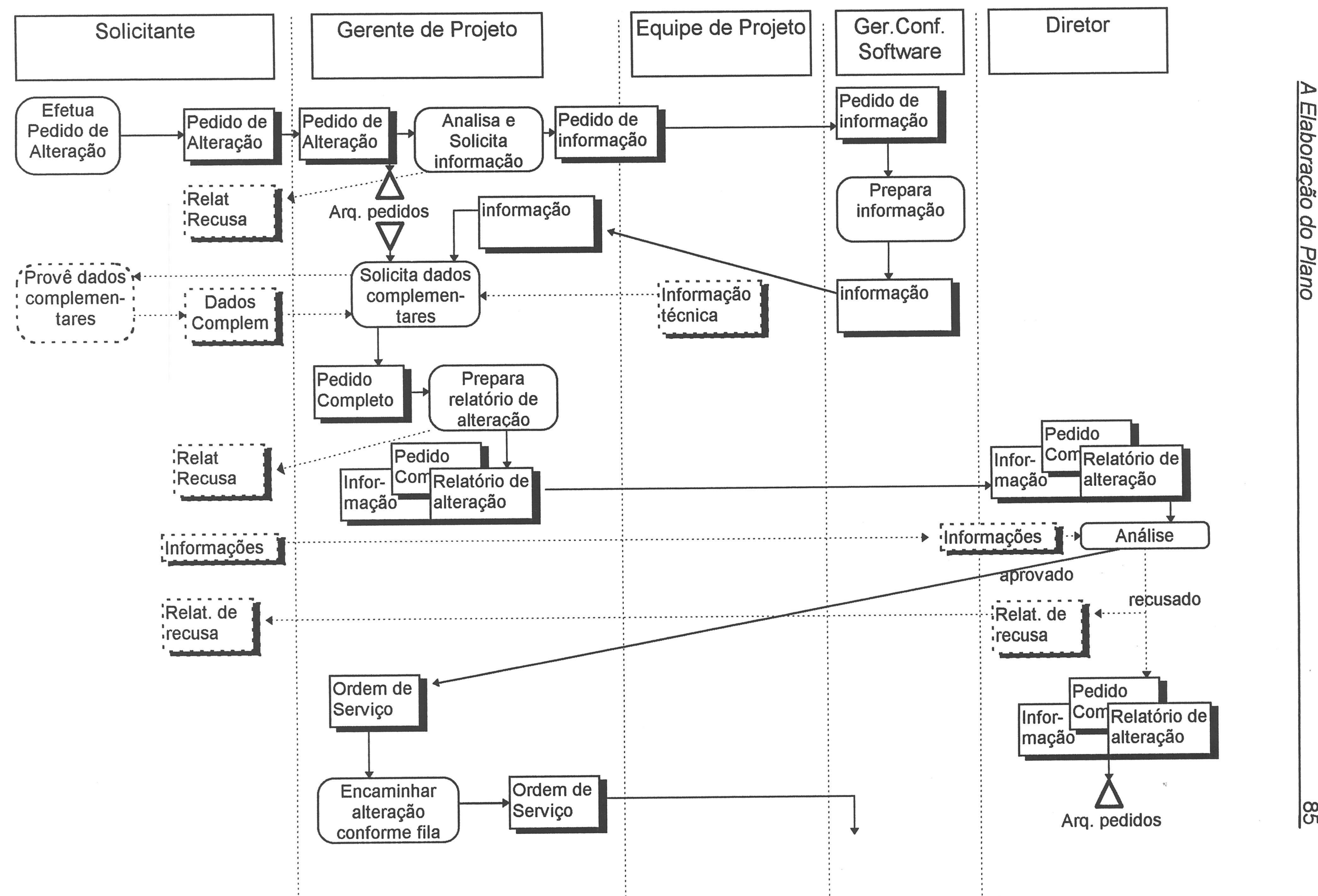




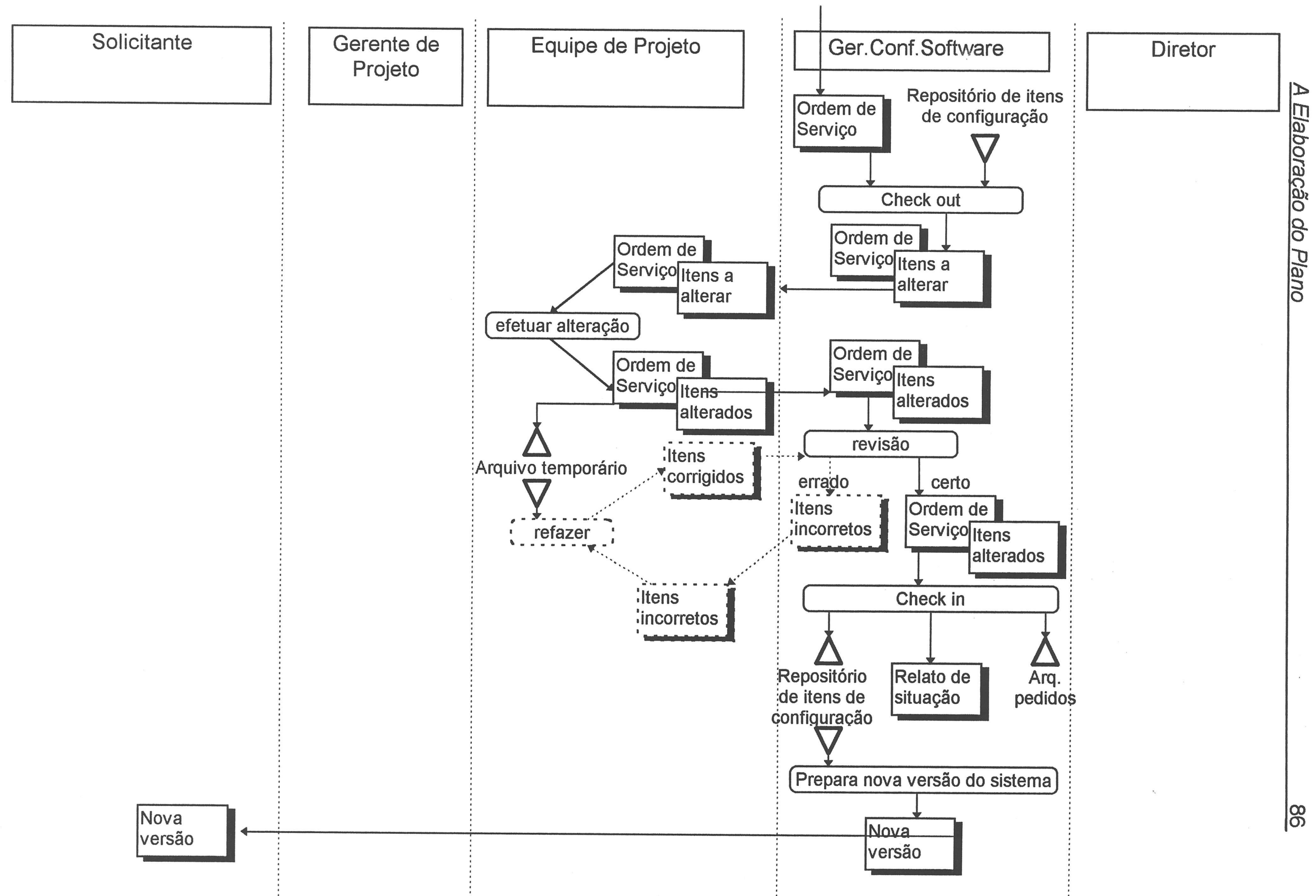


Os tópicos seguintes descrevem a forma como devem ser tratadas as alterações.

\subsection{1- Pedido de alteração}

Os itens de informação que ainda não passaram por uma linha de referência podem ser alterados livremente, porém todas as alterações em itens de informação no repositório da configuração só poderão ser efetuadas após formalmente solicitadas e aprovadas. O pedido de alteração deve ser feito em formulário ou registro eletrônico próprio, e encaminhado ao gerente do projeto. No pedido de alteração devem constar, no mínimo, as seguintes informações:

- número identificador do pedido;

- identificação do autor do pedido;

- data do pedido;

- nome e versão do item de informação que se pretende modificar;

- problema com o item;

- descrição da alteração pedida;

- indicação da urgência.

\subsection{2- Avaliação de alterações}

Para cada pedido de alteração encaminhado, o gerente do projeto deve fazer uma avaliação sobre o impacto da alteração sobre o projeto. Durante a análise recorre-se à documentação do sistema, e, se necessário, ao solicitante e à equipe de desenvolvimento para obter informações que determinem os custos e benefícios envolvidos com a alteração. Os resultados desta avaliação são escritos em um relatório de alteração e este é anexado ao pedido de alteração.

\subsection{3- Aprovação ou rejeição de alterações}

O diretor da empresa é quem aprova ou rejeita as alterações solicitadas. Caso a alteração seja recusada, o cliente deve ser informado sobre as razões e o pedido de alteração é arquivado. Para as alterações aprovadas, o diretor deve 
informar a prioridade de sua execução e encaminhar o pedido, o relatório de alteração e as informações- agora chamados de ordem de serviço - ao gerente do projeto. Pedidos de alteração que claramente envolvam baixos custos e grandes benefícios podem ser aprovadas pelo gerente do projeto, desde que o diretor da empresa assim o determine.

\subsection{4- Implementação de alterações}

O gerente do projeto encaminha as ordens de serviço ao gerente de configuração que retira os itens de configuração necessários do repositório e os coloca na área do membro da equipe de desenvolvimento designado pelo gerente do projeto. Tendo em mãos a ordem de serviço e os itens de configuração, os membros da equipe de desenvolvimento efetuam a alteração. Após uma revisão, o gerente de configuração de software deve armazenar as novas versões dos itens alterados nos locais adequados, registrar quais itens foram alterados, arquivar a ordem de serviço, preparar uma nova versão do sistema, gerar um relatório de versão, e enviar ao cliente.

\section{3- RELATO DA SITUAÇÃO DA CONFIGURAÇÃO}

O gerente da configuração de software é o responsável pela disponibilização das informações sobre a situação da configuração de software às pessoas autorizadas. Dois tipos de relatórios devem ser preparados:

- Toda vez em que uma nova versão do sistema for criada, deve ser preparado um relatório de versão de sistema que apresenta todos os componentes do sistema e suas versões.

- Periodicamente deve ser preparado um relatório que apresenta os sistemas ou itens que possuem novas versões e principais características dessas versões.

\section{4- AUDITORIA DA CONFIGURAÇÃO}

Não será efetuada auditoria na configuração, As falhas nos procedimentos de gerenciamento de configuração devem ser encontradas pelo gerente de configuração durante as revisões feitas antes de armazenar os itens no repositório. 


Nesta tarefa não está envolvida a determinação de erros de software.
Erros de software não são de responsabilidade do gerenciamento de configuração.
3.5- CONTROLE DE INTERFACE
Não será efetuado. Só haverá controle de interface quando os itens de
informação que são controlados sofrerem alterações freqüentes, causadas por
itens não controlados.
3.6- CONTROLE DE SUBCONTRATADOS E FORNECEDORES
Não será efetuado. Só haverá controle de subcontratados e fornecedores
quando houver muitos itens produzidos externamente.

\subsection{Elaboração da Seção 4 do Plano Roteiro}

A implantação e execução do plano de gerenciamento de configuração seguem um roteiro previamente estabelecido. Esse roteiro (ou cronograma) estabelece a seqüência entre as atividades de implantação do plano como também demarca os principais pontos de controle na sua execução. $O$ estabelecimento dos prazos de execução de cada etapa é ditado pelas necessidades do projeto em que o gerenciamento de configuração está sendo implantado.

A primeira parte do roteiro abaixo apresenta as atividades que são executadas durante o processo de adaptação da empresa para a implantação de gerenciamento de configuração.

A segunda parte do roteiro apresenta graficamente o momento em que as atividades de gerenciamento de configuração são efetuadas dentro do ciclo de vida do software em uma empresa que já implantou gerenciamento de configuração.

Ambas as partes do roteiro são utilizadas em todos os projetos da empresa. 


\section{4 - Roteiro}

A implantação e execução do plano de gerenciamento de configuração seguem um roteiro previamente estabelecido. Na primeira fase a empresa prepara as pessoas e constrói uma infra-estrutura que permitirá a utilização do gerenciamento de configuração em muitos projetos.

Nas empresas que já implantaram gerenciamento de configuração, a primeira parte é bastante rápida e serve para treinamento de novos e antigos funcionários, para correções de deficiências das ferramentas ou falhas na aplicação de atividades, e também para uma análise do funcionamento do gerenciamento de configuração. Quando forem efetuadas alterações nos procedimentos, o plano deverá ser também alterado.

As atividades necessárias para a adaptação da empresa ao gerenciamento de configuração são:

- Designar pessoas aos cargos de gerente de projeto e gerente de configuração.

- Fornecer cursos/treinamento em gerenciamento de configuração aos gerentes designados.

- Fazer reuniões locais de motivação e estudos sobre gerenciamento de configuração de software entre todos membros da empresa.

- Analisar previamente a viabilidade da implantação do gerenciamento de configuração.

- Definir o formato dos formulários e relatórios.

- Adquirir ou desenvolver as ferramentas de apoio a serem utilizadas (ex: controlador de versões, banco de dados de pedidos de alteração,).

- Fazer treinamento no uso dos sistemas e das ferramentas QVCS.

- Treinar a equipe de projeto nos novos procedimentos administrativos.

- Analisar novamente a viabilidade da implantação do gerenciamento de configuração. 


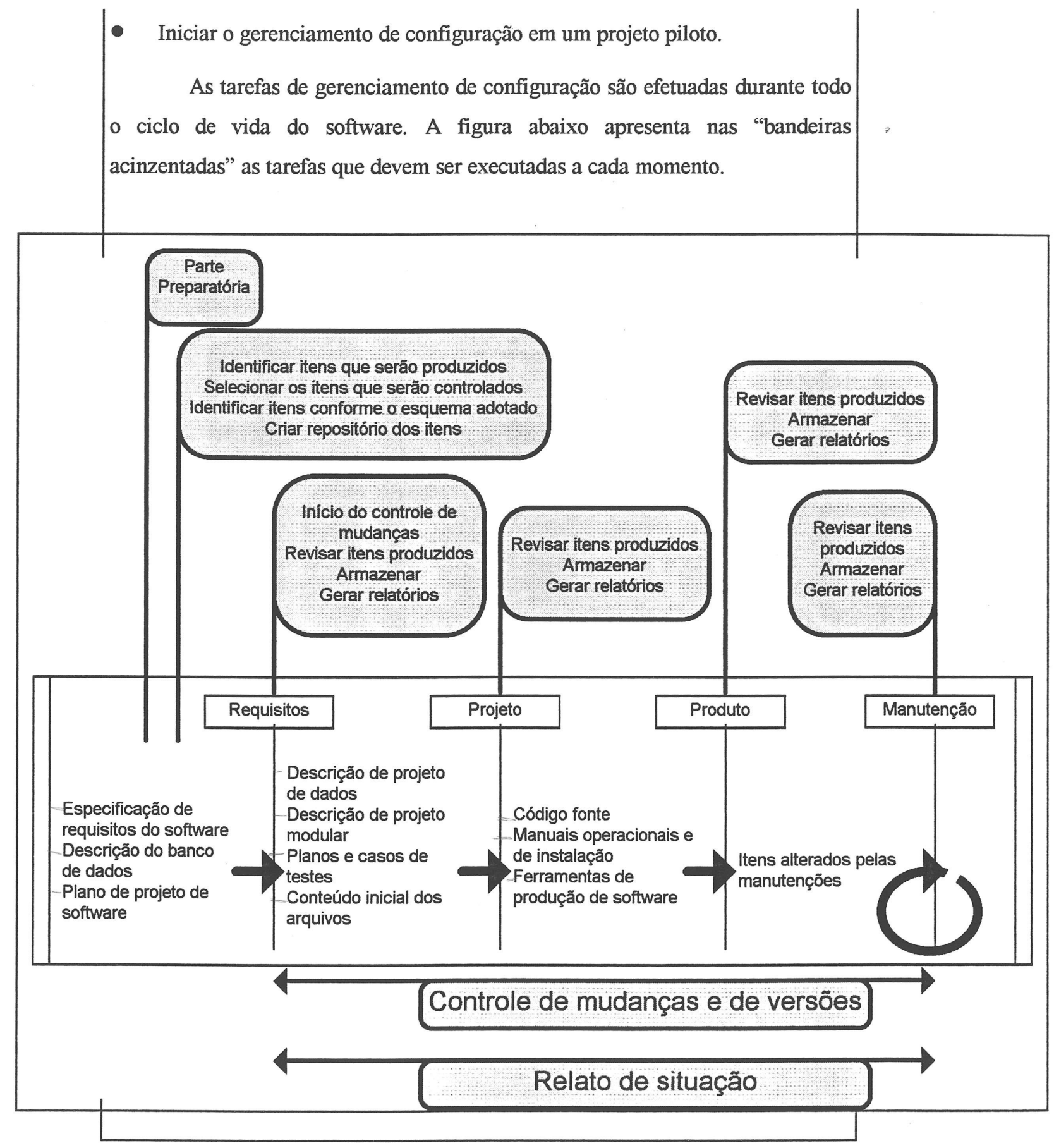

\subsection{Elaboração da Seção 5 do Plano Recursos}

$\mathrm{Na}$ elaboração da seção 5 , de recursos, leva-se em consideração o fato de que as empresas de pequeno porte precisam de soluções de muito baixo custo. 
É indicado que se utilizem os equipamentos, sistemas operacionais, editores de textos, gerenciadores de banco de dados e redes já existentes na empresa. A ferramenta Quma Version Control System (QVCS) sugerida para automatizar o controle versões e de configurações é shareware, com recursos de compactação das versões, para minimizar o uso de espaço em disco e tem interface amigável, reduzindo despesas com treinamento. Normalmente não são necessárias contratações de novas pessoas, mas apenas treinamento nas novas tarefas que ficam distribuídas entre as pessoas já existentes na empresa. Talvez haja necessidade de se contratar uma pessoa para atuar como gerente de configuração.

\section{5-Recursos}

Os recursos necessários durante a execução do plano de gerenciamento de configuração podem ser classificados em pessoas, equipamentos e ferramentas.

Pessoas:

Gerente de configuração: analista de sistemas experiente e organizado, com conhecimentos em gerenciamento de configuração de software.

Equipe de projeto: programadores com treinamento na aplicação das técnicas de gerenciamento de configuração de software

Gerente de projeto: analista de sistemas experiente e empreendedor, interessado em implantar gerenciamento de configuração de software.

Equipamentos:

CPU:486/pentium

Memória: mínimo $8 \mathrm{Mb}$

Sistemas Operacional: Windows 95/NT

Disco rígido, no servidor:

QVCS: 2,4Mb; 
Repositório de itens: aproximadamente 10 vezes o espaço ocupado pela primeira versão de cada item a ser armazenado;

Área de trabalho de cada desenvolvedor: espaço para armazenar uma cópia de cada item de informação.

Rede local: qualquer rede compatível com Windows 95/NT.

Impressoras: 1 impressora matricial 80 colunas ou jato de tinta para impressão dos relatórios.

\section{Ferramentas:}

QVCS (Quma Control Version System)

Aplicação: gerenciamento de versões e de configurações.

Recursos: check in, check out, controle de versões, bloqueio, controle de acesso por senha, controle de acesso distinto para cada usuário, janelas de ajuda, nomenclatura de versões de itens e de configurações do sistema, interface gráfica ou comando de linha.

Onde obter: via internet

endereço: http://www.clark.net/pub/jimv/qvcsman.htm.

Custo: shareware - US\$ 25,00/ano (versão de demonstração disponível, com validade de 30 dias, renováveis)

Técnica utilizada: Check in - Check out com compressão através de delta negativo.

Editor de textos: MS-Word / Word Perfect / ou outros

Aplicação: geração de itens de informação (documentação em formato texto), geração de relatórios.

Banco de dados: Access / FoxPro / Dbase / Clipper ou outros.

Aplicação: banco de dados de solicitações de alteração (opcional).

Os quadros seguintes relacionam as tarefas de gerenciamento de configuração de software aos recursos utilizados: 


\begin{tabular}{|c|c|}
\hline tarefa & Identificação da configuração \\
\hline ferramentas & QVCS, banco de dados do projeto, editor de textos \\
\hline técnica & identificação hierárquica \\
\hline pessoal & gerente de configuração de software e equipe de desenvolvimento \\
\hline treinamento & uso experimental do software necessário, reuniões \\
\hline tarefa & Controle de versões \\
\hline ferramentas & QVCS, banco de dados do projeto \\
\hline técnicas & check in - check out/ delta negativo \\
\hline pessoal & gerente de configuração \\
\hline treinamento & Curso externo, livros, telas de auxílio, uso experimental do software necessário \\
\hline tarefa & Controle de mudanças \\
\hline ferramentas & banco de dados do projeto \\
\hline técnicas & controle administrativo no fluxo de documentos \\
\hline pessoal & Diretor, gerente do projeto, gerente de configuração, equipe de projeto \\
\hline treinamento & reuniões entre os elementos envolvidos \\
\hline tarefa & Relato de situação \\
\hline ferramentas & banco de dados de solicitações de alteração, QVCS, editor de textos \\
\hline técnicas & consultas ao banco de dados e ao QVCS, reuniões de acompanhamento, boletins \\
\hline pessoal & gerente de configuração de software \\
\hline treinamento & uso experimental do software necessário \\
\hline
\end{tabular}

\subsection{Elaboração da Seção 6 do Plano Manutenção}

$\mathrm{Na}$ elaboração da seção 6 , de manutenção do plano, leva-se em consideração o fato de que a comunicação interna nas empresas de pequeno porte é simples e eficaz - todos conversam com todos. Isso facilita a discussão e divulgação de novas soluções encontradas no gerenciamento de configuração. Além disso, no início de cada novo projeto, é feita uma análise da forma como o gerenciamento de configuração vem sendo aplicado.

\section{6- Manutenção do plano}

O plano de gerenciamento de configuração de software deve refletir a forma como o gerenciamento de configuração está sendo aplicado. É esperado, que a forma de execução das tarefas de gerenciamento de configuração de 
software se alterem, com o decorrer do tempo, como uma evolução natural. O
gerente de configuração de software deve atualizar o plano, cada vez que novas
soluções forem aprovadas pelo diretor da empresa.
O melhor momento para a discussão e atualização do plano é durante a
parte preparatória de implantação de gerenciamento de configuração de software,
que ocorre no início de cada projeto. Porém, se necessária, a atualização do plano
pode ocorrer a qualquer momento e deve, obrigatoriamente, ser informada a todas
as pessoas envolvidas.

\subsection{Final}

Neste capitulo foi apresentado um plano de implantação de gerenciamento de configuração de software adequado à realidade das empresas de desenvolvimento de software de pequeno porte.

As conclusões e trabalhos futuros são apresentados no capítulo que se segue. 


\section{Conclusões e Trabalhos FUTUROS}

\subsection{Conclusões}

No contexto de melhoria de qualidade do processo de software, em empresas de pequeno porte, ressalta-se neste trabalho a relevância de um processo de gerenciamento de configuração adequado para essas empresas.

No modelo Capability Maturity Model (CMM) [Paulk, 1993a], o gerenciamento de configuração de software é colocado como uma das primeiras práticas chaves necessárias para que uma empresa saia do nível de maturidade considerado caótico. Através de procedimentos técnicos e administrativos, o gerenciamento de configuração de software permite controlar todas as alterações nos itens de informação que se processam durante o desenvolvimento e a manutenção do software.

Uma das grandes dificuldades no estabelecimento de gerenciamento de configuração em empresas de pequeno porte é o desconhecimento da importância dessa atividade e, outras vezes, a associação que é feita a essa tarefa como um serviço burocrático que apenas causa atraso.

As motivações e orientações que poderiam minimizar essa visão distorcida de gerenciamento de configuração constam de livros, revistas e planos que muitas vezes não são acessíveis ou não são compreensíveis para os profissionais de empresas de pequeno porte. 
Além disso, mesmo aqueles que procuram melhorar a qualidade do processo de software e que têm conhecimento teórico sobre gerenciamento de configuração, se defrontam com o problema do custo das ferramentas que apoiam essa atividade, visto que ela é trabalhosa e necessita, em algumas tarefas, de apoio automatizado.

Assim, desenvolveu-se neste trabalho um plano que possibilita a implantação de gerenciamento de configuração de software em empresas de pequeno porte. Neste plano são apresentados como os organogramas, cargos, responsabilidades, tarefas administrativas, controles e outras tarefas de gerenciamento de configuração de software podem ser implantados nas empresas de pequeno porte, inclusive com roteiro de implantação e instruções de utilização da ferramenta de controle de versões.

Para a elaboração desse plano, primeiramente foi efetuada uma pesquisa empírica procurando-se determinar como o gerenciamento de configuração é realizado nas empresas de pequeno porte, com o intuito de elaborar um plano de implantação que melhor se adequasse à forma como o gerenciamento de configuração é aplicado nessas empresas.

Para orientar a pesquisa foi utilizado o método Goal / Question / Metric (GQM) [Basili e Weiss, 1984] que fornece um mecanismo que orienta a determinação dos objetivos da pesquisa e o refinamento de cada objetivo em um conjunto de questões, com o propósito de quantificá-los. Foram feitas questões específicas sobre gerenciamento de configuração de software e também questões sobre outras características da empresa, envolvendo infraestrutura e ambiente cultural. A pesquisa foi realizada em sete empresas do noroeste do estado de São Paulo e apresentou um resultado desanimador: o gerenciamento de configuração de software não é adequadamente aplicado.

Devido a isso, não foi possivel escrever um plano apropriado à maneira como as empresas de pequeno porte efetuam o gerenciamento de configuração de software. Assim, adotou-se as tarefas apresentadas pelo padrão de plano de gerenciamento de configuração de software escolhido, 
fazendo-se as devidas adaptações às características das empresas de pequeno porte identificadas na pesquisa.

Para a seleção do padrão do plano de gerenciamento de configuração de software, foram estudados os padrões propostos pelo Instituto dos Engenheiros Eletro-Eletrônicos americano (IEEE) [IEEE Std 828-1990], os padrões de plano propostos pela NASA [NASA-Sfw-DID-04] e pelo DoD [DIMCCR-80030A]. Através de uma análise comparativa desses padrões, onde foram consideradas a funcionalidade, facilidade de uso, completitude, adaptabilidade, correção, consistência e adequação ao ciclo de vida, optouse pelo padrão IEEE Std 828-1990.

$\mathrm{Na}$ adaptação das seis tarefas indicadas pelo padrão IEEE Std 8281990 para as necessidades das empresas de desenvolvimento de software de pequeno porte, exigiu-se a execução das tarefas de identificação da configuração (com o estabelecimento de linhas de referência e esquema de identificação), controles (controle de mudanças através de procedimentos administrativos e controle de versões apoiada pela ferramenta QVCS) e relato de situação (bastante simplificado).

Outras tarefas, como auditorias, controle de interface e controle de subcontratados e fornecedores, foram dispensadas.

Paralelamente à realização da pesquisa, foi feita uma busca por ferramentas de baixo custo, com boa interface e funcionalidade e que auxiliassem o gerenciamento de configuração de software. A primeira ferramenta identificada, o Revision Control System (RCS) [Babich,1986], foi encontrado inicialmente em sua versão UNIX, que foi descartada por utilizar um sistema operacional inadequado às empresas de pequeno porte, e depois na versão Windows-NT, que foi descartada por não utilizar uma interface gráfica, mas apenas comandos de linha, dentro da janela do MS-DOS. Algumas outras ferramentas foram identificadas e descartadas, devido ao alto custo (Ex: PVCS [Intersolv, 1997], VCS-UX [Diamond, 1997]. A ferramenta Quma Version Control System (QVCS) [Voris, 1997] possui as 
características desejadas, provendo recursos de controle de versões de itens e de configurações em uma interface gráfica e com baixo custo. $O$ uso dessa ferramenta foi indicado no plano proposto.

\subsection{Trabalhos Futuros}

Como a tarefa de controle de mudanças envolve um fluxo de trabalho pré-estabelecido, poder-se-á utilizar ferramentas work-flow na automatização desses procedimentos. Com o uso das ferramentas de work-flow, é possível garantir que seja sempre seguida a seqüência estabelecida de atividades, aumentando-se assim, a eficiência da atividade de controle de mudança.

Num passo seguinte, poderão ser criados mecanismos que integrem as ferramentas de work-flow ao ciclo de vida do software. Se esses mecanismos armazenarem dados para o cálculo métricas sobre o processo de produção de software, poderão ser encontrados gargalos no processo, possibilitando a sua otimização.

Outra proposta é o estudo aprofundado da tarefa de especificação dos relacionamentos existentes entre os itens de configuração. Isto auxiliará a tarefa do gerente de configuração de software na identificação dos efeitos colaterais provocados pelas alterações.

Também poderá ser feito um estudo do custo dos recursos necessários para o gerenciamento de configuração de software, visando a viabilidade econômica de sua implantação.

Para a validação do plano proposto, é recomedável a sua aplicação em um projeto piloto em uma empresa de pequeno porte. Esse projeto apontará as falhas existentes no plano, que, para ser melhorado, poderá despertar a necessidade de novas pesquisas.

Um complemento ao plano de implantação de gerenciamento de configuração de software é um plano de treinamento e motivação, indicado às pessoas que não possuem qualquer conhecimento sobre a área. Esse 
programa, deverá considerar conceitos básicos de engenharia de software e, através de atividades práticas, apresentar todos os conceitos de gerenciamento de configuração de software. 


\section{REFERÊNCIAS BIBLIOGRÁFICAS}

[Ambriola, 1990]

[Babich, 1986]

[Basili e Weiss, 1984]

[Basili et alii, 1986]

[Basili e Rombach, 1988]

[Basili, 1990]

[Bersoff, 1979]

[Bersoff, 1980]

[Bersoff, 1984]

[Berlack, 1992]

[Boas, 1994]

[Bounds, 1993]

[Brown, 1991]

[Buckley, 1993]

[Capretz, 1992]
AMBRIOLA, V.; BENDIX, L.; CIANCARINI, P. The Evolution of Configuration Management and Version Control. Software Engineering Journal, v.5, n.6, p.303-10, 1990.

$\mathrm{BABICH}, \mathrm{W}$. Software Configuration Management. 1.ed. Reading Mass. Addison-Wesley, 1986.

BASILI, V.R. e WEISS, D.M. (1984) - A Methodology for Collecting Valid Software Engineering Data - IEEE Transaction on Software Engineering, Vol.SE-10, No. 6, p.728-738

BASILI, V.R.; SELBY, R.W. e HUTCHENS, D.H. (1986) Experimentation in Software Engineering - IEEE Transaction on Software Engineering, Vol.SE-12, No.7, p.733-743

BASILI, V. e ROMBACH, H.D. (1988) - The Tame Project - IEEE Transaction on Software Engineering, Vol.14, No. 6, p.761-762

BASILI, V.R. (1990) - Viewing Maintenance as Reuse-Oriented Software Development - IEEE Software, p.19-25

BERSOFF, E.H.; HENDERSON, V.D.; SIEGEL, S.G. Software Configuration Management: A Tutorial. IEEE Computer, v.12, n.1, p.614, 1979.

BERSOFF,E.H.; HENDERSON, V.D.; SIEGEL, S.G. Software Configuration Management - An Investiment in Product Integrity, Prentice Hall, Englewood Cliffs, NJ, 1980.

BERSOFF,E.H. Elements of Software Configuration Management. IEEE Transactions on Software Engineering, v.se-1.0, n.1, p.79-87, 1984.

BERLACK, H.R. Software Configuration Management. 1.Ed. New York, John Wiley, 1992.

BOAS, A.V. RCS-Revision Control System. Departamento de Sistemas de Operação-Projeto ASSISTE CPqD-TELEBRÁS, 1994.

BOUNDS, NADINE M.; DART, S. A. Configuration Management (CM) Plans: The Begining to Your CM Solution. Pittsburg, Software Engeneering Institute, Carnegie Mellon University, 1992 (Tech. Report CMU/SEI-92-TR ?).

BROWN, H. Like a Version. Computer Languages, v.8, n.8, p.59-81, 1991.

BUCKLEY, F. J. Implementing a Software Configuration Management Environment IEEE Computer, v.27, n.2, p.56-61, 1994.

CAPRETZ M.A.M.. CONFORM - A Software Maintenance Method Based on Software Configuration Management Discipline. In: Conference on Software Maintenance, Orlando. Procedings. p.183-92, 1990. 
[Capretz, 1994]

[CMFAQ, 1996]

[Dart, 1991]

[Diamond, 1997]

[DoD-STD-2167A]

[DI-MCCR-80030A]

[Feiler, 1991]

[Gallagher e Lyle, 1991]

[Harter, 1989]

[Humphey, 1988]

[Humphrey, 1989]

[IEEE 983-1986]

[IEEE Std 610.12-1990]

[IEEE Std 828-1990]

IEEE Std 1042-1986]

[Intersolv, 1997]

[Karakas, 1992]

[MIL-STD-483A-1979]

[Narayanaswamy, 1987]

[NASA-Sfw-DID-04]

[Newman, 1995]

[Ould, 1990]
CAPRETZ M.A.M.; MUNRO M. Software Configuration Management Issues in the Manitenance of Existing Systems. Software Maintenance: Research and Practice, v.6,p.1-14, 1994.

[EATON, D.W. - Configuration Management Frequently Askey Quastions http//www.iac.honeywell.com/Pub/Tech/CM/CMFAQ.html, 1996 [Acesso em 11/09/96]

DART, S. A. Concepts in Configuration Management Systems. In: International Workshop on Software Configuration Management, 3, Trondheim, 1991. Proceedings. p.1-18

http://www.DiamondOS.com acessado em 19/03/1997

DoD-STD-2167A, Military Standard for Defense System Software Development, Department of Defense. Jun, 1985.

DOD DI-MCCR-80030A, Dataltem Description for the Software Development Plan, Department of Defense, Jun, 1986

FEILER, P. H. Configuration Management Models in Commercial Environments. Pittsburgh, Software Engineering Institute, Carnegie Mellon University, 1991. (Tech.report CMU/SEI-91-TR-7)

GALLAGHER e LYLE (1991) - Using Program Slicing in Software Maintenance - IEEE Transaction on Software Engineering, Vol. 17, No. 8, p.759-761

HARTER,R. Configuration Management. HP Professional, vol.3, n.6, jun. 1989.

HUMPHREY, W. S. Characterizing the Software Process - A Maturity Framework. IEEE Software, v.5, n.2, p.73-79, 1988.

HUMPHREY, W. S. Managing the Software Process. 1.ed. Massachesetts. Addison-Wesley, 1989.

Software Engineering Standards, $3^{a}$ edição, IEEE, 1989.

IEEE Standard Glossary of Terminology in Software Engineering. In:IEEE Software Engineering Standar Collection, p.07-83, 1991.

IEEE/ANSI Standard 828-1990. Software Configuration Management Plans. In: IEEE Software Engineering Standard Collection, 1990.

IEEE/ANSI Standard 1042-1987: IEEE Guide to Software Configuration Management. In: IEEE Software Engineering Standard Collection, 1987.

http://uww.intersolv.com/products/demo-pvcs-vm.htm acessado em 16/09/1997

KARAKAS, G. ; KAZAI, G.; KUNTH, E. Project Management by Configuration Inheritance. Annual Review of Automatic Programming, v.16, p.109-16, 1992.

DoD MIL-STD-483-A, Configuration Management Practices for Systems, Equipment, Muintions, and Computer Programs, 1979.

NARAYANASWAMY,K.; SCACCHI,W. Maintening Configurations of Evolving Software. IEEE Transactions on Software Engineering, v.se-13, n.3, p.324-34, 1987.

NASA Sfs DID 04, Software Configuration Management Plan Data Item Description, National Aeronautics and Space Administration, Version 3.0. Out, 1986.

NEWMAN, W.E.; Software Configuration Management Process Definition. Rear Adimiral, U.S. Navy, 1995.

OULD, M.A. Managing Software Engineering. The Management of Risk 
[Pressman, 1995]

[Paulk, 1993a]

[Paulk, 1993b]

[Rombach, 1987]

[Rombach e Ulery, 1989]

[Rombach, 1990

[Saiedian, 1995]

[Sanches, 1993]

[Schneidwind, 1987]

[Shepperd, 1990]

[Voris, 1997]

[Whitgifh, 1991] and Quality, John Wiley, Chinchester, 1990.

PRESSMAN, R.S. Engenharia de Software. 3.Ed Rio de Janeiro. Makron Books, 1995.

PAULK M. C. et al. Capability Maturity Model for Software. versão 1.1, Pittsburgh, Software Engineering Institute, Carnegie Melon University, 1993. (CMU/SEI-93-TR-24)

PAULK M. C. et al. Key Practices of the Capability Maturity Model. versão 1.1. Pittsburgh, Software Engineering Institute, Carnegie Mellon University, 1993. (CMU/SEI-93-TR-25)

ROMBACH, H.D. (1987) - A Controlled Experiment on the Impact of Software Structure on Maintainability - IEEE Transaction on Software Engineering, Vol. SE-13, No. 3), p.344-354

ROMBACH, H.D. e ULERY, B.T. (1989) - Improving Software Maintenance through Measurement - Proceedings of the IEEE, Vol.77, No.4, p.581-595

ROMBACH, H.D. (1990) - Design Measurement: Some Lessons Learned - IEEE Software, 17-24

SAIEDIAN, H. and KUZARA, R. SEI Capability Maturity Model's Impact on Contractors. IEEE Computer, v.28, n.1, p.16-26, 1995.

SANCHES, R. A Influência do Software e de seu Processo de Manutenção no Esforço de Manutenção. Tese (Doutorado), Faculdade de Economia, Administração e Contabilidade, Universidade de São Paulo, São Paulo, 1993.

SCHNEIDWIND N.F. The State of Software Maintenance. IEEE Transaction on Software Engineering, v.se-13, n.3, p.303-310, 1987.

SHEPPERD, M. (1990) - Design Metrics: An Empirical Analysis Software Engineering Journal, Vol. 5, No. 1, p.3-10

http://www.clark.net/pub/jimv/qvesman.htm acessado em 16/09/1997

WHITGIFH, DAVID Methods and Tools for Software Configuration Management. John Wiley \& Sons, 1991. 